Portland State University

PDXScholar

Fall 12-3-2019

\title{
Bone Mineral Density of the Common Bottlenose Dolphin, Tursiops truncatus: a Proposed Model for Monitoring Osteological and Ecosystem Health
}

James Wright Burrus Powell

Portland State University

Follow this and additional works at: https://pdxscholar.library.pdx.edu/open_access_etds

Part of the Animal Sciences Commons, Animal Structures Commons, and the Biology Commons Let us know how access to this document benefits you.

\section{Recommended Citation}

Powell, James Wright Burrus, "Bone Mineral Density of the Common Bottlenose Dolphin, Tursiops truncatus: a Proposed Model for Monitoring Osteological and Ecosystem Health" (2019). Dissertations and Theses. Paper 5344.

https://doi.org/10.15760/etd.7217

This Dissertation is brought to you for free and open access. It has been accepted for inclusion in Dissertations and Theses by an authorized administrator of PDXScholar. Please contact us if we can make this document more accessible: pdxscholar@pdx.edu. 
Bone Mineral Density of the Common Bottlenose Dolphin, Tursiops truncatus:

A Proposed Model for Monitoring Osteological and Ecosystem Health

by

James Wright Burrus Powell

A dissertation submitted in partial fulfillment of the requirements for the degree of

Doctor of Philosophy

in

Biology

Dissertation Committee:

Deborah Duffield, Chair

Bradley Buckley

Jason Podrabsky

Randall Wells

Virginia Butler

Portland State University

2019 
(C) 2019 James Wright Burrus Powell 


\begin{abstract}
Bone mineral density (BMD) in the pectoral flipper of the common bottlenose dolphin, Tursiops truncatus, was examined to address the need to define a comprehensive target site for clinical osteodensitometric assessment and to establish ranges of observed bone density values for this species. Radii were analyzed using dual energy X-ray absorptiometry (DXA), the accepted standard in human medical studies. Multiple loci within the radius were identified and assessed for their correlation to BMD of the entire bone. Radii BMD were also examined for differences based on sex, age, total body length, handedness, geographical affinity, and nutritional status at time of death. No statistically significant differences were observed in BMD measurements for male and female dolphins or right and left flippers. Additionally, no statistically significant differences were observed based on geographical region or nutritional status at time of death. These results support the inclusion of all specimens used in this study as a descriptive reference dataset for bone density values in bottlenose dolphins and detail a primary skeletal site for clinical assessment of bone density for the species. The values utilized in this study represent the largest dataset published on BMD in any wildlife or marine mammal species to date.

In the skeletal specimens analyzed, BMD increased with age and body length; however, the variance of bone density values that was observed at any given age was of such magnitude that it precludes the use of this single parameter as a reliable estimator of age. The clinical measurement of an individual's bone density at any given time is a direct reflection of that individual's skeletal health. Reducing osteodensitometry to a static age estimation tool would inherently disregard the biological and physiological function of
\end{abstract}


calcified tissues. Variation of bone density values at any given age may be an indicator of altered skeletal health due to numerous factors including overall health, nutritive status, contaminant exposure, body condition, or metabolic and endocrine related disorders.

Despite its accuracy, precision, and widespread use, DXA has limitations and clinical shortcomings. The technology is not appropriate for all healthcare and screening applications due to the inherent use of radiation, large size of units, relatively high associated costs, and limited access and availability. Quantitative ultrasound (QUS) methods for bone assessment have demonstrated potential to determine bone quality and to provide information about BMD. QUS is beneficial in that it is portable, nondestructive, noninvasive, less expensive than X-ray technology, and does not expose patients or technicians to radiation. To circumvent limitations in traditional radiographic bone density assessment, a custom QUS device and protocols were developed for assessment of live bottlenose dolphins. In laboratory measurements on disarticulated pectoral flippers collected post-mortem, a strong correlation was established between BMD as measured with QUS and DXA. Initial trials to develop clinical protocols and establish ultrasonic assessment of bone as non-aversive were conducted on dolphins managed under human care. Findings support the application of quantitative ultrasonic assessment of bone density to assess skeletal health in free-ranging dolphins during capture-release health assessments and in populations of dolphins under human care.

Bottlenose dolphins are utilized as indicators of ecosystem health in capture-release health assessments. BMD measurements have not previously been incorporated into these projects despite evidence that exposure to a suite of anthropogenic contaminants, episodic 
prey depletion events, and resultant malnutrition lead to decreased bone density in laboratory animals and wildlife species. To establish bone density as a useful health and life history parameter for the bottlenose dolphin, normative reference ranges must be established from healthy individuals in order to facilitate evaluation of health and disease status of individuals from impacted populations and habitats. Repeatability assays were conducted on dolphins under human care to define the precision error for this novel QUS application. Ultrasonic bone density assessments of live, free-ranging dolphins were conducted during capture-release health assessments from 2014-2019. Individuals were selected from this long-term population study for the development of a normative bone density dataset of dolphins with nutritive body condition within normal limits and the lack of obvious disease or health issues. This study represents the first use of QUS to assess bone density in a marine mammal species, and the BMD values as assessed with QUS represent the first normative BMD dataset for live, free-ranging marine mammals. Application of this technology during capture-release health assessments adds a valuable resource to biologists and wildlife veterinarians investigating dolphin and overall ecosystem health.

Future studies and applications are suggested to investigate associations between anthropogenic contaminant exposure and BMD in free-ranging dolphins and renal dysfunction or metabolic disorder and BMD in managed care dolphins. Continued longterm monitoring of bone density in live, free-ranging bottlenose dolphins using the established reference population will allow for more in-depth investigation of life history questions, particularly with regard to large-scale prey mortality events associated with 
toxic algal blooms and resultant malnutrition. Technological advancements to assess BMD in additional skeletal sites is encouraged to facilitate additional research questions that may not be as readily addressed using the pectoral flipper as an examination site. 


\section{Acknowledgements}

I would like to thank my doctoral dissertation committee for the support they have provided throughout this project and the critical review of the various components that have led to this dissertation. Additional research collaborators were instrumental in assisting me through the development of this project to ensure that from the beginning it had the scope and capacity to be fully integrated into the marine mammal research field. This project would not have been possible without the additional support and collaborative efforts made by the following researchers: Dr. Cynthia Smith and Dr. Lori Schwacke (National Marine Mammal Foundation), Dr. Leslie Hart (College of Charleston), Dr. Spencer Fire (Florida Institute of Technology), Gretchen Lovewell and Rebeccah Hazelkorn (Mote Laboratory and Aquarium), Dr. Gangming Luo (CyberLogic, Inc.), and Dr. Mitch Finnegan and Margot Monti (Oregon Zoo).

I am forever grateful to Wayne McFee who is ultimately responsible for this project even existing. He provided me the opportunity to pursue my dreams of studying marine mammals by allowing me to join his staff in 2006 and then mentoring me through my early career. I am fortunate to have had Wayne in my life as a mentor and role model not only as a scientist but also as a husband and father.

I would also like to convey how truly grateful I am to Dr. Jonathan Kaufman, a biomedical engineer from Brooklyn, New York, who had not even seen a bottlenose dolphin in person until he was practically forced into the water during the 2012 Sarasota Dolphin Research Program Health Assessments in my (successful) attempt at convincing 
him to join me on this crazy adventure. As unlikely as our pairing is, he has been an amazing and gracious mentor, research partner, and friend.

In retrospect, as a young child growing up in landlocked West Tennessee claiming that I was going to "grow up and study dolphins" I had no idea what that meant. I was extremely lucky to have had teachers in my life at a very early age who challenged me to be the best student I could in order to pursue that dream. In a large part, for me, this dissertation represents that dream forming into a reality. One of the greatest hopes I have for my daughter is for her to have teachers come into her life that are as formative and cherished as Mrs. Patricia Prescott and Mrs. Sandra Todd are for me. I have grown up feeling extremely fortunate for the roles they both played in molding who I am today.

Dr. Randy Wells welcomed me into the Sarasota Dolphin Research Program and provided a place for me to transition a research idea from a theoretical laboratory concept to an applied technique on live dolphins. I am humbled to have been able to pursue my research under his guidance and am grateful for his support and assistance. Beyond the platform he has now provided to a generation of researchers, his program has given many of us a family of Sarasota Siblings that, for me, is personally far more meaningful than the research questions we are answering.

It is not possible for me to have found a more amazingly supportive and caring major advisor than Dr. Deb Duffield. Coming to Portland State University to study under her was one of the greatest decisions I ever made. I very tentatively returned to graduate school as a still new father of a 3-year-old daughter. Raegan, Macy, and I will be forever grateful for Dr. Duffield's support of my life balance, ensuring that I was able to be the 
father I wanted to be while also training to be the scientist I came to Portland to develop into. I am honored to have been a Duffield Lab student and to have shared my time there with Kessina Lee and Kyle Tidwell, who assisted greatly in my personal and professional development. My time as a member of the Duffield Lab and the years we spent together has forever shaped and impacted all aspects of my life for the better.

In addition, I am grateful for the countless hours provided by marine mammal stranding response staff and volunteers at NOAA's Center for Coastal Environmental Health and Biomolecular Research in Charleston, South Carolina, and Mote Marine Laboratory and Aquarium in Sarasota, Florida. Natural history collections are invaluable resources for studies as the opportunistically collected and archived specimens provide a platform for the application of new technologies and the development of advanced methods that were often unimagined when the specimens were collected. I hope this dissertation serves as an example of the fields of study and areas of inquiry that can be generated and explored based on biological collections, highlighting the importance of biological research collections in conservation, health, and global environmental monitoring.

I am especially grateful to the staff and volunteers of the Sarasota Dolphin Research Program and the dolphins of Sarasota Bay for making the capture-release health assessments and the research those efforts support safe and possible. I also appreciate the staff and dolphins at Brookfield Zoo and Dolphin Quest Oahu for their participation in this project and for exemplifying a commitment to research that increases knowledge and better understanding of marine mammals using animals managed under human care. 
In addition to the support provided by the multitude of research collaborators on this project, this research was made possible through financial support from the National Science Foundation Small Business Innovation Research Program (NSF SBIR), Disney Conservation Fund, American Military University Faculty Research Grant, Greenville Zoo, Forbes-Lea Endowment Fund for Graduate Research, Portland State University Travel Grant Program, and U.S. Environmental Protection Agency Science to Achieve Results (EPA STAR) Graduate Research Fellowship. 


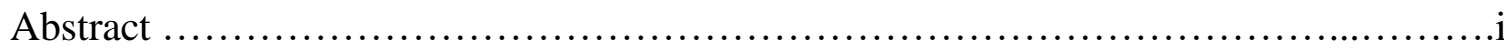

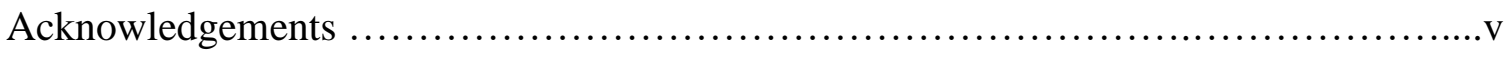

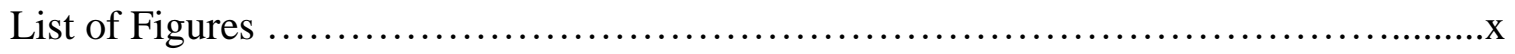

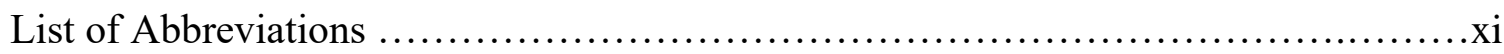

Chapter 1

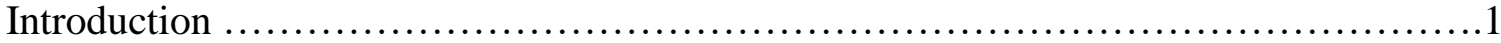

Chapter 2

Bone Density Cannot Accurately Predict Age in the Common Bottlenose Dolphin,

Tursiops truncatus ............................................................ 17

Chapter 3

Bone Mineral Density of the Common Bottlenose Dolphin Radius: A Primary Skeletal Site for Clinical Bone Densitometry and Descriptive Dataset Using Archival Specimens

Chapter 4

Quantitative Ultrasonic Assessment of Bone Density in the Pectoral Flipper of the Common Bottlenose Dolphin, Tursiops truncatus

Chapter 5

Precision Error and Normative Reference Values for Ultrasonic Bone Density

Measurements in Live Common Bottlenose Dolphins, Tursiops truncatus

Chapter 6

Conclusions and Future Studies

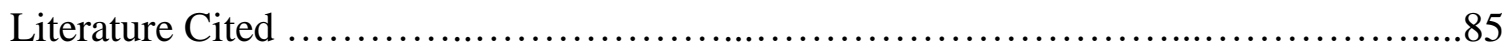

Appendix A. Bone mineral density (BMD) values as defined with dual-energy X-ray absorptiometry (DXA) for bottlenose dolphins, Tursiops truncatus, in this study provided as an open-source descriptive dataset for bottlenose dolphin BMD values

Appendix B. Quantitative ultrasound (QUS) values from bone mineral density (BMD) repeatability assay conducted on dolphins managed under human care

Appendix C. Bone density measurements of live, free-ranging bottlenose dolphins during capture-release health assessments from 2014-2019 .107 


\section{List of Figures}

2-1 Norland Sabre pDEXA densitometer of a dolphin pectoral flipper ................22

2-2 Bone density distribution from bottlenose dolphin radii relative to age ............23

3-1 Bottlenose dolphin flipper, digital radiograph, and labelled flipper bones ...........38

3-2 Bottlenose dolphin radius and pDEXA scan with labelled ROIs .................39

3-3 BMD values at selected ROIs and whole radius BMD ......................40

3-4 BMD vs. age for 279 bottlenose dolphins ............................. 41

3-5 BMD vs. total body length for 279 bottlenose dolphins .....................42

4-1 Primary ROI on dolphin pectoral flipper, radiograph, and pDEXA scan .........54

4-2 CyberLogic-designed portable quantitative ultrasound system ................55

4-3 Soundwave propagated through bottlenose dolphin radius and soft tissue ........56

4-4 Dolphin BMD correlation between DXA and quantitative ultrasound ............57

4-5 Ultrasonic bone densitometer testing on a live bottlenose dolphin ...............58

5-1 Bone sonometer quantitative ultrasound scan on a dolphin flipper ..............72

5-2 Locating primary region of interest (ROI) on the dolphin pectoral flipper .........73

5-3 In-water bone density assessment of managed care bottlenose dolphins ..........74

5-4 Ultrasonic BMD scan of live, free-ranging bottlenose dolphin ................ 75

5-5 Scatterplots of BMD for free-ranging bottlenose dolphins $\ldots \ldots \ldots \ldots \ldots \ldots \ldots \ldots . \ldots 6$ 


\section{LIST OF ABBREVIATIONS}

$\mathrm{BMC}$ - bone mineral content

$\mathrm{BMD}$ - bone mineral density

BUA - broadband ultrasonic attenuation

CHES - Charleston Harbor Estuarine System (Charleston, SC, USA)

DDT - dichlorodiphenyltrichloroethane

DWH - Deepwater Horizon (oil spill)

DXA - dual-energy radiograph (X-ray) absorptiometry

EPA - United States Environmental Protection Agency

$\mathrm{GC}$ - geometric center (ROI at geometric center of radius)

NTD - net time delay

$\mathrm{PAH}$ - polycyclic aromatic hydrocarbons

PBDE - polybrominated diphenyl ethers

PCB - polychlorinated biphenyl ethers

pDEXA - peripheral dual-energy radiograph (X-ray) absorptiometry

PHCs - persistent organohalogen contaminants

POPs - persistent organic pollutants

QA - quality assurance

$\mathrm{QC}$ - quality control

QCT - quantitative computed tomography

QUS - quantitative ultrasound

ROI - region of interest

SOS - speed of sound

SSB - Sarasota Bay (Sarasota, FL, USA)

$\mathrm{TL}$ - total length

WHO - World Health Organization 


\section{CHAPTER 1}

\section{INTRODUCTION}

Effectively assessing the population health of large, marine vertebrates has gained increasing urgency over the last decade as human impacts on the environment, including global climate change, and other factors facilitate a more rapid transmission of new pathogens and diseases and the spread of pollutants (Harvell et al. 1999, Salazar and Denkinger 2010). Health assessments of marine apex predators, such as common bottlenose dolphins (Tursiops truncatus), are critical in areas where populations show signs of epidemic disease, high mortality, low reproductive success, and/or where ecosystems are being altered or impacted by human activities (Townsend et al. 2018). Numerous techniques have been developed for evaluating different aspects of animal health in the field, and among these, osteological examination is gaining an increased focus in studies of wildlife disease and pathology.

In veterinary medicine, health has been defined as "a state of physical and psychological well-being and of productivity, including reproduction" and health indices as "observable parameters that can be used as an indication of the individual animal's or group of animals' health" (Blood and Studdert 1999). Development of species-specific health indicators for wild, free-ranging wildlife is critical to comprehensively assessing individual and population health and to fully understand the effects of anthropogenic and environmental impacts. In human medicine, assessment of skeletal health has developed as an accepted component to defining an individual's health, particularly with increasing age. Quantitative assessment of bone mineral density (BMD) is currently considered the best predictor of skeletal health. Bone densitometry, or the measurement of BMD, is a vital 
tool for the diagnosis of medical conditions such as osteoporosis, predicting fracture risk, and monitoring bone mineral density in treated and untreated patients (Miller 2017). BMD is the amount of bone mineral, calcium hypoxyapatite, per volume of bone tissue or per unit area.

Bone densitometry is an emerging diagnostic tool in zoo and wildlife medicine as osteological assessment and skeletal investigation can reveal critical information about an individual (Duckler and Van Valkenburgh 1998). Evidence of chronic physical illness and acute injury can manifest itself in skeletal material in animals much in the same manner as for humans (O’Connor 2000). Skeletal examination of animals, despite its importance in diagnostic and forensic studies, is often overlooked or neglected during routine veterinary postmortem work (Cooper and Cooper 2008). By increasing the universal understanding of animal skeletal health, coupled with the appropriate use of more readily accessible medical technologies, entire lines of research and diagnostics previously limited to human medical studies can be made available to those in the wildlife and conservation medicine field.

In the preface to her text on bone densitometry in clinical practice, Sydney Bonnick (2010) highlights that bone densitometry is an extraordinary clinical tool that provides a safe, non-invasive view of skeletal health allowing a physician, clinician, or researcher to obtain vital information that cannot currently be obtained in any other way. Notably, she also urges caution, noting that with the increase in the number of densitometry devices and individuals involved in densitometry, there has been occasional misuse of the technology and lapses in quality, devaluing the field of densitometry. Despite the increased access to bone densitometry through the proliferation of densitometers throughout the medical field, 
it is imperative that skeletal radiography and imaging densitometry be used as it was developed, with keen attention paid to quality control and caution paid to avoid inaccurate or improper application of densitometry results (Bonnick 2010).

While use of bone densitometry for the diagnosis, treatment, and monitoring of patients in human medicine is robust, the application of those technologies to fields such as wildlife research and conservation medicine is emerging. Comprehensive reviews of animal models of osteoporosis (Turner et al. 2001), animal models for fracture treatment (Egermann et al. 2005), and nonprimate, large animal models for osteoporotic research (Reinwald and Burr 2008) have been published; however, a comprehensive review of osteodensitometry studies in the zoologic context of application to managed care animals and free-ranging wildlife has not yet been conducted.

\section{WHAT IS BONE AND WHY STUDY IT?}

Bone is a dynamic, metabolically active tissue with diverse functions that surpass its essential role in structural support and mechanical function of the musculoskeletal system. Bone assists in growth, $\mathrm{pH}$ balance, blood production, endocrine regulation, reproduction, and mineral and energy storage (Currey 1984). Bone is a composite material formed of collagen and hydroxyapatite. These are deposited and reabsorbed throughout an organism's life in a process referred to as bone turnover (Buckwalter et al. 1996). At the gross level, mammalian bone is comprised of solid, dense bone (compact or cortical bone) and a more spongy, porous underlying material (cancellous or trabecular bone), surrounded by periosteum, a thin, vascularized membrane responsible for supplying nourishment to living skeletal tissue (Marks and Odgren 2002). Detailed reviews of the physical, 
geometric, and mechanical properties of bone as a tissue, and bones as organs, have been published by Burr $(1980,2002)$ and Currey $(1984,2002)$.

The cellular process of bone dynamics is driven by osteoblasts, cells that form bone, and osteoclasts, cells that resorb bone. This system of bone turnover occurs through separate processes of modeling and remodeling (Buckwalter et al. 1996). Bone develops, grows, and achieves its specific and ultimate geometry through the process of modeling (Olsen, et al. 2002). Bone formation and bone resorption are spatially and temporally independent in the modeling process; however, remodeling is a temporally and spatially constrained process where bone is sequentially removed and replaced by new bone (Frost 1992). Normal bone remodeling requires a tightly regulated system of bone resorption and bone formation to ensure that bone mass and bone quality are not altered. This highly regulated process declines with age, in patients with diseases of bone remodeling, and in osteoporotic patients (de Vernejoul 1989). Disorders of bone remodeling, in addition to menopause-associated and age-related osteoporosis, include glucocorticoid-induced and immobilization-induced osteoporosis, renal osteodystrophy, Paget's disease, osteopetrosis and rickets (Feng and McDonald 2011). There are numerous additional secondary causes of osteoporosis, resulting in bone disorders; for example, secondary complications of various medical conditions, consequences of changes in physical activity, or adverse results of therapeutic interventions for specific disorders (Marcus et al. 2008).

BMD is positively correlated with age and body mass in humans and other animals (Blake et al. 2000) up to the point at which the bone resorption increases relative to bone formation (Lin and Lane 2004). The real impacts of this late age loss of bone, or any acute impact that results in altered skeletal homeostasis, are partly influenced by the same factors 
that lead to the development of peak bone mass, the highest BMD value that an individual attains during its lifetime (Ott 1990). Given the vast importance of the functions bone serves, any alteration or disturbance in BMD or other bone quality, despite the underlying cause, could have significant consequences on the individual's overall health, physiology, or behavior. Conversely, these skeletal alterations and disturbances provide researchers and clinicians mechanisms to detect and monitor potential impacts to an individual's or population's health. Therefore, information derived from skeletons may be used to elucidate a better understanding of population biology and individual health (Metcalfe 2007).

Bone densitometry and radiography provide snapshots of an animal's net bone balance at a moment in time during an individual's life or when assessed either perimortem or postmortem. Factors influencing peak bone mass and bone mineral density (BMD) include age, sex, menopausal status, nutrition, health status, hormonal factors, weight or body mass, and skeletal loading through locomotion and exercise (Matkovic et al. 1990, Torgerson et al. 1995). At skeletal maturity, bone turnover is balanced so there is no resultant net change in bone mass; however, with increasing age, altered health status, or incidence of disease, an individual's relative efficiency to resorb and replace bone may be altered and result in net disturbances in bone mass, density, and architecture (Allen 2003). Diseases with health impacts that include disorders in bone mass may have disturbances in both bone formation and resorption, ultimately altering the balance maintained by bone remodeling. Alterations to osteoclastic activity, that are not accompanied by an analogous osteoblastic response, could result in a suite of negative health consequences including, but not limited to, a marked and measurable decrease in BMD. The loss of estrogen production 
in menopausal women results in increased bone resorption, driven by an increase in osteoclastic activity, and consequently decreases in bone mass (Civitelli et al. 1988). The most commonly accepted examples of this type of bone loss are osteoporosis and osteopenia in post-menopausal females.

According to the World Health Organization (WHO), osteoporosis is "a systemic skeletal disease characterized by low bone mass and microarchitectural deterioration of bone tissue with consequent increase in bone fragility and susceptibility to fracture" (Kanis et al. 2008). Osteopenia is a characterization of bones that have become thinner and less dense than normal but have yet to progress to the more severe bone loss definitive of osteoporosis. The WHO operational definitions of normal bone density, osteopenia, and osteoporosis are based on BMD measurements taken by dual energy X-ray absorptiometry (DXA), where measured BMD values are compared with reference BMD values. BMD can be expressed as a T-score and a Z-score, which represent the number of standard deviations away from a reference average value (Pisani et al. 2013). T-scores describe the difference between the BMD of the individual and the mean BMD of a standard, young adult population at peak bone mass. Z-scores describe the difference between the BMD of the individual and the mean BMD of age- and gender-matched controls. The WHO classifies BMD based on the T-score as normal $(\geq-1.0)$, osteopenia ( $<-1.0$ but $>-2.5)$, and osteoporosis $(\leq-2.5)$.

Conservation medicine is an interdisciplinary, emerging field that focuses on the relationship between human and animal health, as well as environmental conditions (Jacobsen et al. 1995). In the marine context, conservation medicine addresses the application of biomedical technology and principles to issues of ecology and environmental 
health (Dierauf et al. 2001). The use of nonhuman organisms as early warning systems for human health risk dates back to the late $19^{\text {th }}$ century where canaries were used to signal lethal carbon monoxide levels (Burrell and Seibert 1916). Modern studies on the effects of endocrine-disrupting compounds have utilized species across an array of taxa to demonstrate reproductive abnormalities in wildlife as well as humans (Colborn 1993). The increased role of diseases in limiting the survival of species can be traced to global anthropogenic changes and impacts that have both direct and indirect influences on the health of wildlife species (Deem et al. 2001).

From a veterinary perspective, the prevention, early diagnosis, treatment, and monitoring of skeletal disease in animals under human care is paramount. Metabolic disorders and associated skeletal health impacts have been observed in animals across many taxa, including marine (e.g., Venn-Watson et al. 2011), terrestrial (e.g., Stevenson and Wilson 1963, Galateanu et al. 2013), and avian (e.g., Adkesson and Langan 2007) species. Better understanding of the underlying causes, prevalence, and treatment options for these disorders is critical to ensuring the health of these animals. While it is unlikely that sentinel species data can be used as the sole determining factor for evaluating issues regarding human health, data gained from such studies can be valuable as a risk assessment tool, method of early detection, or for monitoring populations over time (van der Schalie, et al. 1999).

\section{BONE DENSITOMETRY TECHNIQUES}

Osteodensitometry, or the standardized method of measuring BMD, has been advancing since early radiographers developed in vivo radiographic densitometry of 
mineralized tissues to ascertain information on the mineral mass of bones and teeth in both humans and animals (Garn 1962). Quantitative methods to non-invasively determine bone density and accurately diagnose bone diseases were being developed by the turn of the $20^{\text {th }}$ century, when the first reported uses in dental radiology were published (Dennis 1897, Price 1901). These early approaches to densitometric assessment utilized plain skeletal radiography in such a manner that demineralization was only apparent after $40 \%$ or more BMD had been lost (Johnston et al. 1981).

More advanced, automated, analyses of roentgenograms, or X-ray photographs, has led to more accurate measurements of bone mineral content (Reich et al. 1958, Schraer et al. 1959). Plain radiography methods become more quantitative when based on optical densities of the imaged skeleton when compared to simultaneously X-rayed standards of known density, such as an aluminum step wedge (Mack et al. 1959). Image-processing algorithms to quantitatively determine bone area and mineral density in digitized radiographs can accurately determine the cortical outline of the bone and have provided reliable data and statistics for studies of small animals (Haidekker et al 2004). Densitometry technologies have evolved as the understanding of normal skeletal formation and skeletal disease processes have increased, and the earlier techniques have mostly fallen into disuse (Bonnick 2010) as digital radiography has almost completely replaced the use of film-screen radiography in the evaluation of BMD (Kinds et al. 2011).

Radiography is a critically important diagnostic tool that is unsurpassed in its ability to provide images of internal anatomy and is a well-established and universally accepted approach to assess bone integrity and health (Thrall 2018). In addition to its use to diagnose fractures, detect anatomical anomalies, and locate foreign bodies such as fishing hooks or 
bullets, digital field radiography has been suggested as an advancement that could allow for bone density assessment in applications where portability is clinically essential (Lewbart et al. 2018). Recent advancements in digital radiography (e.g., Vet Rocket X1, Santa Clara, California 95050, USA) have led to the development of portable, fully battery powered, wireless digital radiography systems designed specifically for veterinary applications. Other even smaller handheld, battery-operated units have been designed to perform dental radiography (Seilern-Moy, et al. 2017). However, while future use of such devices to elucidate bone density values in a field setting is possible, bone densitometry is currently limited to laboratory or clinical applications.

Prior to the advent of more modern, highly accurate and precise quantitative densitometry techniques, bone density was commonly assessed by radiographic photodensitometry, radiographic absorptiometry, and both single- and dual-photon absorptiometry (Pisani et al. 2013). However, over the past 30 years, non-invasive densitometric methods have been developed that rely on the attenuation of ionizing radiation to quantify BMD at multiple skeletal sites. The most commonly used of these newer technologies is dual energy X-ray absorptiometry (DXA).

Bone mineral density and bone mineral content studies on humans using DXA technologies are widespread (Grier et al. 1996). The basic principle involved in DXA for the measurement of bone density is that two photoelectric peaks are emitted from an X-ray tube at a target bone tissue and a measurement of density is generated based on attenuation of the X-ray waves after passage through the region of interest. BMD measured by DXA does not represent volumetric density (i.e., grams per cubic centimeter), but rather areal density (i.e., grams per square centimeter) (Ott 1997). 
Greater resolution due to a more stable radiation source and a greater difference between energy levels has led to DXA technology becoming the accepted industry standard in the field of bone densitometry (Sartoris and Resnick 1990). DXA is rapid, non-invasive, allows for precise BMD measurements throughout a skeleton, and permits clinicians to perform replicate and subsequent scans at a specific region of interest. Lewiecki and Binkley (2017) summarize the support for DXA as the "gold standard" for measuring BMD based on a strong correlation between DXA-quantified BMD and bone strength as defined in biomechanical studies (Lotz et al. 1991), epidemiological studies documenting a strong correlation between low BMD and increased fracture risk (Nielson et al. 2011), and overall superior accuracy and precision (Mazess et al. 1992) compared to prior clinical approaches such as single-photon and dual-photon absorptiometry.

Despite its accuracy and precision, DXA has limitations and clinical shortcomings. The technology is not appropriate for all healthcare and screening applications due to the inherent use of radiation, the large size of DXA units, the relatively high costs associated with DXA screening, and the still limited access and availability.

To address the limitations of DXA, quantitative ultrasound (QUS) methods for bone assessment have been developed and demonstrated that they can determine bone quality and provide information about bone density (Kaufman and Einhorn 1993; Njeh et al. 1997). QUS is nondestructive, noninvasive, less expensive than X-ray technology, and does not expose patients or technicians to radiation (Glüer 1997). But, despite the potential of QUS as a tool for comprehensive, non-invasive assessments of bone strength and composition, its applicability to medical studies and the research field must be validated independently (Glüer et al. 1994). 


\section{BONE DENSITOMETRY APPLICATIONS}

In laboratory animals and wildlife

Bone density studies involving animals have historically been primarily limited to laboratory research animals in the context of pharmacological studies to address human metabolic disorders and diseases such as osteoporosis from a preclinical or clinical evaluation perspective. In humans, osteoporosis is the most common metabolic bone disorder, affecting over 200 million individuals globally (Lin and Lane 2004). As the prevalence of the disorder continues to increase and underdiagnosis and undertreatment continue, the need for rigorous testing and clinical development continues. DXA has become the most common method for measuring BMD of small animals in metabolic bone disease research (Kim et al. 2018). Animal models that have been used to investigate pathogenesis of skeletal diseases include non-human primates (Black and Lane 2002, Smith et al. 2011), dogs (Martin et al. 1981, Nagai and Shindo 1997), cats (Jowsey and Raisz 1968, Cheon et al. 2012), rabbits (Castañeda et al. 2006; Wen et al. 2015), goats (Fulton et al. 1994, Leung et al. 2001), sheep (Thorndike and Turner 1998, Lill et al. 2000), pigs (Inui et al. 2004), and rodents (Sophocleous and Idris 2014), all of which have advantages and disadvantages (Turner 2001).

While many published studies focus on the testing of pharmacological agents on bone density, with regard to the model organisms themselves, there are few studies that characterize normal variation in BMD within a species or attempt to establish normative reference datasets by which to assess individual skeletal health. This is somewhat understandable as these studies are directed specifically at testing the efficacy of a treatment regimen or therapeutic intervention with the intent to translate those findings to 
human medicine rather than to more fully understand bone density in the model organism. However, there is a need for species-specific reference standards to allow researchers to evaluate the status of animals both in the context of the translational human medicine studies and for a general understanding of the model organisms directly being studied, particularly in the fields of wildlife research and conservation medicine.

As the veterinary science field has progressed and the understanding of how to manage the various species under human care has expanded, lifespans of these animals have been prolonged. Both survival rate and life expectancy for dolphins in U.S. zoological facilities have increased significantly over the last $25 \mathrm{yrs}$, with dolphins today living at least as long as those in wild populations (Jaakkola and Willis 2019). The prevalence of age-associated disorders, historically observed only in humans, have coincidentally increased. As with many veterinary procedures, the size alone of some animals under human care often requires adjustments to clinical diagnostic tools. In equine medicine, for example, DXA is problematic in that it is not portable and is not applicable to a conscious, standing horse or other large animal. Studies have demonstrated the potential for using ultrasound to assess bone quality in horses (McCarthy et al. 1990) and such approaches may be applicable across other taxa where application of DXA is problematic.

Overcoming obstacles such as these is paramount in advancing the field of bone densitometry into large animal veterinary and wildlife applications. More advanced research is necessary before this approach can be used reliably in clinical applications; however, the technology has much promise in applications where other radiographic methods are not applicable or are not feasible. 
Published studies on bone densitometry of free-ranging wildlife are rather limited, although relevant studies have been increasing in the last decade as the requisite technology has become more accessible and interest in the topic has broadened. DXA has been applied to measure bone density for several species to examine bone condition in longitudinal studies (Zotti et al. 2009). As the volume of information gained from these studies continues to grow, it is evident that there is much to be learned by applying the concepts from human medicine studies on skeletal health to wildlife species. Despite the inherent challenges, the need for effective wildlife health investigations including both surveillance and research is widely recognized (Ryser-Degiorgis 2013).

\section{In bottlenose dolphins}

Common bottlenose dolphins are long-lived marine mammals that can live in the wild to more than 63 yrs (Wells 2014) and as such are susceptible to health effects of aging as well as long-term anthropogenic impacts and contaminant exposure. Therefore, bottlenose dolphin health studies must account for demographic differences such as age, sex, and geographical affinity, as well as disease status and level of pollutant exposure. Where examined, bone density has been shown to be impacted by all these factors. For example, studies on baboons (Papio hamadryas), another long-lived mammal, demonstrated effects of age, sex, and heredity on bone mass and bone density (Kammerer et al. 1995). A study was subsequently conducted at a biomedical research and primate research facility to characterize normal variation in $P$. hamadryas $\mathrm{BMD}$ and to assess the effect of age and sex on this variation (Havill et al. 2003). Decreases in BMD of archived polar bear skulls was associated with elevated exposure to contaminants such as 
polychlorinated biphenyl ethers (PCBs) and polybrominated diphenyl ethers (PBDEs) (Sonne et al. 2004). Endocrine disrupting compounds, such as organochlorines, have been reported in bottlenose dolphins from the western North Atlantic Ocean, Indian Ocean, US Atlantic coast, and the Gulf of Mexico (O’Shea 1999). For comprehensive osteological health studies to be conducted on dolphins, similar research on BMD is needed to establish a normative reference dataset across age and sex in order to interpret bone density in context of the myriad impacts affecting this long-lived species.

Recent studies have attempted to establish BMD as a tool to estimate age in dolphins (Guglielmini et al. 2002; Butti et al. 2007; Lucić et al. 2010). While these studies demonstrated increases in BMD of dolphin humeri with increasing age and total length, the authors highlighted potential limiting factors, such as small sample sizes and specimens not representing the full lifespan of the species. A more robust study design with a large sample size of specimens spanning the full lifespan of bottlenose dolphins is necessary to determine if BMD can be used to reliably and accurately estimate age. The dolphin humerus and pectoral fin are favorable targets for BMD studies due to their relatively small size, spongious bone composition, and dorsopalmarly flattened orientation (Lucić et al. 2010). Developing research studies and clinical diagnostics focused on this skeletal target site could expand the field of bone densitometry and osteology in marine mammals in a practical and utility-centric manner.

Osteological specimens can serve as a research model to investigate effects of potential contaminant exposure or ecological conditions at a broader scale than is possible by relying solely on soft tissues that are susceptible to rapid post-mortem decomposition. Adaptations of analytical techniques have facilitated advancements in many aspects of 
marine mammal research. Developing bone densitometry as a field of study in wildlife research and conservation medicine, particularly in the context of marine mammal science, would allow for many ecological and environmental lines of research to be pursued. Specifically, utilizing bone density from free-ranging animals or archived skeletal specimens as an indicator of ecosystem health with respect to long-term and acute exposure to anthropogenic contaminants or ecological conditions, would provide a more robust analysis of the effects of environment conditions on apex predators, such as bottlenose dolphins.

\section{SYNOPSIS OF Ph.D. RESEARCH OBJECTIVES}

Animal models have been widely used to correlate in vivo changes in bone mineral density (BMD) with changes in disease state of bone (Egermann et al. 2005, Reinwald and Burr 2008). While BMD is known to increase with age in humans, the rate of ossification and the degree to which bone density increases, ultimately plateau, and especially in light of decreases with prolonged age are still relatively unexplored in animal models, including sentinel marine mammal species such as the bottlenose dolphin (Turner 2001). Correlation of BMD with ontogenetic age of an individual animal has been suggested across multiple taxa (Brain 1967; Binford and Bertram 1977), but the significance of that association has not been comprehensively analyzed.

Altered BMD patterns may be found at different ages of animals belonging to the same species in cases where the density of one skeletal element changes at a different rate than another (Ioannidou 2003) or within the natural variation of BMD values observed at any given age within a species. In human medicine and bone densitometry, T-scores are used to assess skeletal health based on how BMD of the individual compares to the 
expected BMD of a standard, young adult at peak bone mass. In order to investigate environmental or ecological impacts on an individual dolphin's skeletal health or to utilize skeletal health, and specifically BMD, as a life history or health marker, comprehensive research to establish normative bone density values across age, sex, disease status, and nutrition level must be conducted for this species.

To initiate this body of research as applied to the common bottlenose dolphin, a critical and highly studied marine sentinel, the subsequent chapters of this dissertation will specifically address the following primary research aims:

1 - Comprehensively assess the potential of bone mineral density to accurately and reliably estimate age in the common bottlenose dolphin, Tursiops truncatus.

2 - Establish a primary skeletal site for clinical assessment of bone mineral density in the common bottlenose dolphin, Tursiops truncatus.

3 - Provide a preliminary descriptive dataset of bone mineral density in the common bottlenose dolphin, Tursiops truncatus, using museum archival specimens

4 - Develop technology and protocols to ultrasonically assess bone density in the pectoral flipper of the common bottlenose dolphin, Tursiops truncatus.

5 - Perform clinical assessments of bone density in live common bottlenose dolphins, Tursiops truncatus, using quantitative ultrasound.

6 - Correlate body condition and nutritive status with bone mineral density in freeranging common bottlenose dolphins, Tursiops truncatus.

7 - Establish a foundational base of knowledge on bone density in the common bottlenose dolphin, Tursiops truncatus, to facilitate future studies and applications. 


\section{CHAPTER 2}

Bone Density Cannot Accurately Predict Age in the Common Bottlenose Dolphin,

\section{Tursiops truncatus}

The following chapter has been previously published as Powell JWB, Duffield DA, Kaufman JJ, McFee WE. 2019. Marine Mammal Science 35(4):1597-1602.

In marine mammal life history and health studies, knowledge of age is extremely important from both pathological and epidemiological perspectives, transcending population dynamic studies and allowing for a more complete assessment of an individual animal's overall biological health (Hohn 2002, Stolen and Barlow 2003). Ages of small odontocete cetaceans, such as common bottlenose dolphins, Tursiops truncatus, can be determined from either photo-identification records, from which an individual animal is tracked from birth by local research teams (e.g., Wells 2009), or estimated based on skeletochronology, examination of dentinal layers in teeth, from which each set of growth layers represents one year of life (Hohn et al. 1989). Teeth can be collected for age estimation either at time of death or through extraction under local anesthesia during capture-release health assessments.

The impetus for the use of bone density to estimate age is to provide a more rapid, less expensive, noninvasive technique for determining this critically important life history parameter. Further, if bone density could serve as a proxy for age estimation, and if a technique to assess bone density of live dolphins in the field could be developed, an alternative to tooth extraction would be established. Bottlenose dolphins are long-lived 
marine mammals that can live to more than $63 \mathrm{yr}$ (Wells 2014). Pectoral flippers are favorable targets for bone densitometry due to minimal overlying soft tissue, spongious bone composition, and dorsopalmarly flattened orientation.

Previous studies correlated bone density of the dolphin forelimb as measured with dual-energy X-ray absorptiometry (DEXA) with age as estimated with dentinal skeletochronology, and authors of those studies have proposed the utility of this measurement as a reliable predictor for age. The practical applications of this approach would have excellent value in various marine mammal research settings but would require that bone density values at any given age have very limited variance and that the technique should be broadly applicable across all ages. Using DEXA, Guglielmini et al. (2002) examined bone density of flippers archived from 15 age-estimated striped dolphins (Stenella coeruleoalba) that stranded along the Italian coastline. The authors performed a multiple regression analysis on body length, age, and bone density, and the results demonstrated that bone density has a positive correlation with total body length and age, as would be expected under normal bone physiology. The authors noted that their findings are preliminary because of the small sample size and the limited age distribution (up to 14 yr) and state that validation of the study requires larger sample sizes. A similar study was conducted by Butti et al. (2007) on 17 age-estimated bottlenose dolphins, either managed under human care or stranded along the Italian coastline. These authors developed a linear model to predict the age of dolphins by using body length and bone density as predictors. The results were similar to those of Guglielmini et al. (2007) in that bone density was found to correlate positively with total body length and age. The limitations of this study were similar in that the sample size was small and the specimens did not represent the lifespan 
of the species. The 17 bottlenose dolphin specimens used in Butti et al. (2007) only span from birth to 12 years of age, approximately the first $20 \%$ of the lifespan for the species. We suggest that limiting factors of these initial studies, as highlighted by the authors themselves, potentially provide misleading correlations on the utility of bone density to reliably and accurately estimate age.

Bone density is a thoroughly studied life history parameter used in human medical studies. While it is well documented that bone density increases with age, it does so with an accepted variation for any given age in a gender- and ethnic-specific manner necessitating specific normative data for accurate interpretation of bone mineral density measurements (Bianchi et al. 2010). Conversely, there is a range of ages for which a given bone density value can be expected to be observed. For humans, bone density is a quantitative health parameter that clinicians use to determine overall skeletal health and fracture risk; it is not used to predict or estimate age. The use of bone density technologies in forensic anthropology, where investigators have attempted to determine the age at death of human remains, has been mostly unsuccessful (Cunha et al. 2009). These forensic studies have suggested that bone density may be used to characterize remains as belonging to a certain age class; however, the authors recognize that other techniques, such as simple morphometrics, have a much stronger statistical correlation with age (Merritt 2017). Variability in the morphological features used to assess age in the human skeleton (e.g., pubic symphysis, sacro-iliac joint, sternal rib ends) progressively increases from birth to advanced age (Franklin 2010).

To investigate possible limitations of small sample size and limited age distributions in the previous dolphin bone density studies, a much larger sample $(n=206)$ 
of archived bottlenose dolphin specimens spanning a full range of body lengths (94-295 $\mathrm{cm})$ and ages (0-50 yr) was examined. The objective of this study was to comprehensively assess whether bone density is truly a reliable estimator of age for this species. The common bottlenose dolphin skeletal specimens included in this study were obtained from two marine mammal biological collections: the National Oceanic and Atmospheric Administration's Center for Coastal Environmental Health and Biomolecular Research in Charleston, South Carolina $(n=165)$, and the Ruth DeLynn Cetacean Osteological Collection at Mote Marine Laboratory in Sarasota, Florida $(n=41)$. Specimens made available for this study were collected and archived during 1990-2012.

All bone density measurements were conducted on a Norland Sabre pDEXA (peripheral dual-energy X-ray absorptiometry) densitometer (Fig. 1) with Norland Sabre Research software (Version 3.9.2; Norland Medical Systems, Fort Atkinson, WI). The Norland pDEXA unit was developed for clinical use on the human forearm, but the radiographic template and software readily facilitate applications for research specimens. Bone density measurements were made following established protocols that calculate bone density by measuring absorption of two X-ray wavelengths as they pass through the bone generating a two-dimensional areal measurement of density in $\mathrm{g} / \mathrm{cm}^{2}$. To provide continuity with previously published studies, this study focused on the bones of the pectoral flipper, specifically the radius. Of the three bones of the pectoral flipper, the radius is most ideal for osteodensitometry due to its comparatively large surface area, more regular geometry and morphometrically identifiable location within the intact flipper.

Total body length was recorded at time of death for each individual, and the age of each individual was either estimated by dentinal skeletochronology or, if available, known 
from photo-identification studies. Whole radius bone density was examined for a relationship between age and bone density by ordinary least squares regression (OLS) with bone density and total body length as predictors for the response variable, age. As expected, bone density increased with age; however, the variance of bone density values that was observed at any given age (Fig. 2) was of such magnitude (especially in the middle-age range) that it definitively precludes the use of this parameter as a reliable estimator of age. Not only was bone density alone a poor predictor of age $\left(R^{2}=0.50, P<0.001\right)$, but the addition of total body length did not vastly improve the prediction $\left(R^{2}=0.58, P<0.001\right)$. The attempt to establish a usable correlation between bone density, total body length, and age in an effort to use bone density as a predictive tool for estimating age was unsuccessful. In fact, these metrics were no more accurately reliable than estimates based on total length alone $\left(R^{2}=0.48, P<0.001\right)$, which has long been accepted as a poor predictor of age due to the range of total lengths of animals in any given age class (Hohn 1980, Zweifel and Perrin 1980).

In dolphins, as well as in humans, the normal range of bone density values observed at any given age varies, thereby limiting the utility of this single predictor to estimate age across the lifespan of the species. The clinical measurement of an individual's bone density at any given time is a direct reflection of that individual's specific bone physiology and pathophysiology (Bonnick 2010). Reducing osteodensitometry to a static age estimation tool would inherently disregard the biological and physiological function of calcified tissues. Variation of bone density values at any given age may be an indicator of altered skeletal health due to numerous factors including overall health, nutritive status, contaminant exposure, body condition, or metabolic and endocrine related disorders. 
Further studies to investigate potential causes of the observed age-specific variation in bone density, as well as differences between sexes and variation within age class rather than across all age classes, are warranted but are unlikely to provide any support for use of this parameter as a proxy for age.

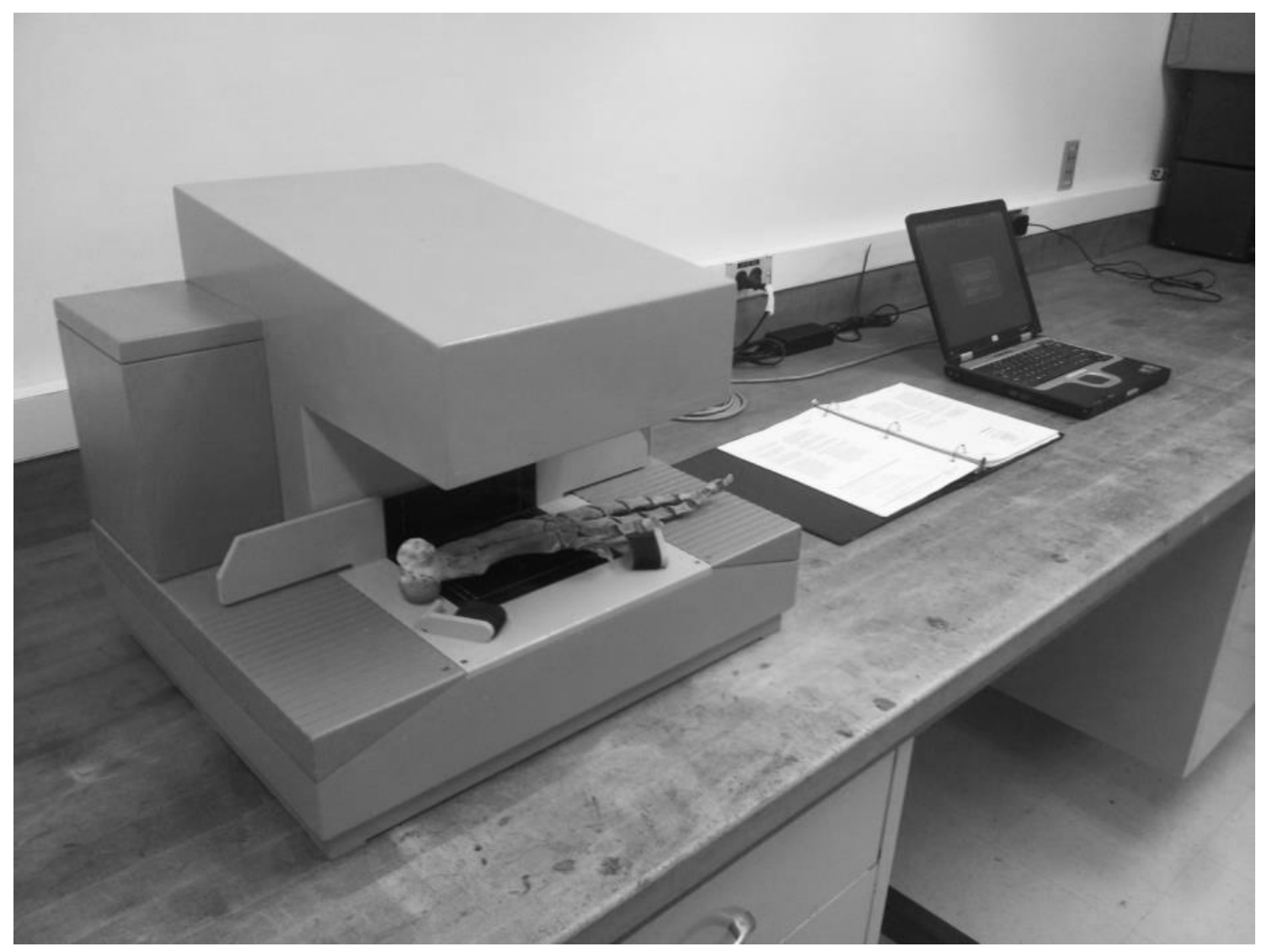

Figure 2-1. Bottlenose dolphin pectoral flipper skeletal specimen on a Norland Sabre pDEXA densitometer (Norland Medical Systems, Fort Atkinson, WI). 


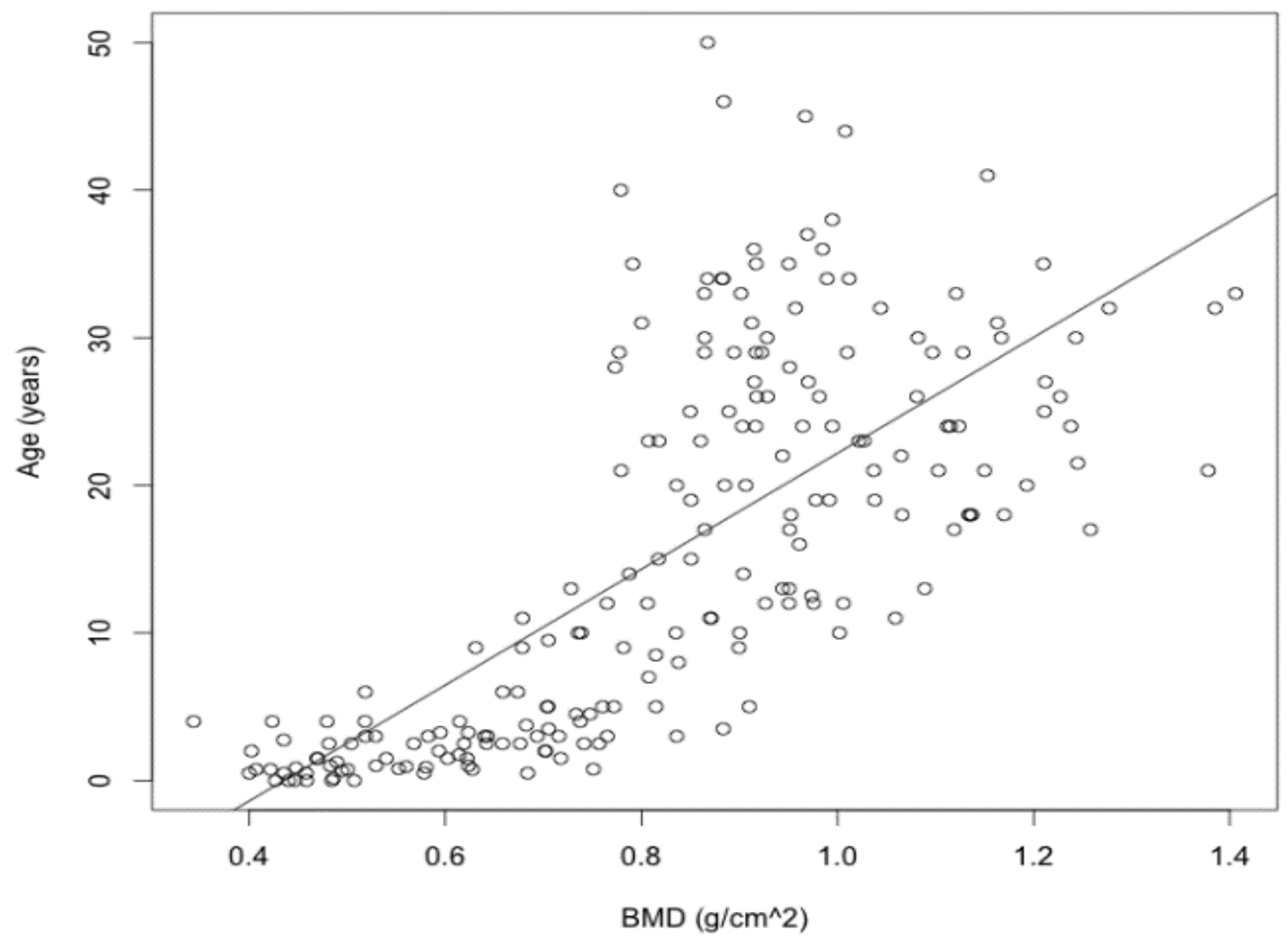

Figure 2-2. Distribution of bone density values from bottlenose dolphin radii relative to age. Bone density increased with age, as expected $\left(R^{2}=0.50, P<0.001\right)$; however, the variance of bone density values observed at any given age definitively precludes the utility of this parameter as a reliable estimator of age. 


\section{CHAPTER 3}

Bone Mineral Density of the Common Bottlenose Dolphin Radius: A Primary Skeletal Site for Clinical Bone Densitometry and Descriptive Dataset Using Archival Specimens

\section{ABSTRACT}

We examined bone mineral density (BMD) in the pectoral flipper of the common bottlenose dolphin, Tursiops truncatus. These data addressed the need to define a comprehensive target site for clinical osteodensitometric assessment and to provide a preliminary descriptive bone density dataset for this species. 388 radii from 279 bottlenose dolphins were analyzed using dual energy X-ray absorptiometry (DXA), the accepted standard in human medical studies. Multiple regions of interest (ROIs) were identified and assessed for their correlation to BMD of the entire bone. Radii were examined for differences based on sex, age, total body length, handedness, geographical affinity, and nutritional status at time of death. BMD increased with age and body length $\left(R^{2}=0.58\right.$, $p<0.05)$. No statistically significant differences were observed in BMD measurements for male and female dolphins $(t=-1.60 ; \mathrm{p}>0.05)$ or right and left flippers $(t=-1.76, p>0.05)$. Additionally, no statistically significant differences were observed based on geographical region $(t=-0.190, p>0.05)$ or nutritional status $(F=0.83, p>0.05)$. These results support the inclusion of all specimens used in this study as a preliminary descriptive dataset for bone density values in bottlenose dolphins and detail a primary skeletal site for clinical assessment of bone density for the species. As this study relies on archived museum specimens collected from dolphins at time of death, further studies regarding bone density may be better addressed using live dolphins with known health status. 


\section{INTRODUCTION}

Assessing marine mammal health is a fundamental aspect of understanding and monitoring marine ecosystems, particularly with regard to anthropogenic impacts. Health assessments of common bottlenose dolphins, Tursiops truncatus, are critical in areas where populations show signs of epidemic disease, high mortality, and/or where ecosystems are being altered or impacted by human activities (Wells et al. 2004). Because bone mineral density (BMD) may be affected by malnutrition and limited access to food (Talbot et al. 1998; Swift et al. 2012), as well as exposure to environmental contaminants (Staessen et al. 1999; Sonne et al. 2004), the capability to determine BMD and understand how those values fit within ranges observed in the species could be an important tool for dolphin health assessments.

The research presented herein seeks to develop assessment capabilities through the comprehensive evaluation of bottlenose dolphin BMD and to provide a preliminary descriptive BMD dataset for this species. There exists little knowledge about bone health, and specifically about BMD, of the bottlenose dolphin, and no reference datasets are available as there are for humans. Reference datasets used in human clinical settings establish a context by which an individual is compared against a normative distribution of values observed within appropriate demographic classifications in order to diagnose a patient within a range of osteoporotic categories (Bhudhikanok et al. 1996).

This study focuses on the bones of the pectoral flipper, specifically the radius, as it is the best target for diagnostic assessment on intact, live animals and is the skeletal site used in previous dolphin studies (Guglielmini et al. 2002; Butti et al. 2007). By establishing 
a descriptive dataset using this bone, translation of findings from analyses of disarticulated specimens collected from stranded, beachcast animals to applications on live animals can be readily facilitated. Pectoral flippers are favorable targets for BMD studies as there is minimal overlying soft tissue, spongious bone composition, and dorsopalmarly flattened orientation (Lucic et al. 2010). Of the three bones of the pectoral flipper, the radius is best for osteodensitometry due to its comparatively large surface area, more regular geometry and morphometrically identifiable location within the intact flipper (Figure 3-1).

Morphometrically identifiable regions of interest (ROIs) are defined as target skeletal sites used for clinical assessment of a patient. For example, a common clinical BMD measurement for the human forearm is the distal third radius (i.e., 1/3 radius or 33\% radius), and this is defined as an ROI centered at a distance equal to one-third of the forearm length measured from the distal end of the radius (Shepherd et al. 2002). Measurements at ROIs allow clinicians to facilitate diagnostics by establishing readily identifiable locations by which to compare individuals within a population or demographic subgroup. Targeted ROIs should, most importantly, have BMD values indicative of the entire assessed bone.

An extensive set of archived bottlenose dolphin radii was used to establish BMD patterns at multiple loci within the radius to support the selection of a single, target ROI for clinical osteological assessment. Intra-individual differences in BMD from paired left and right radii; differences in BMD in male and female individuals; and differences associated with residency patterns and varying nutritional status at time of death were assessed at the selected skeletal site. 


\section{METHODS}

Specimens

Bone specimens were obtained from extensive collections maintained by the National Ocean Service's Center for Coastal Environmental Health and Biomolecular Research (CCEHBR) in Charleston, South Carolina, and Mote Marine Laboratory (Mote) in Sarasota, Florida. Specimens were collected from dead, stranded bottlenose dolphins under Letters of Authorization from the National Marine Fisheries Service. Associated data including sex, total body length, residency patterns, and nutritional status at time of death were available for subsets of the specimens. Routine necropsy procedures followed by both organizations (CCHEBR and Mote) included the collection and archival of at least one pectoral flipper from each stranded animal. Ages of individual dolphins were known either from photo-identification records from local research teams, which track an individual animal from birth (e.g., Wells 2009), or were estimated based on examination of dentinal layers in teeth, each set of growth layers representing one year of life (Hohn et al. 1989).

Radii ( $n=388$ ) from 279 individual bottlenose dolphins were analyzed. BMD of the whole radius and at multiple loci within the radius was measured to establish BMD distribution patterns within the bone and to facilitate selection of an ROI indicative of the overall bone BMD. A subset of radii $(n=274)$ with an approximately even male-female distribution were used to investigate differences in sex. Paired left-right radii $(n=218)$ were available to assess bilateral variation in dolphin radius BMD (i.e., handedness). The 279 dolphins included in the dataset represented animals that stranded in two distinct geographical regions, the Atlantic coastline and inland waters of South Carolina $(n=214)$ and the Gulf of Mexico coastline and inland waters near Sarasota, Florida $(n=66)$. Of these 
individuals, residency patterns were known for 39 individuals ( $n=24$ in Charleston, SC; $n=15$ in Sarasota Bay, FL). Nutritional status at time of death (i.e., robust, undernourished, or emaciated) was available for 116 dolphins. Nutritional status for stranded dolphins is a qualitative assessment of body condition based on morphological observations such as depression caudal to blowhole, concavity ventrolateral to dorsal fin, and visibilty of ribs (Joblon et al. 2008). Ages and total body lengths were available for 205 dolphins and used for developing descriptive BMD curves.

DXA (dual-energy X-ray absorptiometry)

All BMD measurements were conducted on a Norland Sabre pDEXA (peripheral dual-energy x-ray absorptiometry) densitometer and analyzed with Norland Sabre Research software (Version 3.9.2; Norland Medical Systems, Fort Atkinson, WI). The Norland pDEXA unit was developed for use on the human forearm with a radiographic template to accommodate osteological research applications. Bone density measurements were made following established protocols that calculate BMD by measuring absorption of two X-ray wavelengths as they pass through the bone generating a two-dimensional areal measurement of density in $\mathrm{g} / \mathrm{cm}^{2}$. The software interface allows the analysis of up to five ROIs of adjustable size and shape at user-specified loci. Whole bone BMD was measured for each radius using user-defined, adjustable polygons surrounding the entire radius. BMD values were also measured in each radius at four $1 \mathrm{~cm}^{2} \mathrm{ROIs}$ that were readily and repeatably identifiable based on morphometric landmarks and included: the geometric center of the radius, distal-third radius along the central midline of the bone, maximum BMD value across the width at the distal-third of the radius, and at the center of the 
maximum distal width of the radius (Figure 3-2).

\section{Statistical analysis}

The relationship between BMD of each ROI and BMD of the whole radius was analyzed using ordinary least squares (OLS) linear regression analyses to establish the statistical significance of each ROI as a predictor for BMD of the whole radius. This both supported the selection of a single ROI for all subsequent tests and demonstrated the repeatability, accuracy, and precision with which ROIs were positioned during analyses. Radii from dolphins of known sex were compared to assess differences in male and female BMD using a Welch's two sample t-test. Paired left-right radii were tested for bilateral differences using a paired t-test.

Bone mineral density measurements cannot be interpreted in isolation. Since the same BMD measurement on a 1-year old and 30-year old dolphin would indicate problematic BMD in the older dolphin, but be deemed normal for the younger dolphin, BMD needs to be interpreted in context with age and total body length. To provide an ageand length-corrected BMD, Principal Component Analysis (PCA) was used to reduce the dimensions of the three biological variables (age, total body length, and BMD) to a synthetic variable (PCI). Age and total length corrected BMD values were established using PCA to investigate differences in BMD based on geographical residency patterns and nutritional status at time of death.

To evaluate the effects of confounding variables associated with ecology, ecotype, and environment, age and total length corrected BMD for individuals with established residency in two distinct geographic regions was established using Principal Component 
Analysis and a Welch's t-test was performed to determine if differences were observed. An analysis of variance (ANOVA) was performed to examine differences in the PCI scores for each of three categories of health status at time of death (i.e., robust, undernourished, or emaciated). A post-hoc Tukey Honestly Significant Difference (HSD) test was used to examine for any difference in means observed in pairwise comparisons amongst the three nutritional status categories to determine if decreased nutritional health at time of death is associated with decreased BMD.

As body size and maturation are major determinants of BMD (Zemel et al. 2010), the univariate relationship of BMD values and total body length, independent of age, for all dolphins in this study was examined.

\section{RESULTS}

OLS regression models for pair-wise correlations between whole radius BMD and BMD at each ROI showed strong, positive linear relationships ( $\mathrm{R}^{2}$ values from 0.94 to 0.97 , $\mathrm{p}<0.001$; Figure 3-3). The strong correlations observed support the selection of any of the ROIs as a valid skeletal target site. All subsequent analyses utilized the BMD value measured at an ROI located in the geometric center of the radius as the BMD for each respective animal. Bone density values and life history metrics for all 279 dolphins in this study are available as an open-source reference dataset for T. truncatus (Appendix A).

Dolphins used to study the relationship between age and BMD ranged in age from 0 to 50 years. BMD values of animals included in this study ranged from 0.3436 to 1.406 $\mathrm{g} / \mathrm{cm}^{2}$, with a mean of $0.8269 \mathrm{~g} / \mathrm{cm}^{2}$ and a standard deviation of $\pm 0.23 \mathrm{~g} / \mathrm{cm}^{2}$. The best-fit line to represent the relationship between dolphin age and radius BMD is curvilinear with 
BMD following a rapid, nearly linear increase up to approximately 20 years of age before plateauing over the remainder of the dolphins' lifespan (Figure 3-4). Similar to findings in other species, there is a wide distribution of observed BMD values at any given age, particularly as age increases.

Differences in BMD of radii from male and female dolphins across all ages were not statistically significant ( $p>0.05$ ). Mean radial BMD of the male subset was 0.8367 (s.d. $0.2676 \mathrm{~g} / \mathrm{cm}^{2}$ ), vs. the female subset mean of 0.7925 (s.d. $0.1770 \mathrm{~g} / \mathrm{cm}^{2}$ ).

The range of BMD values for paired left and right radii was similar (0.337 to 1.357 $\mathrm{g} / \mathrm{cm}^{2}$, and 0.319 to $1.406 \mathrm{~g} / \mathrm{cm}^{2}$, respectively). Mean values were also very similar in left and right radii $\left(0.816 \mathrm{~g} / \mathrm{cm}^{2}\right.$ and $0.807 \mathrm{~g} / \mathrm{cm}^{2}$, respectively). Bone mineral density did not differ significantly between the left and right radii $(\mathrm{p}>0.05)$.

Age and total length corrected BMD values (i.e., $\mathrm{PCI}$ ) measured in radii from dolphins with established residency patterns were compared. Median values are very similar between the two groups, with considerable overlap in the range. The two geographic group means were not statistically different from one another $(t=-0.190$, $P>0.05)$.

Median PCI values relative to qualitative nutritional status at time of death data were not statistically different among the three groups, but there was considerable overlap. An ANOVA performed on these PCI scores indicated no significant differences among the three nutritional status conditions $(F=0.83, P>0.05)$. A post-hoc Tukey HSD test confirmed that the difference in means between the three conditions was not significantly different from zero (Robust vs Emaciated, $\mathrm{p}=0.41$; Emaciated vs Undernourished $\mathrm{p}=0.64$; Robust vs Undernourished $\mathrm{p}=0.88$ ). 
Bone mineral density values were plotted against total body length to establish normative trends in bone density in relation to skeletal maturation, independent of age (Figure 3-5). The statistical relationship between total body length and BMD can best be described by a polynomial regression $\left(R^{2}=0.79\right)$ where BMD increases with age until peak bone mass is reached.

\section{DISCUSSION}

Using a robust set of archived skeletal specimens, we aimed to establish preliminary descriptive bone density values and a primary skeletal site for clinical bone densitometry in bottlenose dolphins. Since very little research has been conducted on BMD in dolphins, this study effectively serves as the foundation for osteodensitometry in the species. Human clinical bone density assessment relies on a vast baseline of reference data. Reference data are used to assess bone health and disease status including osteoporosis and establish agebased normative distributions of BMD for males and females of various populations (Bhudhikanok et al. 1996). These applications target specific loci in skeletal sites and cover an array of body regions to address various clinical constraints and medical contexts. At each skeletal site, specific morphometrically identified regions of interest (ROI) are targeted. Considerable effort has been devoted to characterizing the most suitable bone and ROI for skeletal analysis in a manner that will facilitate application to live bottlenose dolphins rather than being limited to the assessment of archived skeletal specimens and bones collected during post-mortem examination.

Establishing a descriptive BMD dataset based on a readily identifiable ROI using morphometrics fosters a smooth transition into next generation diagnostics. This approach, 
and the selection of any of the targeted ROIs, is justified by the strong statistical significance of the relationship between the BMD of each ROI and the BMD of the whole radius. The decision to select the geometric center of the radius as the definitive BMD target was multi-faceted: (1) the geometric center ROI is more easily located within a fully intact flipper, facilitating ease of field-based assessments while maximizing accuracy and precision of ROI placement; (2) proposed next generation ultrasonic bone density assessment (see Chapter 4) is a through-transmission technology that requires access to both sides of the bone; and (3) bone densitometry accuracy is enhanced in a region of higher BMD compared to a region of lower BMD.

Much interest has been generated in utilizing BMD to estimate age in bottlenose dolphins (Guglielmini et al. 2002; Butti et al. 2007). The practical application of this technique would have great value in various marine mammal research settings, but it would rely heavily on BMD values at any given age having a very limited variance. Using a much larger dataset than the aforementioned studies, an attempt to confirm a usable correlation between BMD and age as a predictive tool for estimating age in bottlenose dolphins, especially for adults, was unsuccessful (Powell et al. 2019). The authors noted that variation in BMD values observed at any given age may represent natural variation in the species but also could be an indicator of altered skeletal health due to factors including overall health, nutritive status, contaminant exposure, body condition, or metabolic and endocrine related disorders.

To establish a descriptive BMD dataset, potentially confounding life history variables needed to be examined to justify the inclusion of all specimens. Based on information available about dolphins in the study, subsets of the total specimens were used 
to address specific questions. In the coalesced specimens from 279 dolphins, no statistically significant differences were observed between male and female dolphins, left and right flipper bones, dolphins from different geographical regions, or dolphins with different nutritional body condition at time of death.

In human development, well-characterized differences in males and females increase in magnitude with increasing age (Lim et al. 2004). The loss of estrogen production in menopausal women results in increased bone resorption, driven by an increase in osteoclastic activity, and consequently decreased bone mass in comparison to males of the same age (Civitelli et al. 1988). Bottlenose dolphins are long-lived marine mammals that can live to more than 63 yrs (Wells 2014), an age where osteological changes are regularly observed in humans (Sözen et al. 2017). The individuals included in this study that are older than 40 years old exhibit lower than expected BMD if no late age bone loss was occurring. Specifically, 4 of the 5 oldest dolphins are females and may be exhibiting age-related bone loss, low bone density, or osteoporosis. Low sample numbers in this age class reduce the statistical power necessary to address this topic in a robust manner, but there is an obvious trend in decreasing BMD with increased age following the age at which skeletal maturity has been reached. Continued and expanded acquisition of specimens, particularly from older dolphins, may help to address this deficiency and foster investigation of age-related metabolic bone disorders in marine mammals. As there is no statistically significant difference in BMD observed in male and female dolphins, separating the specimens by sex or establishing sex-specific descriptive curves is not necessary. The lack of differences observed may in part be due to the multitude of variants 
inherent in post-mortem collected specimens as health issues associated with the individuals' deaths may result in values that deviate from the values of healthy individuals.

The intra-individual bilateral symmetry observed in BMD provides support for the use of either pectoral flipper to assess BMD for an individual dolphin and lends support to the use of all radii available, regardless of whether they are left or right pectoral flippers. Similarly, no difference in bone density was observed between left and right thoracic limbs in a study of Guiana dolphins, Sotalia guianensis (Azevedo et al. 2015). Bilateral symmetry is beneficial in a practical sense because, due to spatial constraints, routine necropsies and tissue archival protocols at many institutions include retention of partial skeletons, and under field conditions it is not always possible to access the same flipper for every animal. Therefore, in future clinical applications, BMD assessments of live dolphins can justifiably be conducted on either the left or right flipper.

As long-lived apex predators, bottlenose dolphins serve as indicators of ecosystem health (Wells et al. 2004). The specimens utilized in this reference dataset come from two disparate geographical regions and would thereby be impacted by different ecological and environmental factors. Comparisons between animals known to be year-round residents of two locations revealed no statistically significant differences in BMD, providing support for the total inclusion of specimens from both regions into the descriptive BMD dataset.

Dolphins that were deemed emaciated at time of death were not significantly different from dolphins deemed robust or undernourished at time of death. Since postmortem nutritional status assessment is a qualitative metric that describes the animal's body condition at time of death and does not reflect the longevity of the underlying malnourishment, the data here may not be an accurate reflection of actual differences that 
are expected to be seen between live animals of robust and emaciated body condition. Additionally, there is the potential for introduced error as these qualitative determinations were made by multiple stranding response personnel and may have not been characterized in a standardized method. With the specimens available for the current study, it is not possible to know if the emaciated or undernourished conditions observed at time of death were acute, where changes in body condition were rapid enough that osteological changes had not occurred, or chronic, where osteological changes would be expected due to prolonged malnutrition. Given that no statistically significant differences were observed across the three post-mortem nutritional status categories, all specimens regardless of body condition were included in the normative reference dataset. Differences may be delineated in the future from photo-identification records where long-term undernourishment has been recorded for specific individuals in field studies (e.g., Hart et al. 2013) or where body condition can be scored quantitatively. Clinical assessments of live dolphins exhibiting varying body conditions in future studies, particularly studies of live dolphins, may elucidate an association between BMD and nutritive health status.

To the authors' knowledge, the 389 radii utilized in this study represent the largest dataset published on bone density in any wildlife or marine mammal species to date. An approximately even distribution of male and female dolphins from birth to 50 years of age is included, representing a range of life history classifications. Additionally, the dataset includes individuals from two distinct geographical regions of the southeastern United States.

Diagnosis of metabolic bone disorders such as osteoporosis and low bone density (i.e., osteopenia) in humans is based on a statistical comparison to the average BMD values 
for a healthy, young adult at peak bone mass. The descriptive bone density reference dataset established in this study will facilitate a similar diagnostic approach for bottlenose dolphins. Future studies to establish BMD values for a normal, healthy population, perhaps from live, free-ranging dolphins rather than from dead-stranded animals, would enhance the utility of such a reference dataset. With a reference standard by which to compare and diagnose skeletal health in individuals, bone densitometry can be incorporated into health assessment studies of free-ranging bottlenose dolphins and on museum-archived specimens collected by marine mammal stranding response programs. 


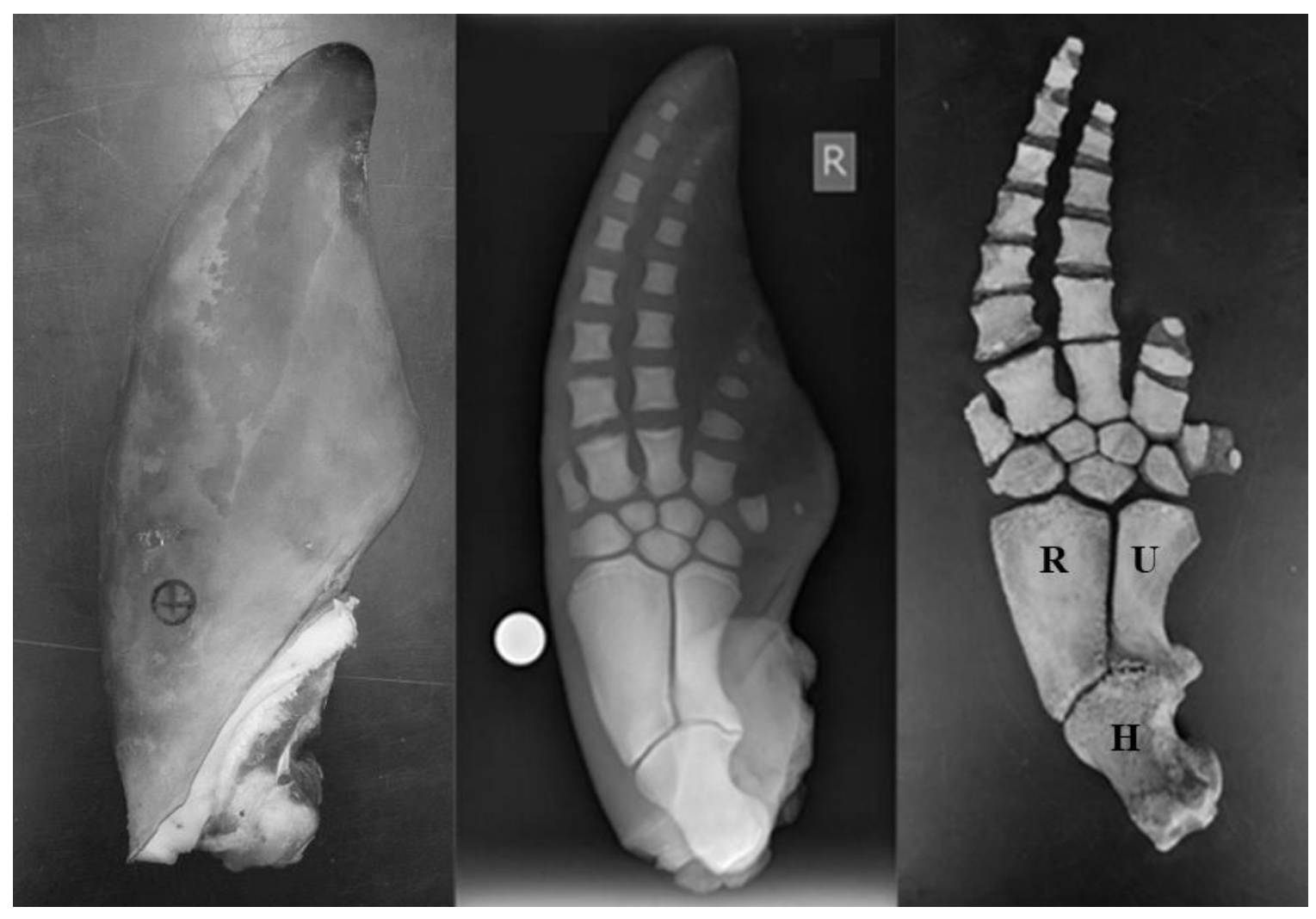

Figure 3-1. (Left to right) typical bottlenose dolphin flipper specimen; standard digital radiograph of a bottlenose dolphin flipper; and museum pectoral flipper bone specimen showing humerus $(\mathrm{H})$, radius $(\mathrm{R})$, and ulna $(\mathrm{U})$. 


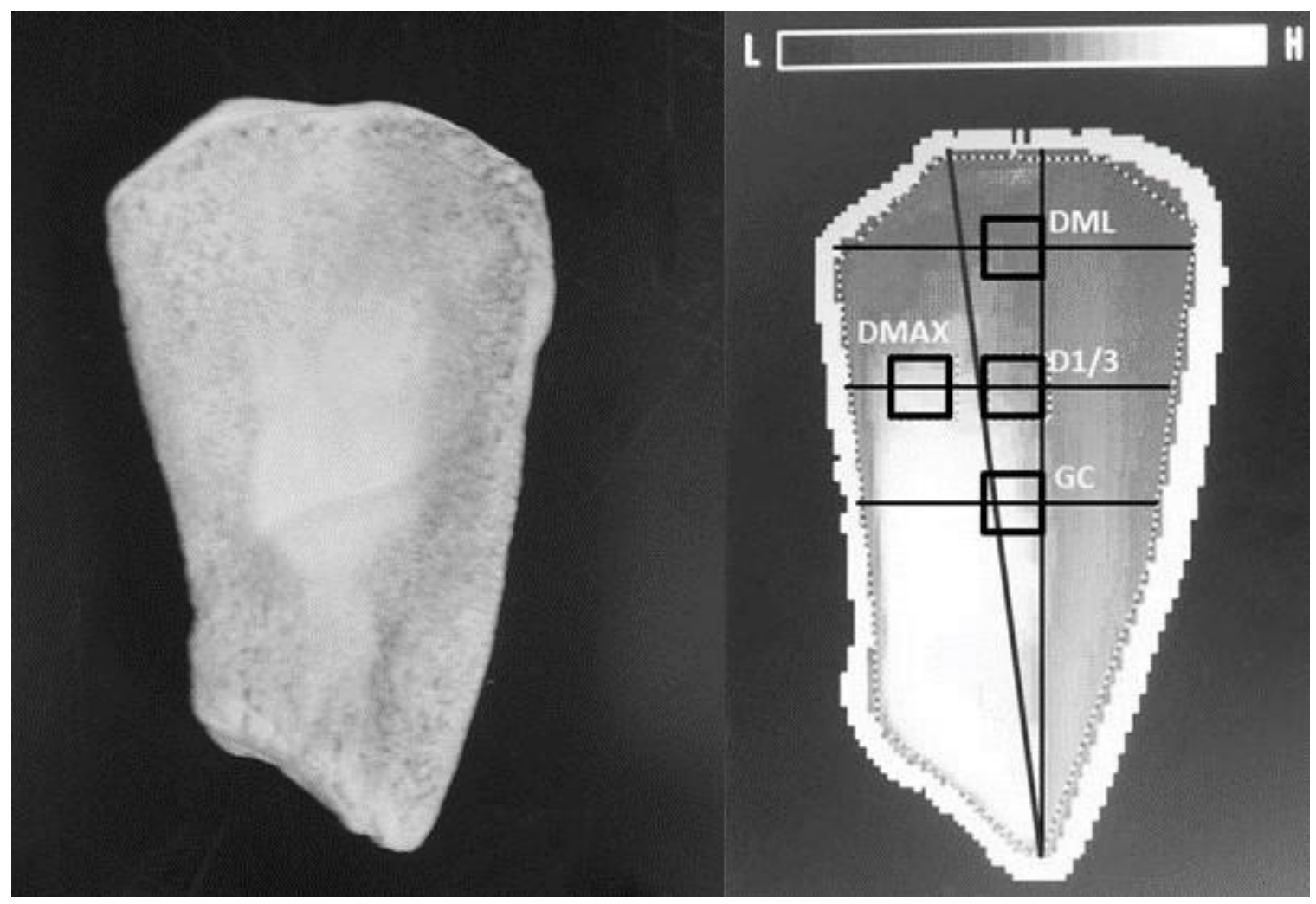

Figure 3-2. Bottlenose dolphin radius (left) and pDEXA software screen capture of a typical radius BMD scan (right). pDEXA software allows for multiple user-defined ROIs on the same scan. The 5 ROIs defined for each radius pDEXA scan include: whole radius (defined by the outer margin of the entire bone), geometric center of the radius (GC), distalthird radius (D1/3), max BMD across the width at the distal-third of the radius (DMAX), and an ROI set in the center of the maximum distal width of the radius (DML). 
A

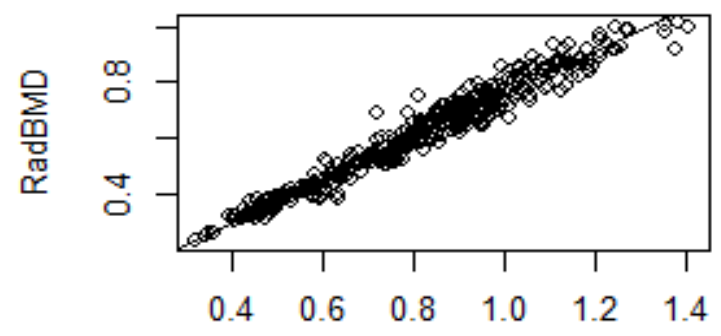

GC

C

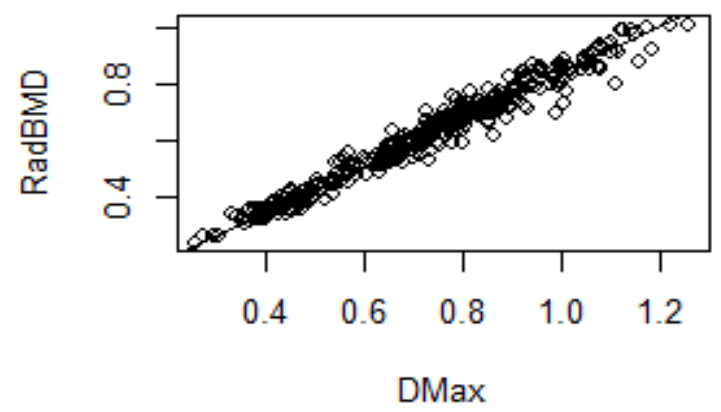

B

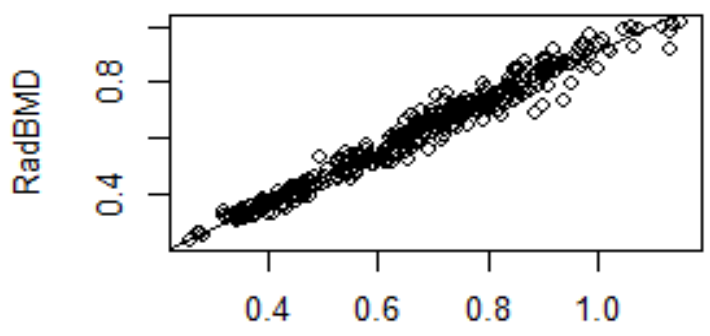

D1_3

D

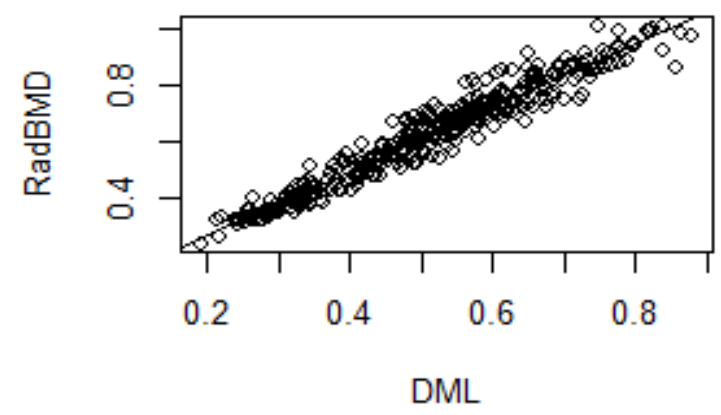

Figure 3-3. BMD values at four selected ROIs (described in Figure 3-2) and the whole radius BMD (RadBMD). The $\mathrm{R}^{2}$ values range from 0.94 to $0.97(\mathrm{p}<0.001)$, thereby supporting the selection of any ROI as a robust representation of whole radius BMD. All subsequent analyses in this study were conducted using an ROI at the geometric center of the radius, depicted in graph $\mathrm{A}$. 


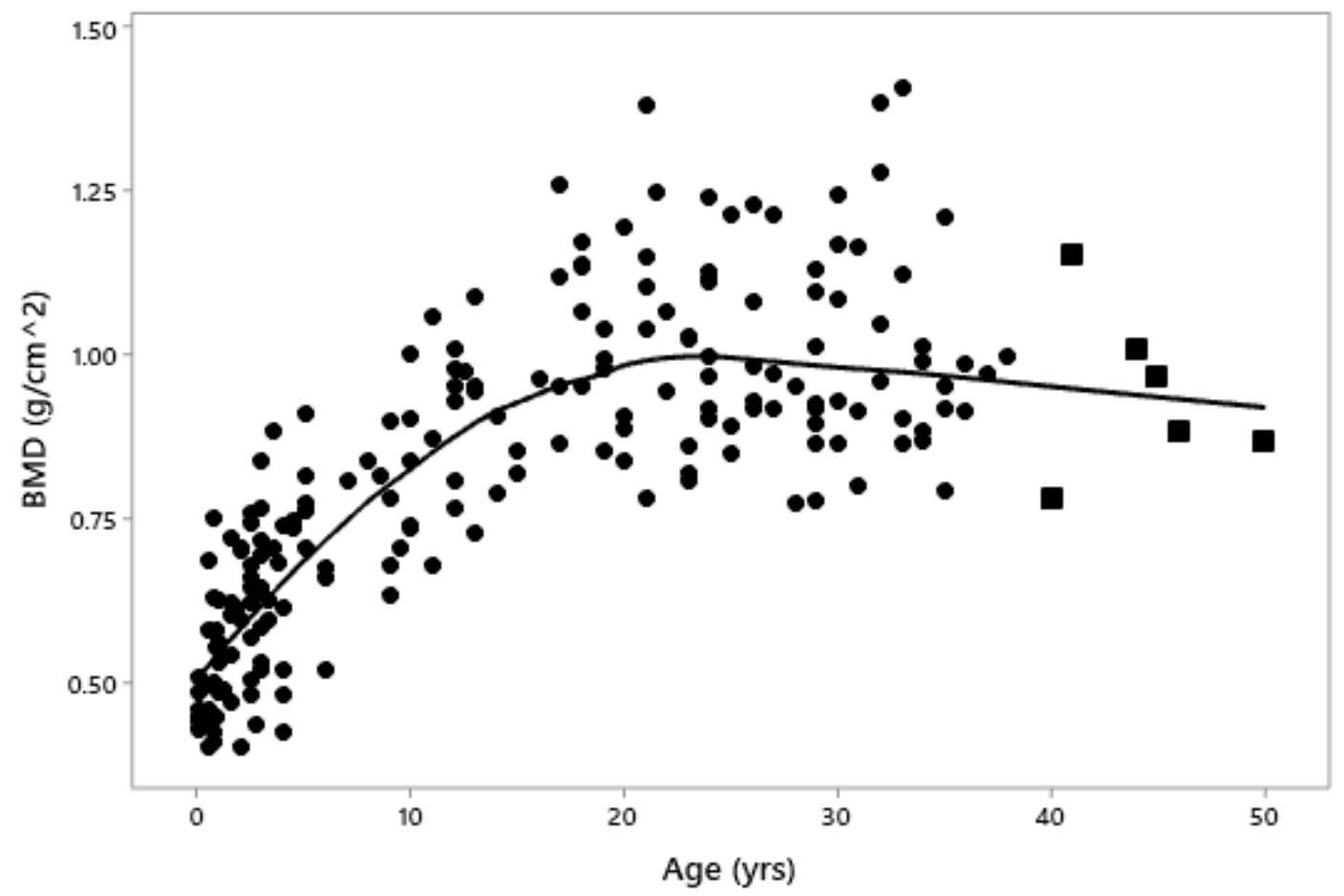

Figure 3-4. Distribution of BMD values from 279 bottlenose dolphins. The Loess curved fit line shows the non-linear relationship between BMD and age as BMD increases with age up to approximately 25 years of age before slowly declining with increasing age. Dolphins 40 yrs old and older are highlighted (घ) for emphasis. 


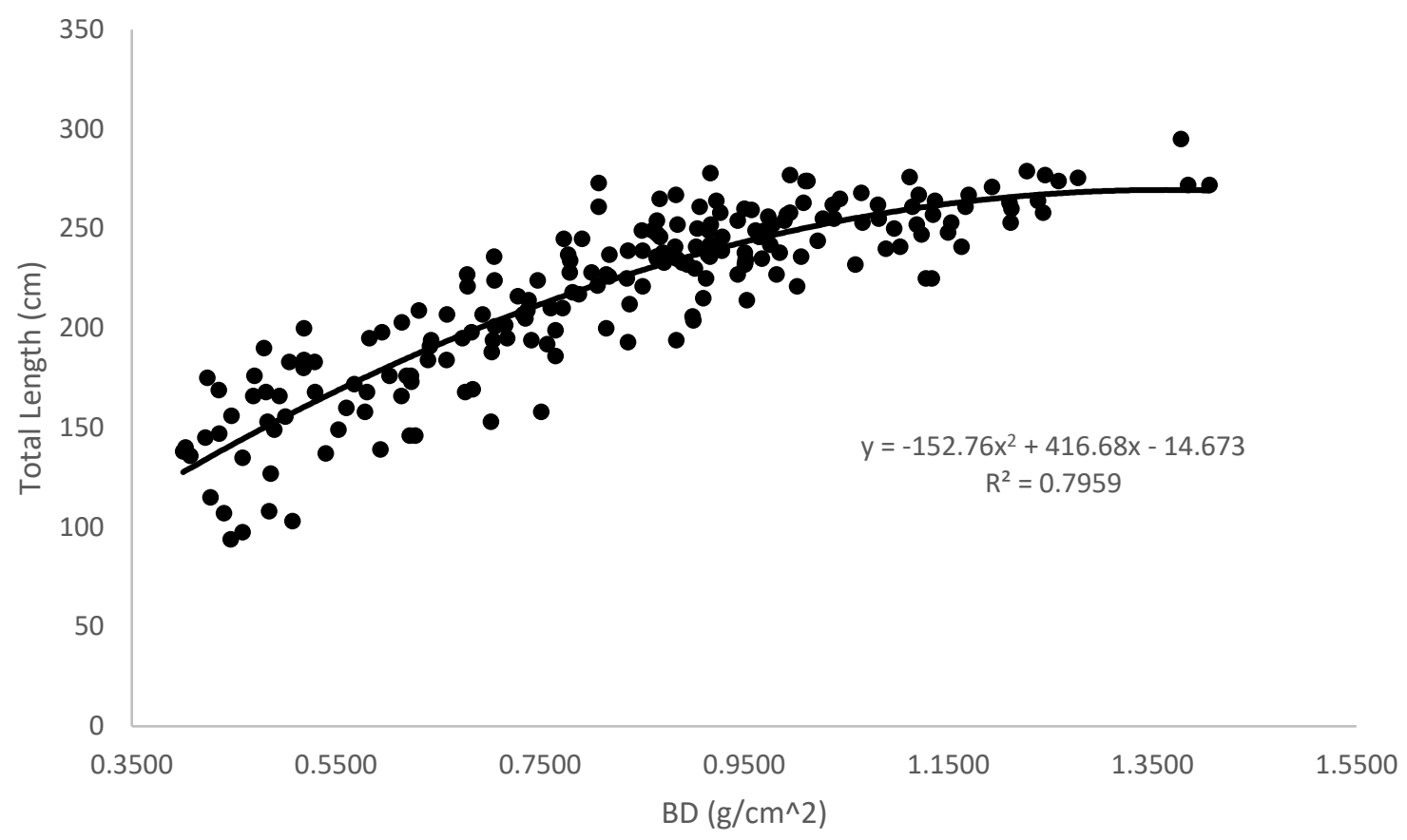

Figure 3-5. BMD vs. total body length for 279 bottlenose dolphins. The polynomial equation represents the best fit of the series of data points and demonstrates how BMD increases with total body length as the skeleton develops during growth and maturation. 


\title{
CHAPTER 4
}

Quantitative Ultrasonic Assessment of Bone Density in the Pectoral Flipper of the Common Bottlenose Dolphin, Tursiops truncatus

\begin{abstract}
In order to circumvent limitations in traditional radiographic bone density assessment, a custom quantitative ultrasound device and protocols were developed for assessment of live common bottlenose dolphins, Tursiops truncatus. In laboratory measurements on disarticulated pectoral flippers collected post-mortem, a strong correlation was established between bone mineral density (BMD) as measured with quantitative ultrasound and X-ray $(\mathrm{r}=0.93)$. Initial trials to develop clinical protocols and establish ultrasonic assessment of bone as non-aversive were conducted on dolphins managed under human care. Findings support the application of quantitative ultrasonic assessment of bone density to assess skeletal health in free-ranging dolphins during capture-release health assessments and in populations of dolphins under human care.
\end{abstract}

\section{INTRODUCTION}

Monitoring the health of marine mammals, including common bottlenose dolphins (Tursiops truncatus), is a crucial component in characterizing and understanding overall ecosystem health. In the following text for brevity, use of the word "dolphin" should be understood to mean "common bottlenose dolphin". Dolphin health assessment is a useful tool in areas where populations show signs of epidemic disease, high mortality, and/or where ecosystems are being altered or impacted by human activities (Rowles et al. 2018). 
Presently, such health monitoring involves an extensive set of measurements and analyses, including morphometric data, physical examination, hematology and blood chemistry, serology, diagnostic ultrasound, anthropogenic contaminant analyses, and hearing tests (Townsend et al. 2018). Digital thoracic and dental radiographs have recently been added which allow for examination of skeletal health, and age estimation approaches using these techniques are being developed (e.g., Barratclough et al. 2019).

Given the vast importance of the functions bone serves, any alteration or disturbance in bone mineral density (BMD) or other bone quality, despite the underlying cause, could have significant consequences on the individual's overall health, physiology, or behavior. Conversely, these skeletal alterations and disturbances provide researchers and clinicians mechanisms to detect and monitor potential impacts to an individual's or population's health. Therefore, information derived from skeletons may be used to elucidate a better understanding of population biology and individual health (Metcalfe 2007). However, there is no current technology to assess bone density for this or any related species in capture-release health assessment research projects.

The most common method for assessing bone relies on estimation of its associated BMD, but present X-ray based methods for estimating BMD are not adaptable to the conditions under which dolphin field health assessments are conducted. In addition to technological limitations, the lack of a normative reference dataset for dolphins has previously precluded placing BMD values into a clinical context for such applications as ecosystem monitoring or diagnosis of an individual's osteological health.

Densitometric methods have been developed that rely on the attenuation of ionizing radiation to quantify BMD at multiple skeletal sites; the most commonly used of these 
technologies is dual energy X-ray absorptiometry (DXA) (Bonnick 2010). Despite its accuracy, precision, and widespread use, DXA has limitations and clinical shortcomings. The technology is not appropriate for all healthcare and screening applications due to the inherent use of radiation, large size of DXA units, relatively high associated costs, and limited access and availability. Quantitative ultrasound (QUS) methods for bone assessment have demonstrated potential to determine bone quality and to provide information about bone density (Kaufman and Einhorn 1993). With the advent of QUSbased medical devices, ultrasonic densitometry has increased in prevalence in human clinical applications (Kaufman et al. 2007; Kaufman et al. 2010; Kaufman and Luo 2017). Diagnostic sensitivity for fracture risk and osteoporosis is similar in BMD measured with DXA and QUS (Njeh et al. 1997). More importantly, from a clinical perspective, QUS is beneficial in that it is portable, nondestructive, noninvasive, less expensive than X-ray technology, and does not expose patients or technicians to radiation (Glüer 1997). Unlike radiographic approaches to densitometry, QUS readings are nearly instantaneous once properly positioned.

The radius was selected as the primary skeletal target due to its relatively consistent shape and thickness as well as its anatomical placement within the pectoral flipper. Additionally, the radius is an established site for skeletal assessment in human medicine and is the skeletal site used in previous studies on dolphin bone density (Butti et al. 2007; Powell et al. 2019). We investigated the use of QUS adapted for assessing bone density in the dolphin radius.

Utilizing archived pectoral flippers collected post-mortem from beach-cast, stranded dolphins, correlations were made between BMD measurements made with DXA 
and a custom QUS device to statistically test the relationship between the two measurements and to establish a predictive equation for use in clinical assessments. Additionally, the QUS device was tested on live dolphins managed under human care in order to demonstrate the non-aversive nature of this novel application. Development of this technology will enable assessment of dolphin bone density by researchers and wildlife veterinarians thereby broadening the understanding of dolphin and, consequently, marine ecosystem health.

\section{MATERIALS AND METHODS}

Specimens

Dolphin pectoral flippers $(\mathrm{n}=29)$ utilized for this project were collected from postmortem stranding response efforts from 1993-2012 at the National Oceanographic and Atmospheric Administration's Coastal Marine Mammal Assessments Program (Charleston, SC, USA). Frozen flippers were thawed to room temperature for DXA and QUS measurements. A typical disarticulated dolphin pectoral flipper and standard digital radiograph with labeled region of interest (ROI) are provided for reference in Figure 4-1.

\section{In-vivo measurements of live bottlenose dolphins}

Methods used on disarticulated flippers were also applied to live dolphins in order to demonstrate the non-aversive nature of this novel application. Initial trials to develop clinical protocols were conducted with two dolphins cared for by the U.S. Navy Marine Mammal Program (Point Loma Naval Base, San Diego, CA, USA). Methods established on disarticulated flippers to readily locate the primary ROI within the pectoral flipper using 
morphometric landmarks were applied to live dolphins, and protocols for performing ultrasonic scans as expeditiously as possible were established. The controlled setting and well-trained animals provided an opportunity to streamline the diagnostic methods so they could be approved and integrated into research projects on free-ranging dolphins.

\section{Peripheral dual-energy X-ray absorptiometry (DXA)}

All DXA measurements were conducted on a Norland Sabre pDEXA (peripheral dual-energy x-ray absorptiometry) densitometer and analyzed with Norland Sabre Research software (Version 3.9.2) (Norland Medical Systems, Fort Atkinson, WI). The Norland pDEXA unit was developed for use on the human forearm with a radiographic template to accommodate osteological research applications. Bone density measurement calculations were based on absorption of two X-ray energy levels as they pass through the bone, generating a two-dimensional areal measurement of density in $\mathrm{g} / \mathrm{cm}^{2}$. BMD was measured at an operator-defined ROI at the geometric center of the radius following established guidelines (Powell et al. in preparation). BMD at the selected ROI has a strong statistical correlation with BMD of the whole radius bone and is a site that is readily identifiable using external morphometric landmarks on an intact flipper. Specifically, the ROI is a $1 \mathrm{~cm}^{2}$ site centered at $50 \%$ of the radial length along the proximal-distal axis and $50 \%$ of the medial-lateral width at that point (Fig. 1).

Quantitative ultrasound and net time delay (NTD)

Unlike attenuation-based radiographic approaches, QUS utilizes ultrasound to noninvasively assess bone. The primary approach is one comparing two acoustic parameters 
of through-transmission: one where an ultrasound signal that has propagated through a medium of interest (e.g., one containing bone) and a second where a signal has propagated through a reference medium of known acoustic properties (e.g., water). Two acoustic parameters which have been typically utilized with QUS are broadband ultrasound attenuation (BUA) and speed of sound (SOS). Neither of these parameters has been found to be highly correlated with BMD, however (Kaufman and Einhorn 1993). In contrast to BUA and SOS, a more recently described acoustic parameter, net time delay (NTD), has been found to have a high degree of correlation with BMD (Kaufman et al. 2008). Briefly, NTD is defined as the difference between the time, $\tau_{\mathrm{s}}$, required for an ultrasound pulse to travel through soft tissue only and the time, $\tau_{\mathrm{b}}$, for an ultrasound pulse to travel through bone and overlying soft tissue of overall equivalent distance, i.e., NTD $=\tau_{\mathrm{s}}-\tau_{\mathrm{b}}$. It can be shown analytically that BMD is directly proportional to NTD, that is $\mathrm{BMD}=\mathrm{k} \cdot \mathrm{NTD}$, and the constant $\mathrm{k}$ depends on the material velocities of ultrasound in net bone and soft tissue, respectively, as well as a conversion factor between bone thickness and its densitometric (X-ray) equivalent (Attix 1986; Kaufman et al. 2007). NTD has been shown to provide a good estimate of BMD in both human cortical and trabecular bone (Kaufman et al. 2007; Kaufman et al. 2008; Le Floch et al. 2008; Stein et al. 2013). In practice, an affine regression (i.e., $\mathrm{BMD}=\mathrm{a} \cdot \mathrm{NTD}+\mathrm{b}$, where $\mathrm{a}$ and $\mathrm{b}$ are parameters determined by the method of least squares) is used to obtain minimum error in the prediction of BMD and explain the behavior of a statistic variable $y$ as an affine function of another statistic variable $x$ (Stein et al. 2013). 


\section{QUS device and signal processing}

Quantitative ultrasound measurements were made using a custom designed QUS prototype (Figure 4-2). The ultrasound system places a pair of transducers in a coaxial, fixed position to ensure the sound waves generated are passed directly from the transmitting transducer to the receiving transducer in a direct path. Transducers are mounted vertically on a slide fixture that allows the device to be adjusted, positioned snugly against flippers of varying size and thickness, and locked to ensure transducer separation remains fixed during measurement.

Two broadband 1.0 MHz circular single element ultrasonic transducers (V303 Olympus NDT, Waltham, MA) are held in the adjustable-width, locking fixture. The source transducer is excited with an approximately -300 volt 1 microsecond duration pulse (Panametrics SR5077PR Pulser Receiver). The ultrasonic waveform, after propagating from the source through the pectoral flipper, is received by a coaxially located receiving transducer. The receiver transducer is connected to an electronic preamplifier and the signal is digitized by a LeCroy (Model 9310A) oscilloscope for sampling at $100 \mathrm{MHz}$. Fivehundred twelve acquisitions of received acoustic waveforms are averaged to obtain the mean received ultrasonic signal which is then downloaded via GPIB (General Purpose Interface Bus) to a personal computer for storage and off-line analysis. A well-defined pulse shape for the soundwave signal is generated after sound has propagated through the pectoral flipper and radius (Figure 4-3). 


\section{In-vitro measurements of archived pectoral flippers}

ROIs were located using external landmarks and standard flipper measurements and confirmed by overlaying a full-scale digital radiograph over the flipper. A circular mark the size of the ultrasound transducer was placed on the ROI to visually guide placement of the transducers (see Figure 4-1).

Ultrasound measurements were conducted at room temperature with ultrasonic coupling gel in contact between transducers and surface of the pectoral flipper. Custom developed, proprietary software was used to analyze the ultrasound signal through the flippers (NTDScope, CyberLogic, Inc., New York, NY). Once the measurement through the flipper was obtained, the transducers were removed from the flipper with the transducer separation maintained by a locking mechanism on the slide fixture. A pure water reference measurement was then obtained with the transducers in the same locked position as they were on the pectoral flipper. The travel time through the water bath, $\tau_{\mathrm{W}}$, was then evaluated from this data set and the distance, $\mathrm{d}$, between the two transducers estimated using $\mathrm{d}=$ $\mathrm{V}_{\mathrm{W}} * \tau_{\mathrm{W}}$, where $\mathrm{V}_{\mathrm{W}}$ is the velocity of ultrasound in the water bath, which was determined using tabulated values of ultrasound velocity as a function of temperature (Afaneh et al. 2011). Finally, $\tau_{\mathrm{S}}$ was computed using $\tau_{\mathrm{S}}=\mathrm{d} / \mathrm{Vs}$, where Vs was obtained as the value which maximized the correlation of NTD with BMD, as measured with DXA; for this study, Vs was found to be equal to $1450 \mathrm{~m} / \mathrm{s}$.

\section{Statistical analysis}

The relationship between radiographic (DXA) assessed BMD and quantitative ultrasound measurements (i.e., NTD) of each pectoral flipper was analyzed using ordinary 
least squares (OLS) linear regressions to establish the statistical significance of the correlation between the two measurements.

\section{RESULTS}

The quantitative ultrasound parameter NTD and BMD as measured by DXA demonstrated a statistically significant correlation as determined by OLS linear regression $(\mathrm{r}=0.93, \mathrm{p}<0.001)$ and can be defined by the equation:

$$
y=0.2185 x-0.0499
$$

The linear univariate regression between NTD and BMD produced a standard error of the estimate of $0.06 \mathrm{~g} / \mathrm{cm}^{2}$. The significant linear relationship (Fig. 4) indicates that ultrasound measurements (i.e., NTD) can serve as a reliable proxy for BMD. Further, the linear equation from the regression analysis above can be used to calculate BMD in a dolphin flipper, where $\mathrm{x}$ is equal to NTD.

Trials conducted on live bottlenose dolphins $(n=2)$ successfully demonstrated that ultrasonic assessment of bone using the custom QUS prototype was non-aversive (Fig. 5). Both dolphins voluntarily presented their pectoral flippers and remained stationed with animal trainers during the procedure. No adverse behavioral reactions or physiologic reactions were detected and breathing remained constant and normal throughout the process.

\section{CONCLUSIONS}

Despite the wide-ranging set of health data collected during capture-release health assessments of wild populations, routine veterinary monitoring in managed care settings, 
and post-mortem examinations of beach-cast, stranded animals, there is only limited information available on osteological parameters for dolphins and, prior to this study, no available technology to readily assess BMD during wildlife health examinations. Efforts have been made to rectify the need for a dolphin-specific normative reference dataset for BMD values (Powell et al. in preparation). The current study introduces a custom QUS system and protocols which allow for the ultrasonic assessment of dolphin bone with an extremely strong correlation with BMD as measured with DXA. This new technology estimates BMD with a similar linear correlation as reported in a clinical study of the distal one-third radius in humans (Stein et al. 2013). Further, the same correlation observed in this study led the United States Food and Drug Administration to clear an ultrasound device as a direct estimate of BMD as would be measured by DXA (U.S. Food and Drug Administration 2017).

Technology has been developed to estimate human BMD using an affordable, portable handheld device that relies on ultrasound rather than ionizing radiation (Kaufman et al. 2007); however, additional research was necessary to develop reliable correlations between actual BMD and the parameters measured in ultrasonography. Given this, additional clinical studies in humans have demonstrated a high degree of correlation between DXA and ultrasound-determined BMD (Siffert and Kaufman 2007).

The diagnostic performance of QUS at multiple skeletal sites in humans is comparable with DXA (Hartl et al. 2002). Recent advancements in QUS technology have included ultrasonic assessment of the phalanges in comparison to quantitative computed tomography (QCT) (Louis et al. 2000), a portable real-time ultrasonic bone densitometer to estimate BMD at the calcaneus (Kaufman et al. 2007), a QUS device for measurements 
at the proximal femur (Barkmann et al. 2010), a desktop ultrasonic bone densitometer to assess BMD at the distal radius (Stein et al. 2013), and a dual-mode ultrasonic technique for assessing cortical bone in the tibia (Kaufman and Luo 2017).

When prospectively validated, QUS has proven to be a reliable, low-cost, readily accessible alternative to DXA measurements of bone density (Hans and Baim 2017) especially in resource-constrained settings (Ramteke et al. 2017). Properly designed and tested devices have the potential to become simple, safe, and effective screening tools for bone loss and fracture risk (Kaufman et al. 2010). The National Osteoporosis Society has recently acknowledged that the use of less expensive and more convenient methods, other than DXA, for evaluating BMD and assessment of osteoporosis are appealing (Dhalnaut et al. 2016). Given the World Health Organization's clinical definition of osteoporosis is based specifically on DXA values (Sözen et al. 2017), this is a significant shift in the biomedical industry and is notably indicative of the vast improvements in alternative technologies, such as QUS, in the ability to properly diagnose skeletal disease and fracture risk.

Both DXA and QUS are underutilized tools in zoological and wildlife studies, and as bone densitometry continues to emerge as a field of study these technologies will increase in importance. While the potential use of DXA in field settings is limited, QUS could have boundless utility as a screening tool to investigate bone health in wildlife, especially in applications to live animals. The comparatively affordable costs, radiationfree approach, and portability of devices make this technology an ideal choice for wildlife studies. 


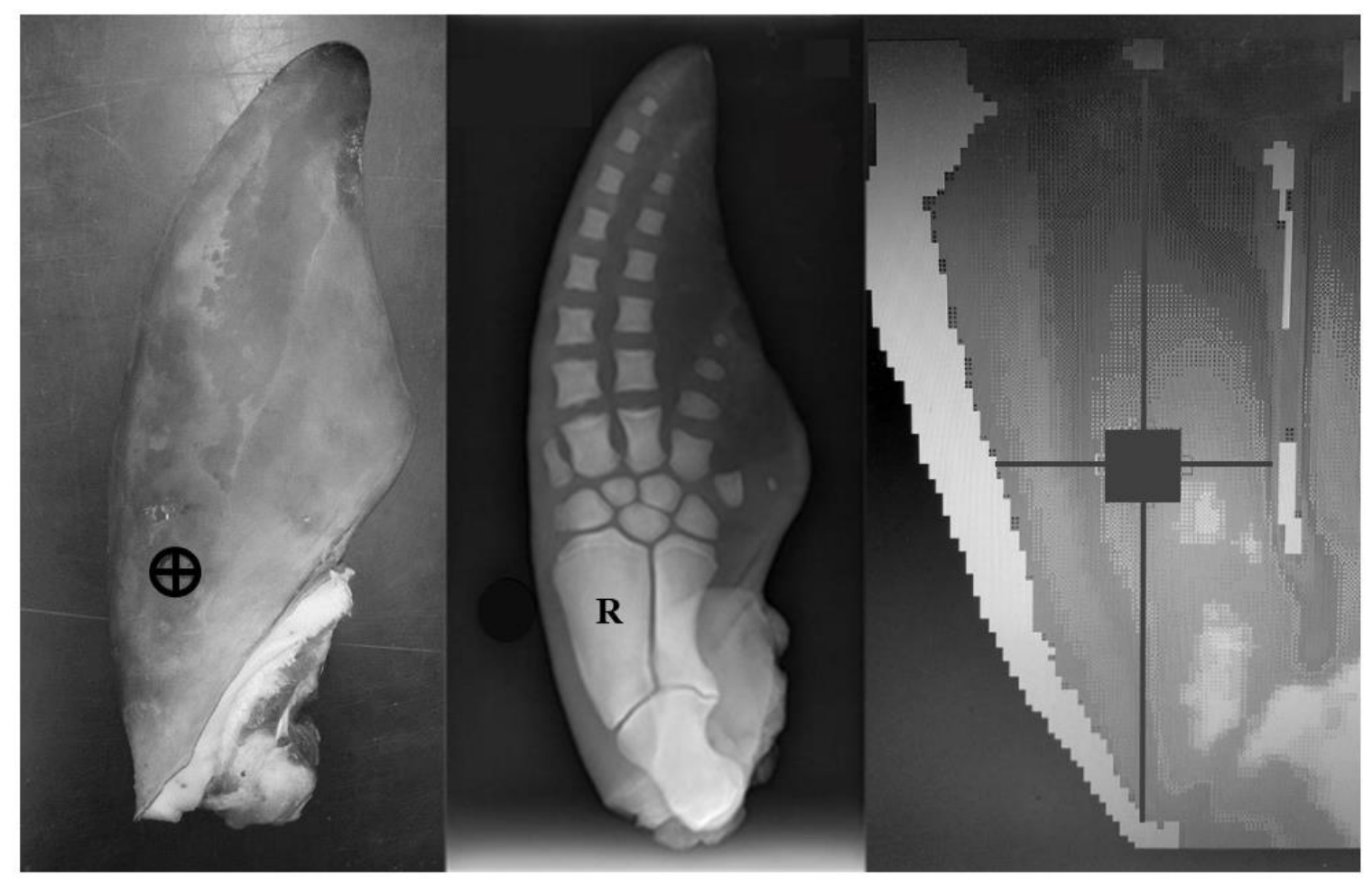

Figure 4-1. Disarticulated dolphin pectoral flipper with geometric center ROI marked (left); standard digital radiograph of a dolphin pectoral flipper with radius labeled (R) (center); and pDEXA scan of radius with $1 \mathrm{~cm}^{2}$ ROI marked at $50 \%$ of the radial length along the proximal-distal axis and $50 \%$ of the medial-lateral width at that point (right). 


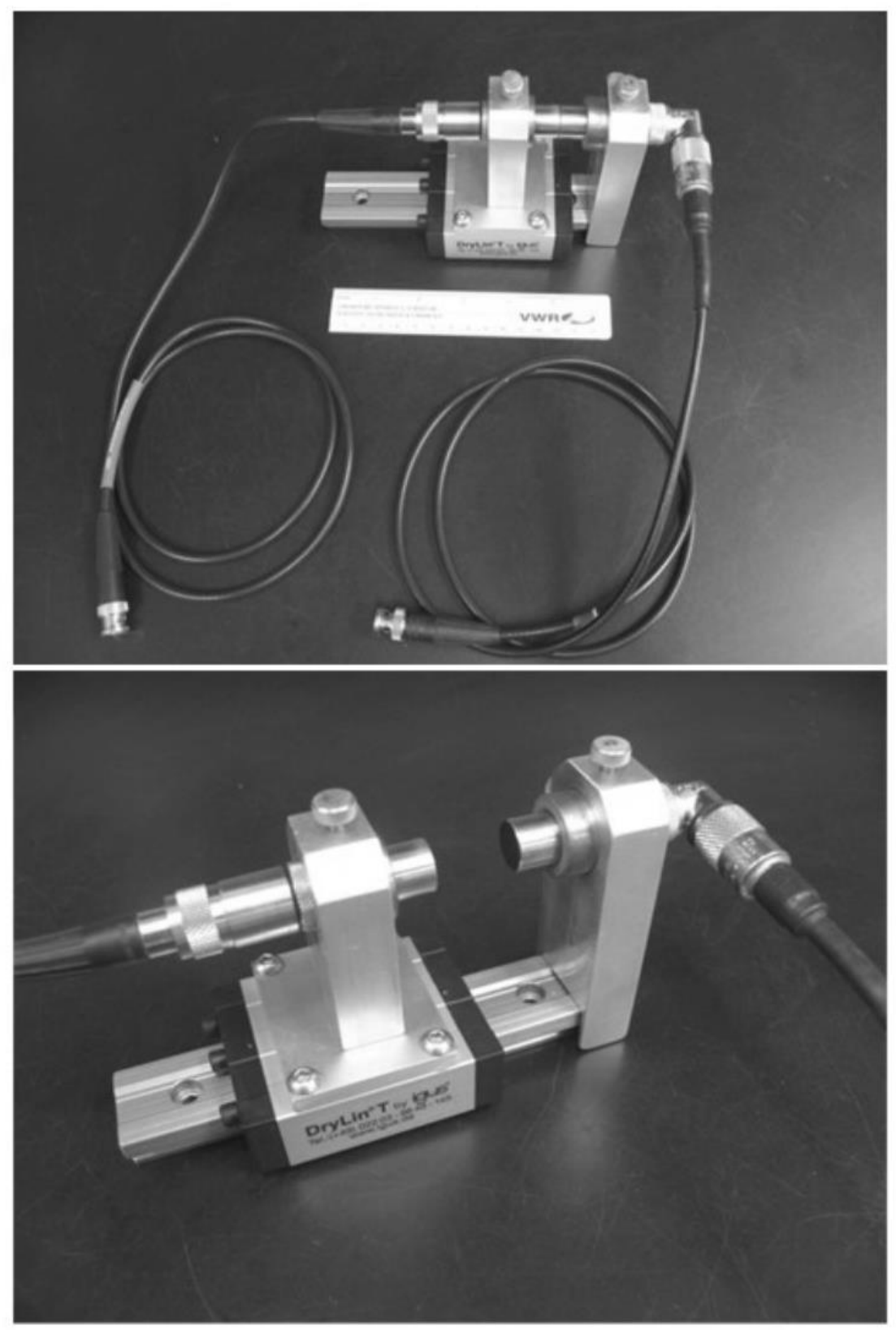

Figure 4-2. CyberLogic-designed portable quantitative ultrasound system. The cables (top image) connect the paired transducers that transmit and receive ultrasound signals through the flipper. The pectoral flipper is positioned by opening and adjusting the slide fixture (bottom image), which is then locked in place with a fixing bolt (not seen in above photos). 


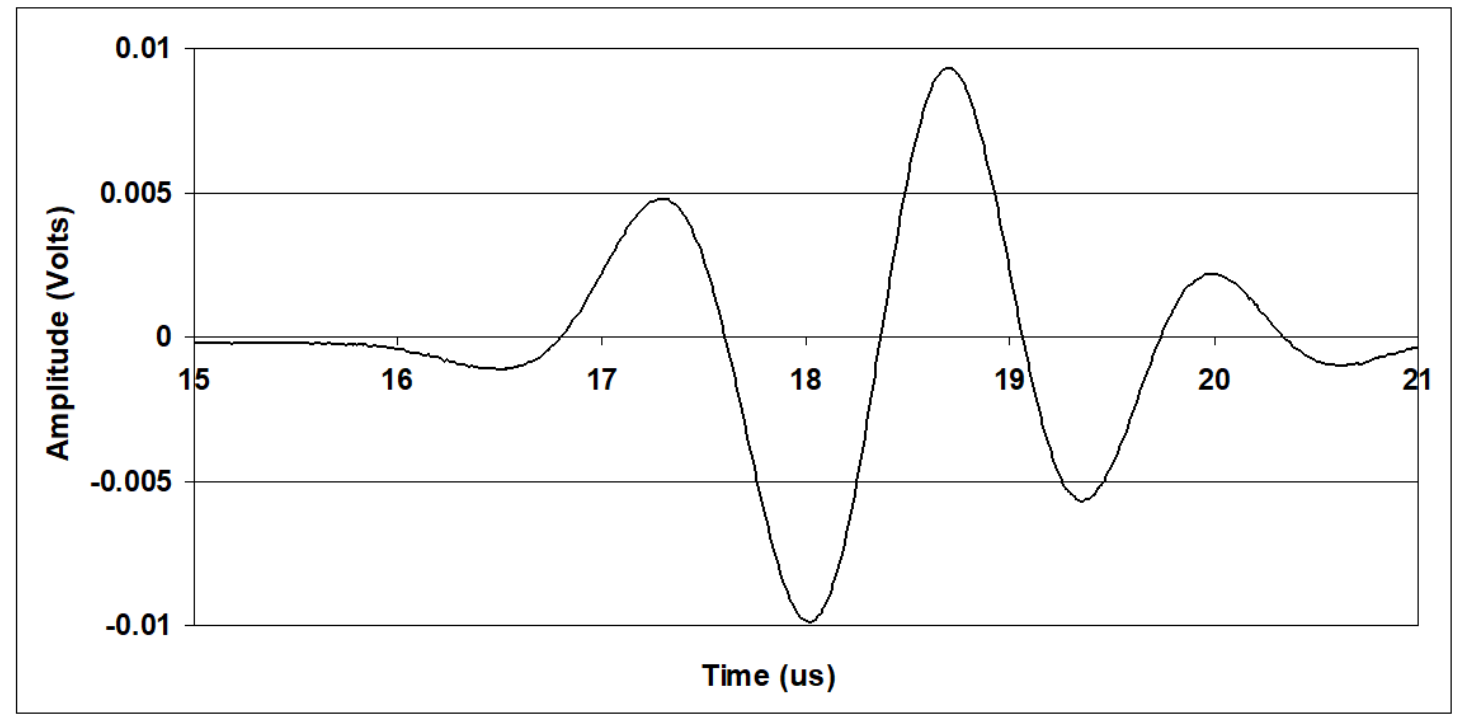

Figure 4-3. Typical soundwave propagated through the soft tissue and radius of a bottlenose dolphin pectoral flipper. Main distinctions (besides reduced amplitude) of the flipper/bone signals compared with the water signals are (i) reduced signal amplitude; (ii) bone signal arrives approximately $3.5 \mu$ s earlier; and (iii) bone signal has a lower center frequency (approximately $700 \mathrm{kHz}$ ). The center frequency for the water reference signal is approximately $1 \mathrm{MHz}$. 


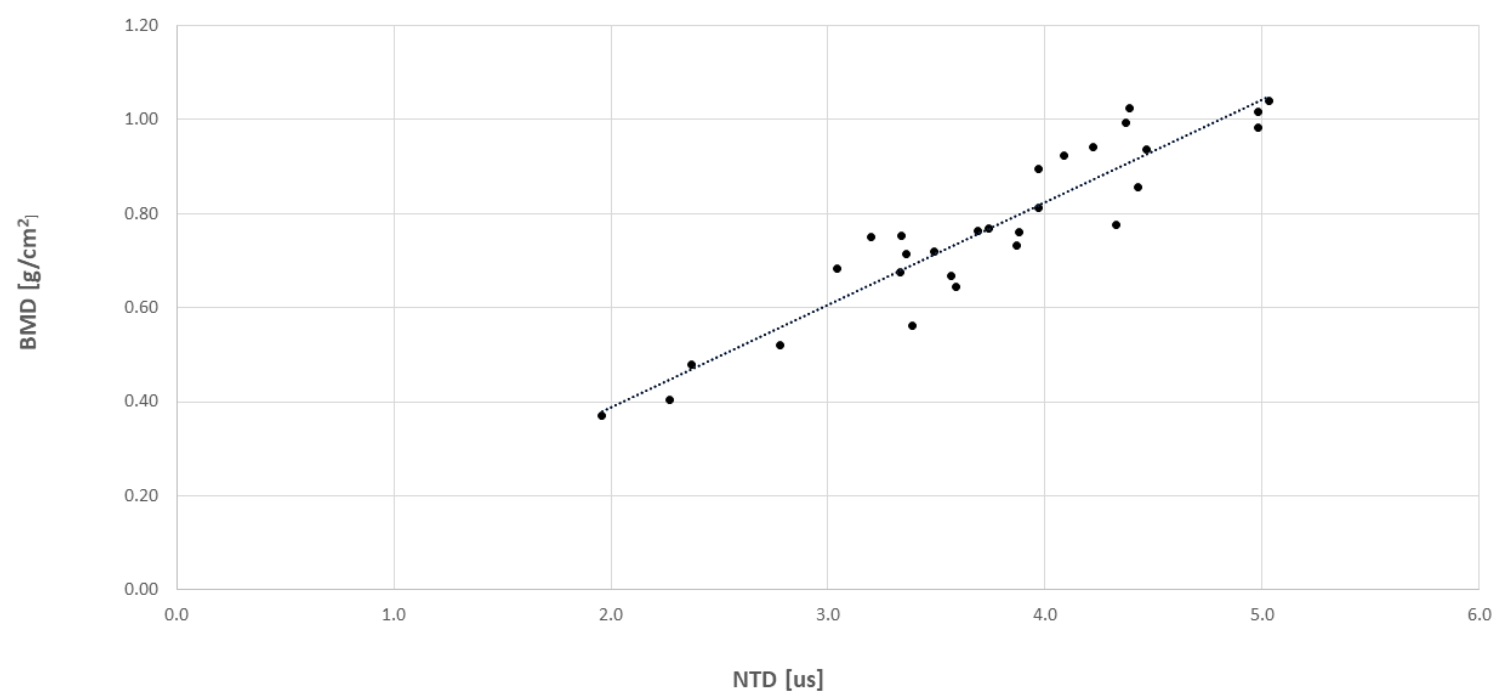

Figure 4-4. Linear regression model depicting the correlation $(r=0.93)$ between bone mineral density (BMD) as measured with DXA and quantitative ultrasound (NTD) at the geometric center ROI of intact (i.e., fresh-frozen) bottlenose dolphin pectoral flippers. 


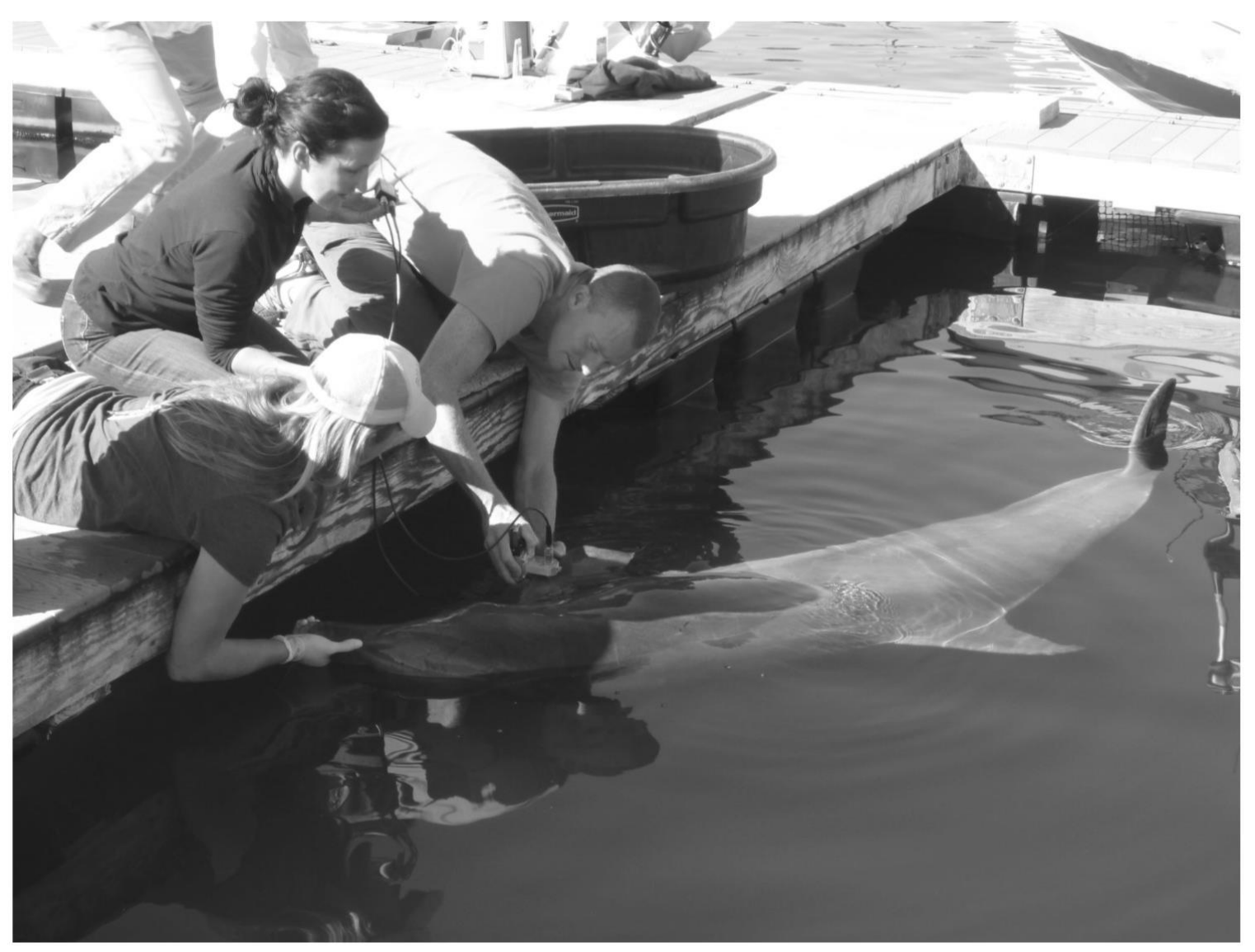

Figure 4-5. Tolerance testing of ultrasonic bone densitometer on a live, managed care bottlenose dolphin. Photo courtesy of U.S. Navy Marine Mammal Program. 


\title{
CHAPTER 5
}

Precision Error and Normative Reference Values for Ultrasonic Bone Density Measurements in Live Common Bottlenose Dolphins, Tursiops truncatus

\begin{abstract}
Common bottlenose dolphins, Tursiops truncatus, are utilized as indicators of ecosystem health in capture-release health assessments. Bone density measurements have not previously been incorporated into these projects despite evidence that exposure to a suite of anthropogenic contaminants, episodic prey depletion events, and resultant malnutrition lead to decreased bone density in laboratory animals and wildlife species. To establish bone density as a useful health and life history parameter for the bottlenose dolphin, normative reference ranges must be established from healthy individuals in order to facilitate evaluation of health and disease status of individuals from impacted populations and habitats. Traditional methods for bone density measurement, such as dual-energy X-ray absorptiometry (DXA), use X-ray scanners that have limited utility in open-water field settings due to inherent constraints of portability, regulation, and radiographic nature of the technology. In this study, we developed methods for quantitative ultrasound (QUS) as a preferable alternative, since it is portable, has a high degree of precision, and does not expose patients or technicians to radiation, thus making it an ideal diagnostic tool for field applications. Repeatability assays were conducted on dolphins managed under human care to define the precision error for this novel QUS application. Ultrasonic bone density assessments of live, free-ranging dolphins were conducted during capture-release health assessments from 2014-2019. Individuals were selected from this long-term population
\end{abstract}


study for the development of a normative bone density dataset of dolphins with nutritive body condition within normal limits and the lack of obvious disease or health issues. This study represents the first use of QUS to assess bone density in a marine mammal species. Application of this technology during capture-release health assessments adds a valuable resource to biologists and wildlife veterinarians investigating dolphin and overall ecosystem health.

\section{INTRODUCTION}

Sentinel species are used to comprehensively evaluate the ecological effects of physical and chemical stressors and to monitor restoration of wildlife, habitats, and human resources impacted by threats such as oil spills and hazardous waste (Barnthouse \& Stahl, 2017). Health assessments of free-ranging wildlife are useful tools in areas where populations show signs of epidemic disease, high mortality, and/or where ecosystems are being altered or impacted by human activities (Rowles et al., 2018). To determine the appropriate type and amount of restoration required to recover a population following a natural resource disaster (e.g., Deepwater Horizon oil spill, EPA Superfund sites), the full extent of injuries must be quantified in a manner that considers long-term impacts and chronic health effects that compromise individuals after acute effects subside (Schwacke et al., 2017).

Monitoring the health of free-ranging common bottlenose dolphins (Tursiops truncatus) is a crucial component in investigating marine and estuarine ecosystem health. To understand impacts and monitor recovery, findings from health assessments of live dolphins are coupled with information gained from photographic monitoring, remote tissue 
sampling, and the examination of dead stranded dolphins and subsequent analysis of their tissues. Such health monitoring has involved a variety of measurements, including morphometric data, veterinary physical examination, hematology, immune function, diagnostic ultrasound, contaminant analyses, and hearing tests (Townsend et al., 2018). Thoracic and dental radiology techniques have recently been added for preliminary examination of skeletal health (C. R. Smith, pers. comm., 8 May 2019), and we have developed a quantitative ultrasound (QUS) device (hereafter "bone sonometer") and protocols to assess bone density in the dolphin pectoral flipper (see Chpt. 4). In human medicine, assessment of skeletal health has been a common component of defining an individual's overall health, particularly with increasing age, and quantitative assessment of bone mineral density (BMD) is currently considered the best predictor of skeletal health. Skeletal alterations and disturbances provide mechanisms to detect and monitor potential impacts to an individual's or population's health. Given the important physiological role played by bone tissue, any external factor altering BMD could have significant harmful consequences to an individual's overall health or behavior. BMD is positively correlated with age and body mass in humans and other mammals (Blake et al., 2000) At skeletal maturity, bone turnover is balanced so there is no resultant net change in bone mass; however, with increasing age, altered health status, or incidence of disease, an individual's relative efficiency to resorb and replace bone may be altered and result in net loss of bone mass and altered bone architecture (Allen, 2003).

Studies of osteological health are traditionally conducted using radiography and gross and microscopic postmortem examination of bones (Metcalfe, 2007). Recent advancements in medical technology that decrease the cost and size of diagnostic devices 
have resulted in skeletal examination becoming more common in studies of wildlife disease. Traditional methods for BMD measurement, such as dual-energy X-ray absorptiometry (DXA), use X-ray scanners that have limited utility in open-water field settings due to inherent constraints of portability, regulation, and the radiographic nature of the technology. To address the limitations of DXA, quantitative ultrasound (QUS) methods for bone assessment have been developed and demonstrated that they can determine bone quality and provide information about bone density (Kaufman and Einhorn 1993; Njeh et al., 1997). QUS is nondestructive, noninvasive, less expensive than X-ray technology, and does not expose patients or technicians to radiation (Glüer, 1997). Additionally, its portability and high degree of precision make it an ideal diagnostic tool for field applications.

Reference intervals are used by veterinarians and physicians to clinically evaluate the health of individuals by comparing observed values of a given parameter against values considered to be representative of a normal, healthy population (Hart et al., 2015). Values below the threshold of the reference interval are considered unusual and typically coincide with a disease state or other harmful impact (Kanis et al., 2008). As with all biological and physiological parameters assessed in epidemiological studies, clinicians need a range of values that describe disease-free individuals or individuals from comparable unexposed populations (Rowles et al., 2018). Such data do not currently exist for BMD in healthy, free-living bottlenose dolphins. Distribution of observed BMD values in bottlenose dolphins using measurements on specimens from dead-stranded individuals have been determined (see Chpt. 3). While dead-stranded animals are a useful resource for investigating marine mammal disease, they have limited utility in evaluating the health of 
living populations or changes in an individual animal's health (Aguilar \& Borrell, 1994). The range in BMD values are presumably confounded by health and disease status associated with the death of the individuals and thus possibly does not represent values from normal, healthy individuals.

Hart et al. (2013) developed $95^{\text {th }}$ percentile reference ranges for body condition of bottlenose dolphins using measurements of total mass, total length, and maximum girth as measured on dolphins during capture-release health assessments conducted in Sarasota Bay, Florida. Baseline reference interval ranges would provide a basis for comparison of health status among individuals and stocks of animals with a reference population (Schwacke et al., 2009). Because body condition reflects nutritional status (Hart et al., 2013) and body composition metrics are positively correlated with BMD (Pluijm et al., 2001), these reference intervals can be used to identify individuals that are within normal limits in nutritive condition during health assessments as a selection criterion for inclusion in a BMD normative distribution reference dataset.

The current study applies QUS to assess BMD in live bottlenose dolphins to establish a normative reference curve based on animals with body condition within normal limits. Additionally, data presented herein demonstrate the precision of the bone sonometer and the repeatability of ultrasonic densitometry measurements on live bottlenose dolphins. The developed normative reference standards will provide a method by which to compare and diagnose skeletal health in individuals from different populations or with compromised health, allowing bone densitometry to be incorporated into the armamentarium of tools used by researchers in health assessment studies on free-ranging, bottlenose dolphins. 


\section{METHODS}

Quantitative Ultrasound Device and Technique

Technical specifications and application of QUS to assess bone density in bottlenose dolphin flippers have previously been described (see Chpt. 4). Briefly, the dolphin bone sonometer uses through-transmission QUS performed with a pair of transducers fixed in a coaxial position on an adjustable slide fixture (Figure 5-1). Time required for an ultrasound pulse to travel through bone and overlying soft tissue (i.e. the radius in the pectoral flipper) vs. time for an ultrasound pulse to travel through a known temperature water bath with transducers at an equivalent distance as set on the flipper are measured to calculate "net time delay" (NTD), an acoustic parameter that is directly proportional to BMD.

Monitoring the stability and consistent performance of the ultrasound device by regular quality control measurements is a precondition for assessment of good measurement quality. Daily quality assurance (QA) scans of a plastic nonanthropomorphic phantom (i.e., non-bone) were performed. As there are currently no universally accepted QUS phantoms, such as those used in radiographic osteodensitometry, manufactured specific non-anthropomorphic phantoms are an accepted alternative for quality assurance and QUS system calibration.

In human clinical medicine, target skeletal sites for measurement of bone density in the radius is facilitated by palpating the visible distal and proximal ends of the bone and measuring the length of the bone in the forearm (Shepherd et al., 2002). However, bones of the dolphin pectoral flipper are encased in dense connective tissue that, once skeletally mature, prevent practitioners from manually locating the margins of the bone in a similar 
approach as in human osteodensitometry. To overcome this limitation, techniques to manually locate the primary region of interest (ROI) (i.e., skeletal target site) for QUS measurement in the dolphin pectoral fin were developed utilizing cetacean morphometric landmarks and a set of standard radiographs (Chpt. 4).

An ROI at the geometric center of the dolphin radius has been characterized and found to have a strong correlation to the bone density of the entire bone, supporting its use as a definitive skeletal target site for clinical assessment of BMD in the bottlenose dolphin radius (see Chpt. 3). The ROI can be readily located in the flipper using two standard flipper morphometrics from Perrin (1975): cranial flipper length (the distance from the cranial insertion of the flipper to the distal tip) and maximum flipper width. This ROI is set at $25 \%$ of the cranial flipper length, measured distally from the insertion along the leading edge of the flipper, and medially a distance equal to $20 \%$ of the maximum flipper width (Figure 52). Pectoral flippers were dried with a towel and the ROI was marked with an indelible ink marker (as seen in Figure 5-2) as a guide for locating during QUS scan.

\section{Study Animals}

Managed Care Dolphins - To diagnose BMD as deviating from normative reference range, or to determine if true biological change has occurred in an individual over time, the

precision error of the densitometry technique used must be known. Repeatability, or precision, refers to the closeness of agreement between test results when the tests are performed by the same technologist, using the same equipment, within a short period of time (Bonnick, 2010). Precision is an approach used to statistically quantify the error of a technique. The smaller the precision error value, the more repeatable the technique. 
Densitometry is not perfectly reproducible; the results of a given patient are not expected to be identical even when the actual BMD value in the patient of interest has not changed (Bonnick, 2010). Real biologic change in BMD has occurred when the precision error of the technique being used has been exceeded. Precision error is quantified through a repeatability assay and is expressed as the root-mean-square standard deviation (RMS-SD) with the same units as the measurement or the root-mean-square \% coefficient of variation (RMS-\%CV), with the average BMD for the group reported. Precision values obtained in a short-term study of young, normal individuals represents the best possible precision (Bonnick, 2001).

To define precision error of the bone sonometer, a preliminary set of repeatability assays was conducted on bottlenose dolphins managed under human care at two facilities: Brookfield Zoo (Chicago, Illinois, USA) and Dolphin Quest (Oahu, Hawaii, USA). A total of 10 individual dolphins ( $\mathrm{n}=4$, Brookfield Zoo; $\mathrm{n}=6$, Dolphin Quest) were included in the repeatability assays. At each facility, repeated measurements were conducted on each animal throughout a single day by the same technologist. Each scan was performed with the dolphin in-water, stationed at an animal trainer with the pectoral flipper voluntarily presented by the dolphin being measured (Figure 5-3).

Free-Ranging dolphins - QUS bone density measurements used for this study were from bottlenose dolphins sampled during capture-release health assessment projects conducted in Sarasota Bay, Florida, between May 2014 and June 2019. Health parameters, morphometrics, and ages were taken on all dolphins sampled. Dolphins ultimately included in this study were those with confirmed age who were deemed to have nutritional body 
condition within normal limits per established criteria (Hart et al., 2013). Determination of body condition used the following measurements: total length, a straight-line measurement to the nearest $\mathrm{mm}$ from the tip of the upper rostrum to the cranial margin of the fluke notch; maximum girth, measured as the circumference of the body immediately cranial to the dorsal fin; and total mass, recorded using a load cell onboard a research vessel.

All pectoral flipper scans were performed with dolphins out of water, onboard a research vessel (Figure 5-4). Regression models were developed for BMD values of all animals that met the selection criteria. Since female bottlenose dolphins grow at a faster initial rate than males and reach asymptotic growth at an earlier age, resulting in sexual dimorphism in total length, maximum girth, and total mass at physical maturity (Read et al. 1993, Tolley et al. 1995), analyses were conducted separately for each sex.

\section{RESULTS}

Calculating individual precision values for every dolphin in a health assessment project that might be measured or followed with bone densitometry is not practical. Thus, it was necessary to establish representative precision values for each skeletal site used for monitoring BMD. Ten dolphins managed under human care and trained to voluntarily present pectoral flippers were scanned four times within a single day (Appendix B). The average ultrasonic BMD NTD value of dolphins in the repeatability assay was $2.566 \mu \mathrm{s}$ and the RMS-CV for QUS as applied to measure BMD in the pectoral flipper of live bottlenose dolphins was $0.06 \mu \mathrm{s}$. 
Free-ranging bottlenose dolphins $(n=45)$ from annual capture-release health assessments conducted from 2014 to 2019 in Sarasota, FL, were selected for this study. Each individual was of known age, sex, and nutritive body condition, and had no apparent underlying health conditions. The resultant data represent the best dataset available to serve as a proxy for normal, healthy bottlenose dolphins. The subset was comprised of 24 females (spanning 2 to 34 years of age) and 21 males (spanning 3 to 28 years of age). Sex-specific scatterplots of BMD values were created to represent the normative increase in bone density with age (Figure 5-5). Each dolphin was measured once and is represented by a single point on the curve. Measured ultrasonic BMD values for each live dolphin in this study and associated life history data are provided in Appendix C.

Both sexes exhibited an initial phase of progressive increase in BMD up to attainment of asymptotic, or peak, bone density. Peak BMD was observed in male dolphins at approximately 20 years of age, while peak BMD in female dolphins was approximately 23 years of age. Notable differences in sex-specific BMD at relative ages were observed, with female dolphins having lower BMD at all ages after approximately 5 years of age and ultimately reaching a lower peak BMD than male dolphins.

\section{DISCUSSION}

The current study demonstrates that ultrasonic bone densitometry can be performed on live bottlenose dolphins in a repeatable and precise manner that can be applied in the field to free-ranging dolphins. Since dolphins from the Sarasota community are typical of the size range observed in the species elsewhere in coastal waters of the northwestern Atlantic and the northern Gulf of Mexico (Sergeant et al., 1973; Mead \& Potter, 1990), and 
because there is little variation in mean growth rates among dolphins from Sarasota, northeastern Florida, and the central Atlantic coast of the United States (Read et al., 1993), the data collected from individuals with body condition within normal limits from the reference population serve as a normative distribution of expected values for the species over the range of ages included in this initial dataset. The differences in rate of BMD increase with age observed in male and female dolphins may be due to the demands of reproduction on females. In Sarasota Bay, dolphins can reach sexual maturity as early as 5 years of age and typically first give birth by 9 years of age (Wells and Scott 2018). Cyclical, and mostly continuous, reproduction (pregnant or lactating) throughout a female dolphin's life could account for both the lower rate of bone density increase and lower peak BMD values. In humans, high calcium demand during pregnancy and lactation increases bone resorption and susceptibility of subsequent osteoporosis (Salari and Abdollahi 2014). Hormonal changes may result in a reversal of bone resorption, but the final net effect of pregnancy and lactation on bone in humans is not clearly understood (Rillo et al. 1994). With the comparably higher number of offspring and shorter inter-pregnancy interval during a female dolphin's life, the relative differences in male and female dolphin BMD could be explained by the demands of pregnancy and lactation.

The bone sonometer demonstrated a high degree of precision during multiple, repeated measurements on a study group of bottlenose dolphins managed under human care. In 2019, the International Society for Clinical Densitometry stated that the minimum acceptable precision for a technologist, expressed as \%CV, was $2.5 \%$ at the femoral neck, $1.9 \%$ at the lumbar spine and $1.8 \%$ at the total hip (ICSD, 2019). The RMS-CV of 0.06 
determined in the repeatability assays of QUS measurements of bottlenose dolphins meets or exceeds the values accepted for DXA-based human clinical applications.

In addition to concerns of long-term skeletal health in aging individuals, osteological studies are conducted to assess a multitude of impacts, including contaminant exposure, malnutrition and starvation, and metabolic disorders. Exposure to anthropogenic contaminants, for example, is known to reduce BMD, alter bone mineral composition, and result in various osteopathies in both terrestrial and marine mammals (Staessen et al., 1999; Sonne et al., 2004; Danion et al., 2011). If decreases in bone density in dolphins can be associated with anthropogenic contaminant exposure, dolphin BMD could be used not only as an indicator of exposure but also an assessment tool for monitoring the recovery of a population or habitat following acute and chronic exposure events.

Bone densitometry is an emerging diagnostic tool in zoo and wildlife medicine, since osteological assessment can reveal critical information about an individual (Duckler \& Van Valkenburgh, 1998). Bone density assessment of free-ranging wildlife could be an extremely valuable addition to research applied in contexts where prey availability studies are of interest. Not only does malnutrition- and starvation-induced changes affect BMD, but episodic toxic algal blooms have been implicated in large-scale fish die-offs that significantly reduce prey availability and impact the nutritional status of bottlenose dolphins (Gannon et al., 2009; Berens McCabe et al., 2010; Powell \& Wells, 2011). Brevetoxin accumulation has been detected in live, free-ranging dolphins and their prey fish (Fire et al. 2008a; Fire et al. 2008b). Bone density assessments of individuals exposed to periods of severely reduced prey availability and dolphin calves that were in utero during 
these prey reduction events may reveal an associative impact on skeletal health similar to effects of starvation and malnutrition observed in other species.

Development of species-specific health indicators for wild, free-ranging wildlife is critical to comprehensively assessing individual and population health. The normative range of BMD values presented herein will serve as a reference standard for bottlenose dolphins and will facilitate examination of individuals and populations to establish associations between BMD and anthropogenic contaminant exposure, malnutrition, or metabolic disease. Longitudinal data can be added to compliment the current crosssectional approach, particularly with animals still in a growth phase of their life history, and better model natural increases in BMD. As episodic prey depletion events continue to increase in prevalence, prenatal and neonatal exposure to maternal malnutrition will increase. It is of great interest to utilize long-term research sites where individuals are known and tracked over the course of their life to elucidate the BMD impacts of these exposure events on dolphins as a marker for health and recovery. 


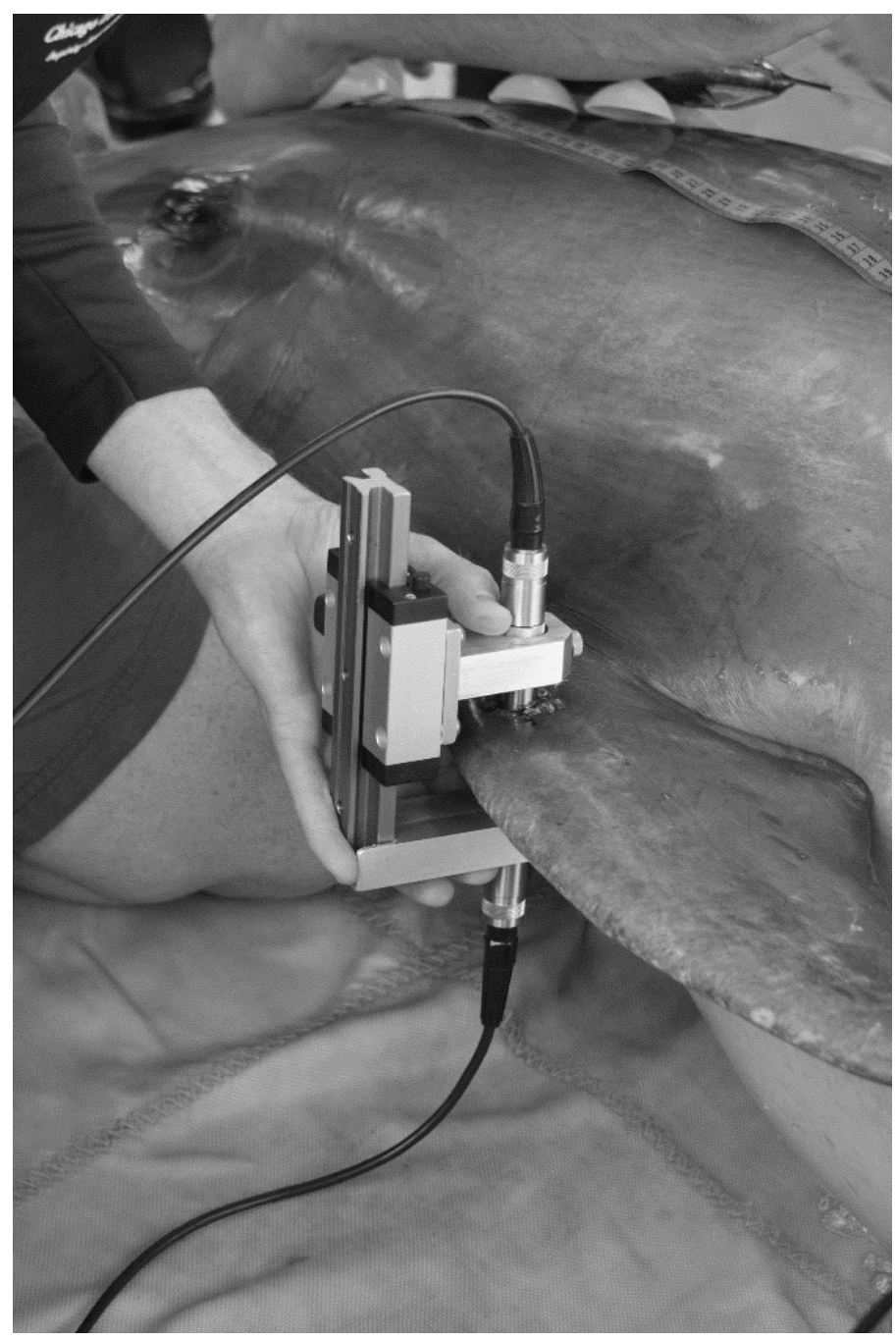

Figure 5-1. Dolphin bone sonometer using through-transmission quantitative ultrasound (QUS) with a pair of coaxial transducers on an adjustable slide fixture positioned on a bottlenose dolphin flipper. Photo taken under National Marine Fisheries Service Scientific Research Permit No. 20455. 

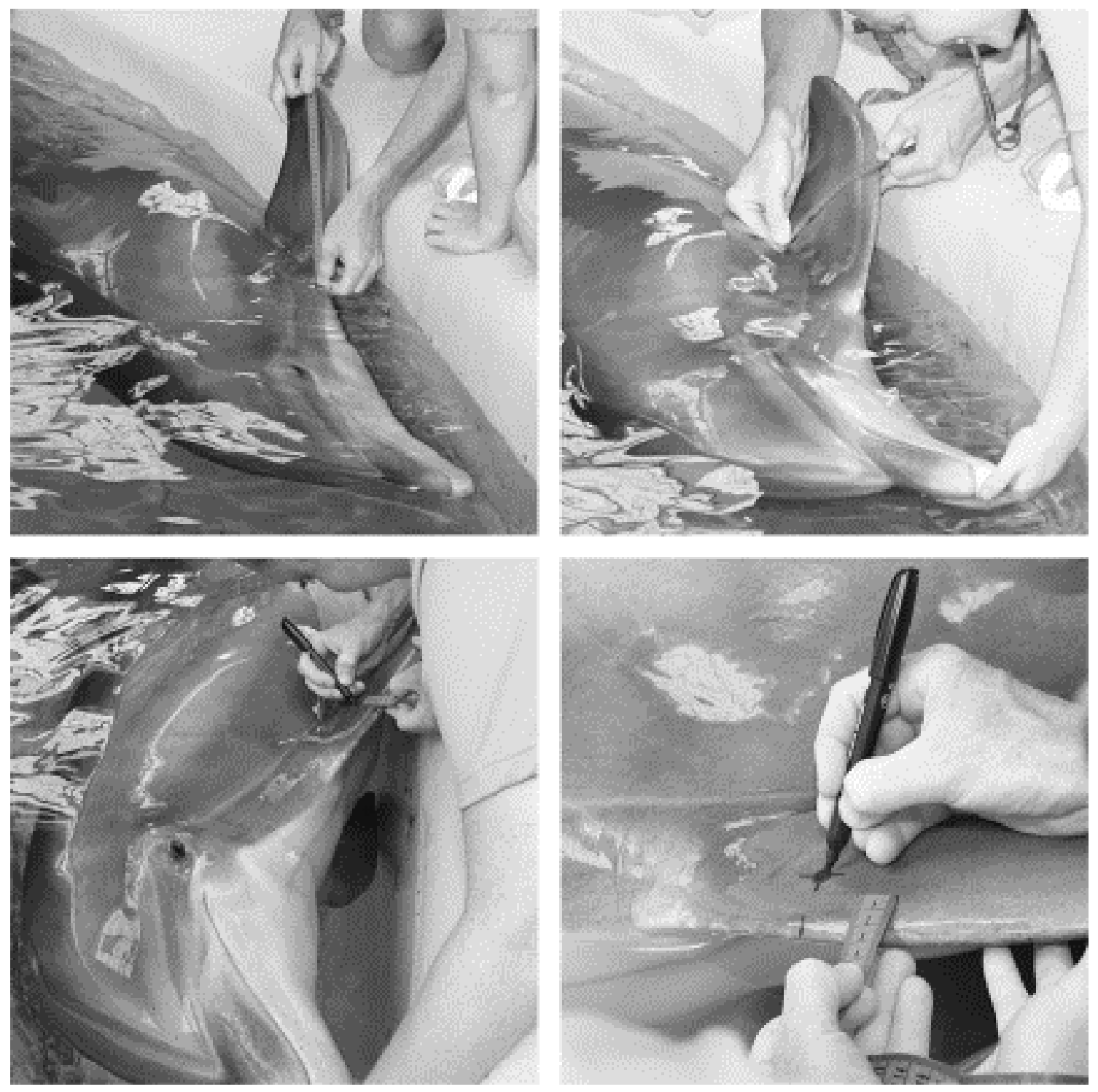

Figure 5-2. Standard cetacean morphometrics are used to locate and mark primary region of interest (ROI) on the dolphin pectoral flipper to measure bone mineral density (BMD) of the radius. Photo provided by Chicago Zoological Society's Brookfield Zoo. 


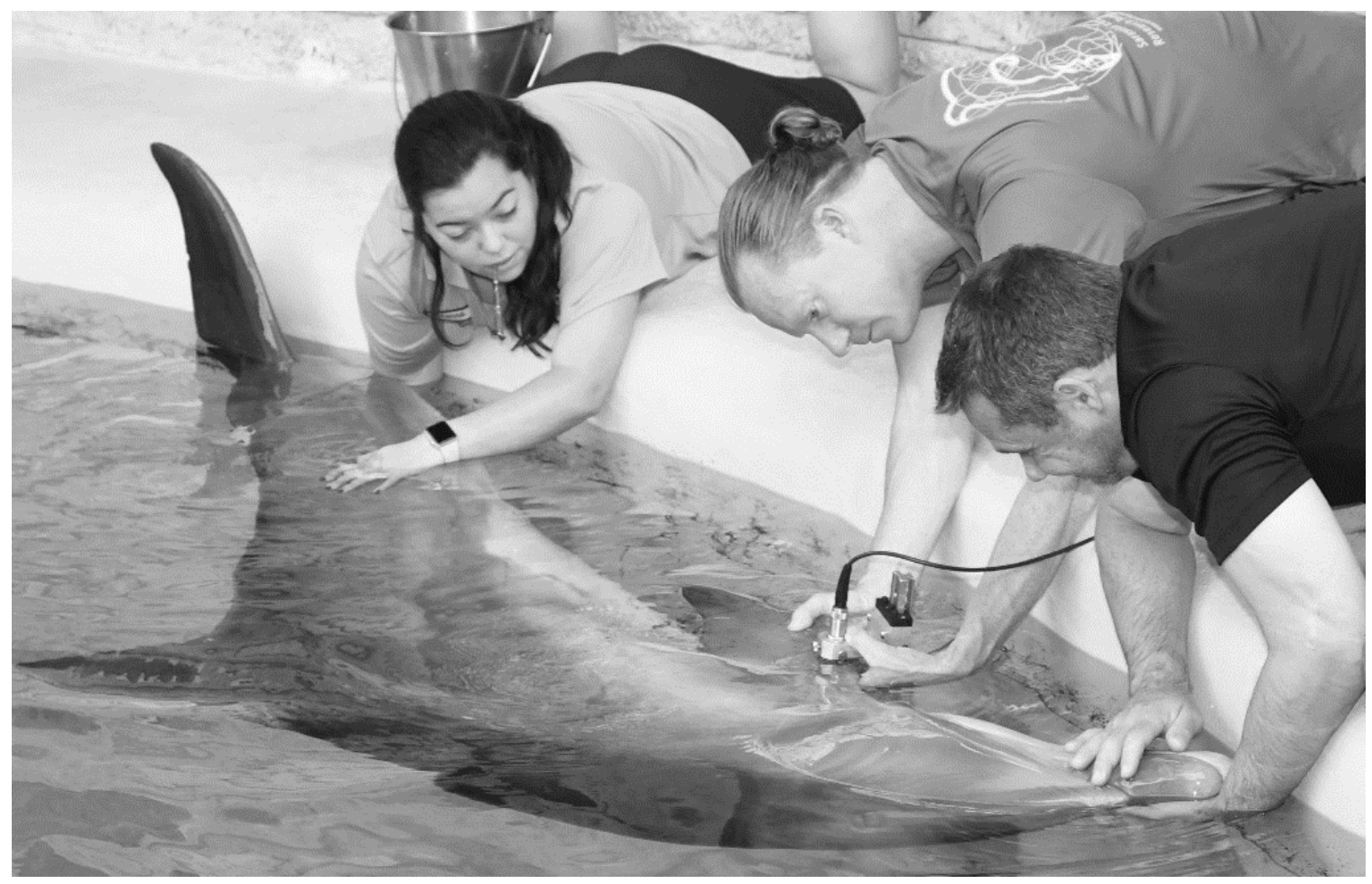

Figure 5-3. In-water bone density assessment of bottlenose dolphins managed under human care. Each scan was performed with the dolphin in-water, stationed at an animal trainer with pectoral flipper voluntarily presented. Photo provided by Chicago Zoological Society’s Brookfield Zoo. 


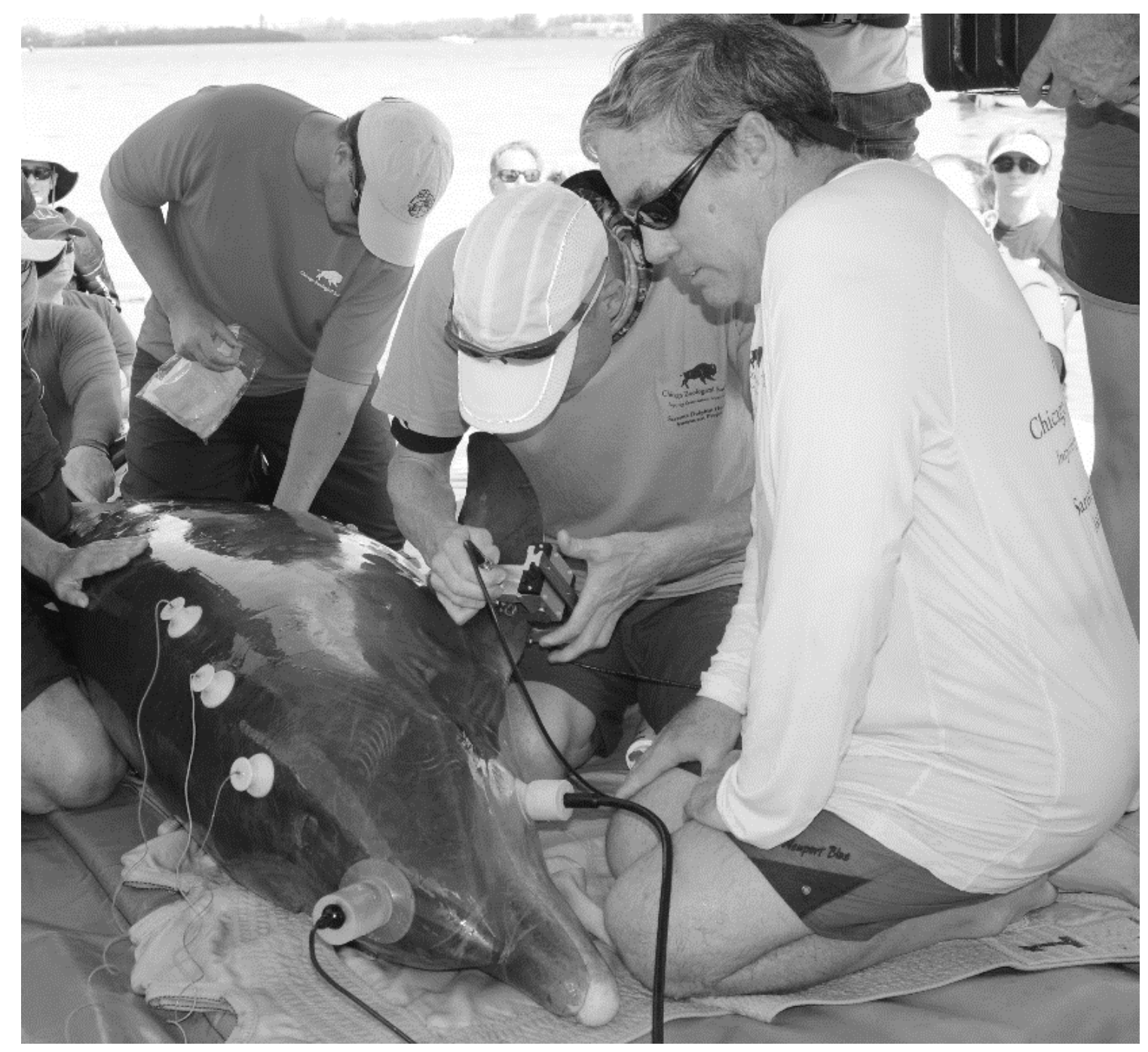

Figure 5-4. Bone density measurements through the pectoral flipper of live, free-ranging bottlenose dolphins were performed with dolphins out of water, onboard a research vessel during capture-release health assessment projects. Additional health assessment procedures are conducted concurrently. Photo taken under National Marine Fisheries Service Scientific Research Permit No. 20455. 

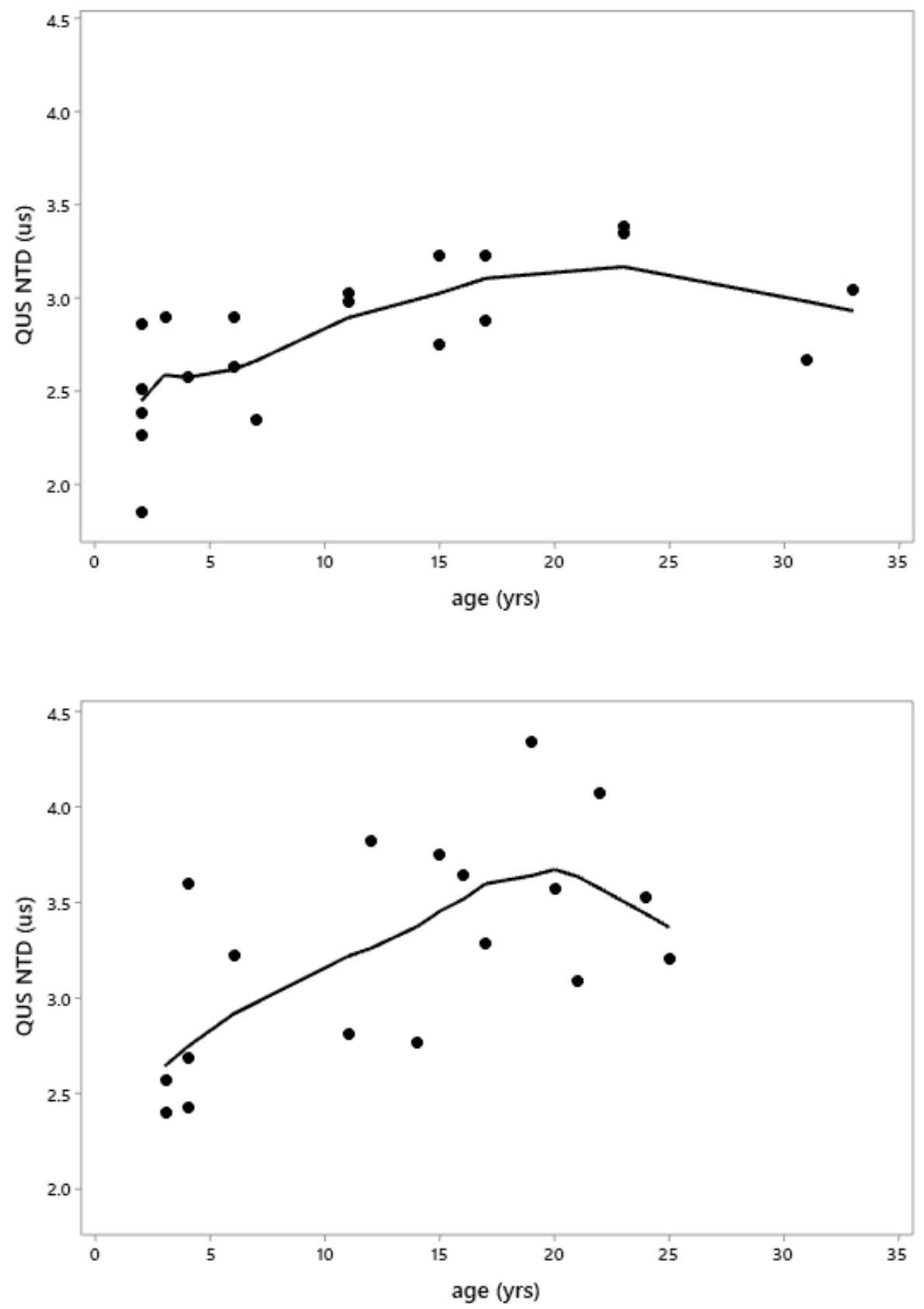

Figure 5-5. Scatterplots of bone density (BMD) for female (above) and male (below) bottlenose dolphins from Sarasota, Florida. As this is a cross-sectional study, each individual was measured once and is represented by a single point on this curve. 


\section{CHAPTER 6}

\section{CONCLUSIONS AND FUTURE STUDIES}

Marine mammals show two very dichotomous trends in bone architecture and histology, significantly reduced bone density and significantly increased bone density. Deep-diving marine mammals have bones that are less dense than homologous skeletal elements in terrestrial mammals. This pattern of reduced bone mineral density (BMD) has been documented in small to medium-sized odontocetes (i.e., toothed whales and dolphins) and some pinnipeds (e.g., seals and sea lions) and is characterized by replacement of cortical bone with cancellous, or trabecular, bone. The alteration in BMD is a hormonecontrolled process resulting in an imbalance between bone resorption and deposition. Interestingly, mean variance for terrestrial mammal bone density is low in comparison to aquatic mammal bone density, potentially due to terrestrial mammals having a relatively narrow optimal range of BMD as a compromise between strength and weight (Wall 1983).

Applications of bone densitometry to wildlife studies have been conducted primarily in the context of evolutionary adaptations, specifically with regard to adaptations to aquatic and marine habitats both from a comparative perspective for similar species and in the evolutionary framework of transitioning from terrestrial to marine habitats. As a result of their fully aquatic lifestyle, sirenians (e.g., manatees and dugongs) and cetaceans (e.g., whales and dolphins) are free of the mechanical constraints that influence limb bone architecture in terrestrial and semi-aquatic mammals (Stein 1989). Some aquatic mammals (e.g., manatees) exhibit significantly higher limb-bone density than terrestrial mammals, theoretically as an adaptation for buoyancy, while other species, such as cetaceans and some pinnipeds have secondarily reduced BMD (Wall 1983). Histological analysis 
demonstrates that high BMD is an aquatic specialization the provides a ballast-like static buoyancy control system for animals living in shallow water, while decreased BMD is associated with dynamic buoyancy control for animals living in deep water habitats (Gray et al. 2007).

Development of species-specific health indicators for wild, free-ranging wildlife is critical to be able to comprehensively assess individual and population health and to fully understand the effects of anthropogenic and environmental impacts. In human medicine, assessment of skeletal health has become an accepted component to defining an individual's health, particularly with increasing age, and quantitative assessment of BMD is currently considered the best predictor of skeletal health. For dolphins, in order to investigate environmental or ecological impacts on an individual dolphin's skeletal health or to utilize skeletal health, and specifically BMD, as a life history or health marker, comprehensive research to establish normative bone density values across age, sex, disease status, and nutrition level must be conducted for this species. This has been the focus of my dissertation research.

\section{DISSERTATION FINDINGS}

In order to conduct comprehensive osteological health studies on bottlenose dolphins, foundational research on BMD was needed to comprehensively understand bone density in the species prior to application or investigation of the myriad impacts that bone density can used to interpret. Since minimal prior research has been conducted on BMD in dolphins, this dissertation effectively serves as the foundation for osteodensitometry in the 
species. To establish a framework for bottlenose dolphin osteodensitometry the following objectives were met:

1. The dolphin radius was comprehensively characterized through the correlation of BMD values at multiple regions of interest (ROIs) to BMD of the entire bone in order to establish a primary skeletal site for clinical assessment. The relationship between BMD of each ROI and BMD of the whole radius was analyzed using ordinary least squares (OLS) linear regression analyses to establish the statistical significance of each ROI as a predictor for whole radius BMD. This both supported the selection of a single ROI for all subsequent tests and demonstrated the repeatability, accuracy, and precision with which ROIs were positioned during analyses. The regression models for pair-wise correlations between whole radius BMD and BMD at each ROI showed strong, positive linear relationships $\left(\mathrm{R}^{2}\right.$ values from 0.94 to $0.97, \mathrm{p}<0.001)$. BMD at the selected ROI, the geometric center of the radius, had the most significant correlation to BMD of the whole radius $\left(\mathrm{R}^{2}=0.97\right)$ and was easily located within a fully intact flipper, facilitating ease of field-based assessments while maximizing accuracy and precision of ROI placement. (Chpt. 3)

2. Radii ( $\mathrm{n}=388)$ archived in museum collections from 279 dead-stranded bottlenose dolphins were analyzed using dual energy X-ray absorptiometry (DXA), an accepted technique in human medical studies. The data generated from this work represent the largest dataset on BMD in any wildlife or marine mammal species to date. The BMD values observed represented the range of values for bottlenose 
dolphins at time of death and the findings represent a robust, comprehensive crosssectional study of dolphin bone density. (Chpt. 3)

3. Intra-individual bilateral symmetry observed in BMD of 218 paired left-right radii provided support for the use of either pectoral flipper to assess BMD for an individual dolphin and lent support to the use of any radii available for future studies and applications, regardless of whether they were left or right pectoral flippers. Bilateral symmetry is beneficial in a practical sense because, due to spatial constraints, routine necropsies and archival protocols at many institutions include retention of partial skeletons, and under field conditions it is not always possible to access the same flipper for every animal. Therefore, in future clinical applications, BMD assessments of live dolphins can justifiably be conducted on either the left or right flipper. (Chpt. 3)

4. Based on the radii from 279 dead-stranded bottlenose dolphins, no statistically significant differences were observed between male and female dolphins, dolphins from different geographical regions, or dolphins with different nutritional body condition at time of death. The lack of differences observed in these subsets support the inclusion of all available skeletal specimens as an acceptable range of observed BMD values for bottlenose dolphins at time of death and provides a metric by which to compare and diagnose skeletal health in individuals. (Chpt. 3)

5. To investigate possible limitations of small sample size and limited age distributions in previous dolphin bone density studies that attempted to use BMD to estimate age, this much larger sample $(n=206)$ of archived bottlenose dolphin specimens spanning a full range of body lengths $(94-295 \mathrm{~cm})$ and ages $(0-50 \mathrm{yr})$ 
was examined for age effects. Bone density increased with age up the age of approximate skeletal maturity and then declined gradually from approximately 25 years of age onward. The variance of bone density values observed at any given age was of such magnitude that it definitively precludes the use of this parameter as a reliable estimator of age for any age above 15 years of age. (Chpt. 2)

6. To circumvent limitations of traditional radiographic bone density assessment, a custom quantitative ultrasound device (i.e. bone sonometer) and protocols were developed for the assessment of BMD in live bottlenose dolphins. Present X-ray based methods for estimating BMD are not adaptable to the conditions under which live dolphin field health assessments are conducted. But, quantitative ultrasound (QUS) methods for bone assessment have demonstrated the potential to determine bone quality and provide information about bone density in human clinical applications. QUS is especially beneficial in that it is portable, nondestructive, noninvasive, less expensive than X-ray technology, and does not expose patients or technicians to radiation. Unlike radiographic approaches to densitometry, QUS readings are nearly instantaneous once the bone sonometer is properly positioned. In laboratory measurements on disarticulated pectoral flippers collected postmortem, a strong correlation was established between bone mineral density (BMD) as measured with quantitative ultrasound and X-ray ( $r=0.93)$. (Chpt 4)

7. Trials to develop clinical protocols for ultrasonic assessment of bone in live dolphins and to establish the technology as non-aversive were conducted under veterinary supervision on dolphins managed under human care at the U.S. Navy Marine Mammal Program, San Diego, California. Dolphins voluntarily presented 
their pectoral flippers and remained stationed with animal trainers during the procedure. No adverse behavioral reactions or physiologic reactions were detected and breathing remained constant and normal throughout the process. (Chpt 4)

8. To define precision error for this novel QUS application, repeatability assays were conducted on dolphins managed under human care at Chicago Zoological Society's Brookfield Zoo (Chicago, Illinois, USA) and Dolphin Quest Oahu (Honolulu, Hawaii, USA). Precision error was determined by repeatedly measuring BMD multiple times throughout a single day, where no real biological change would have occurred. The findings demonstrated a high degree of precision and minimal error in the technique and technology as applied to live dolphins. (Chpt 5)

9. Ultrasonic BMD assessments of free-ranging dolphins were conducted during capture-release health assessments from 2014-2019. Individuals were selected from an established reference population in Sarasota, Florida, for the development of a normative dataset based on nutritive body condition within normal limits and lack of other underlying disease or health issues. This normative dataset included 45 dolphins, 24 females and 21 males, ages 2 to 34 yr. Both sexes exhibited an initial phase of progressive increase in BMD up to attainment of asymptotic, or peak, bone density around 25 years of age. (Chpt 5)

The BMD values utilized in this study represent the largest dataset published on bone density in any wildlife or marine mammal species to date, and the BMD values as assessed with QUS represent the first normative BMD dataset for live, free-ranging marine 
mammals. This study also represents the first use of quantitative ultrasound to assess bone density in a marine mammal species. Development of this technology and protocols for its application during capture-release health assessments will enable assessment of dolphin bone tissue to become part of the armamentarium of biologists and wildlife veterinarians and will broaden the understanding of dolphin and overall ecosystem health.

\section{FUTURE STUDIES}

To build on the foundation laid out in this dissertation and to expand the field of osteodensitometry as applied to marine mammals in general, and bottlenose dolphins specifically, the following future studies and applications are suggested:

1. Comprehensively investigate an association between anthropogenic contaminant exposure and bone density in the common bottlenose dolphin, Tursiops truncatus.

2. Long-term monitoring of bone density in live, free-ranging bottlenose dolphins using the established reference population to investigate life history questions.

3. Track bone density in bottlenose dolphins exposed to large-scale prey mortality events associated with toxic algal blooms or who were in utero during these events.

4. Assess bone density in bottlenose dolphins managed under human care that have a clinical history of renal dysfunction and/or metabolic disorder.

5. Develop a fracture risk assessment model for the bottlenose dolphin by assessing bone density in individuals that present at the time of death or during capture-release health assessments with evidence of skeletal fractures. 
Determination of BMD values observed in bottlenose dolphins has provided fundamental baseline information of species-specific values of a critical health parameter that allows for a more comprehensive evaluation of individual and population health. Technological advancements made during this research study facilitated the assessment of BMD in live, free-ranging dolphins in a manner that was not previously possible. Future studies to more completely understand the effects of anthropogenic and environmental impacts on dolphin health can be conducted with this baseline as a comparison and with the assessment tools developed. BMD assessment of dolphins can now be incorporated into the myriad research projects that utilize this marine sentinel species to model impacts of human activities and monitor marine and estuarine ecosystem health. 


\section{Chapter 1}

\section{LITERATURE CITED}

Adkesson MJ, Langan JN. 2007. Metabolic bone disease in juvenile Humboldt penguins (Spheniscus humboldti): Investigation of ionized calcium, parathyroid hormone, and vitamin $\mathrm{D}_{3}$ as diagnostic parameters. Journal of Zoo and Wildlife Medicine 38:85-92.

Allen MJ. 2003. Biochemical markers of bone metabolism in animals: uses and limitations. Veterinary Clinical Pathology 32:101-113.

Black A, Lane MA. 2002. Nonhuman primate models of skeletal and reproductive aging. Geronotology 48:72-80.

Blake GM, Herd RJM, Patel R, Fogelman I. 2000. The effect of weight change on total body dual-energy X-ray absorptiometry: results from a clinical trial. Osteoporosis International 11:832-839.

Blood DC, Studdert VP. 1999. Comprehensive Veterinary Dictionary. $2^{\text {nd }}$ edition. London, United Kingdom. W.B. Saunders.

Bonnick SL. 2010. Bone Densitometry in Clinical Practice: Application and Interpretation. $3^{\text {rd }}$ Ed. Human Press. 520 pp.

Buckwalter JA, Glimcher MJ, Cooper RR, Recker R. 1996 Bone biology. Part II: Formation, form, modeling, remodeling, and regulation of cell function. Instructional Course Lectures 45:387-399.

Burr DB. 1980. The relationships among physical, geometrical and mechanical properties of bone, with a note on the properties of nonhuman primate bone. Yearbook of Physical Anthropology 23:109-146.

Burr DB, Robling AG, Turner CH. 2002. Effects of biomechanical stress on bones in animals. Bone 30:781-786.

Burrell GA, Seibert FM. 1916. Gases found in coal mines. Miners Circular 14. Washington, DC: Bureau of Mines, Department of the Interior.

Butti C, Corain L, Cozzi B, Podesta M, Pirone A, Affronte M, and Zotti A. 2007. Age estimation in the Mediterranean bottlenose dolphin Tursiops truncatus (Montagu 1821) by bone density of the thoracic limb. Journal of Anatomy 211:639-646.

Castañeda S, Largo R, Calvo E, Rodríguez-Salvanés F, Marcos ME, Díaz-Curiel M, Herrero-Beaumont G. 2006. Bone mineral measurements of subchondral and trabecular bone in healthy and osteoporotic rabbits. Skeletal Radiology 35:34-41. 
Cheon H, Choi W, Lee Y, Lee D, Kim J, Kang J, Na K, Chang J, Chang D. 2012. Assessment of trabecular bone mineral density using quantitative computed tomography in normal cats. Journal of Veterinary Medical Science 74:1461-1467.

Civitelli R, Gonnelli S, Zacchei F, Bigazzi S, Vattimo A, Avioli LV, Gennari C. 1988. Bone turnover in postmenopausal osteoporosis. Effect of calcitonin treatment. Journal of Clinical Investigation 82:1268-1274.

Colborn T, vom Saal FS, Soto AM. 1993. Developmental effects of endocrine-disrupting chemicals in wildlife and humans. Environmental Health Perspectives 101:378-384.

Cooper JE, Cooper ME. 2008. Skeletal pathology of primates and other wildlife. Veterinary Record 162:63-64.

Currey J. 1984. The mechanical adaptations of bones. Princeton, NJ. Princeton University Press. 304 p.

Currey J. 2002. Bones: Structure and Mechanics. Princeton, NJ: Princeton University Press. $456 \mathrm{p}$.

de Vernejoul MC. 1989. Bone remodeling in osteoporosis. Clinical Rheumatology Suppl 2:13-5.

Deem SL, Karesh WB, Weisman W. 2001. Putting theory into practice: wildlife health in conservation. Conservation Biology 15:1224-1233.

Dennis J. 1897. A new system of measurement in X-ray work. Dental Cosmos 39:445-454.

Dierauf LA, Frasca S, Mashima TY. 2001. Careers in marine mammal science. In CRC Handbook of Marine Mammal Medicine. $2^{\text {nd }}$ ed. Dierauf LA, Gulland FMD, eds. CRC Press. pp 97-115.

Duckler GL, Van Valkenburgh B. 1998. Osteological corroboration of pathological stress in a population of endangered Florida pumas (Puma concolor coryi). Animal Conservation $1: 39-46$.

Egermann M, Goldhahn J, Schneider E. 2005. Animal models for fracture treatment in osteoporosis. Osteoporosis International 16(Suppl 2):S129-138.

Feng X, McDonald JM. 2011. Disorders of bone remodeling. Annual Review of Pathology 6:121-145.

Frost HM. 1992. Perspectives: bone's mechanical usage windows. Journal of Bone and Mineral Research 19:257-271. 
Fulton LK, Clarke MS, Farris HE. 1994. The goat as a model for biomedical research and teaching. Institute of Laboratory Animal Resources Journal 36:21-29.

Galateanu G, Hidebrandt T, Maillot A, Etienne P, Potier R, Mulot B, Saragusty J, Hermes R. 2013. One small step for rhinos, one giant leap for wildlife management - imaging diagnosis of bone pathology in distal limb. PLoS ONE 8(7)e68493.

Garn SM. 1962. An annotated bibliography on bone densitometry. American Journal of Clinical Nutrition 10:59-67.

Glüer CC. 1997. Quantitative ultrasound techniques for the assessment of osteoporosis: Expert agreement on current status. Journal of Bone and Mineral Research 12:1280-1288.

Glüer CC, Wu CY, Jergas M, Goldstein SA, Genant HK. 1994. Three quantitative ultrasound parameters reflect bone structure. Calcified Tissue International 49:116-119.

Grier SJ, Turner AS, Alvis MR. 1996. The use of dual-energy X-ray absorptiometry in animals. Investigative Radiology 31:50-62.

Guglielmini C, Zotti A, Bernardini D, Pietra M, Podestà M, Cozzi B. 2002. Bone density of the arm and forearm as an age indicator in stranded specimens of the striped dolphin (Stenella coeruleoalba). Anatomical Record 267:225-230.

Haidekker MA, Stevens HY, Frangos JA. 2004. Computerized methods for X-ray-based small bone densitometry. Computer Methods and Programs in Biomedicine 73:35-42.

Hans D, Baim S. 2017. Quantitative ultrasound (QUS) in the management of osteoporosis and assessment of fracture risk. Journal of Clinical Densitometry 2:322-333.

Harvell CD, Burkholder JM, Colwell RR, Epstein PR, Grimes DJ, Hofmann EE, Lipp EK, Osterhaus AD, Overstreet RM, Porter JW, Smith GW, Vasta GR. 1999. Emerging marine diseases, climate links and anthropogenic factors. Science 285:1505-1510.

Havill LM, Mahaney MC, Czerwinski SA, Carey KD, Rice K, Rogers J. 2003. Bone mineral density reference standards in adult baboons (Papio hamadryas) by sex and age. Bone 33:877-888.

Ioannidou E. 2003. Taphonomy of animal bones: Species, sex, age, and breed variability of sheep, cattle and pig bone density. Journal of Archaeological Science 30:355-365.

Inui A, Itamoto K, Takuma T, Tsutsumi H, Tanigawa M, Hayasaki M, Taura Y, Mamba K. 2004. Age-related changes of bone mineral density and microarchitecture in miniature pigs. Journal of Veterinary Medical Science 66:599-609. 
Jaakkola K, Willis K. 2019. How long do dolphins live? Survival rates and life expectancies for bottlenose dolphins in zoological facilities $v s$. wild populations. Marine Mammal Science DOI:10.1111/mms.12601.

Jacobsen SK, Vaughn E, Miller SW. 1995. New directions in conservation biology: Graduate programs. Conservation Biology 9:5-17.

Johnston CC, Epstein S. 1981. Clinical, biochemical, radiographic, epidemiologic, and economic features of osteoporosis. Orthopedic Clinics of North America 12:559-569.

Jowsey J, Raisz LG. 1968. Experimental osteoporosis and parathyroid activity. Endocrinology 82:384-396.

Kammerer CM, Sparks ML, Rogers J. 1995. Effects of age sex, and heredity on measures of bone mass in baboons (Papio hamadryas). Journal of Medical Primatology 24:236-242.

Kanis JA, Burlet N, Cooper C, Delmas PD, Reginster JY, Borgstrom F, Rizzoli R. 2008. European guidance for the diagnosis and management of osteoporosis in postmenopausal women. Osteoporosis International 19:399-428.

Kaufman JJ, Einhorn TA. 1993. Ultrasound assessment of bone. Journal of Bone and Mineral Research 8:517-525.

Kim HS, Jeong ES, Yang MH, Yang S. 2018. Bone mineral density assessment for research purpose using dual energy X-ray absorptiometry. Osteoporosis and Sarcopenia 4:79-85.

Kinds MB, Bartels LW, Marijnissen ACA, Vincken KL, Viergever MA, Lafeber FPJG, de Jong HWAM. 2011. Feasibility of bone density evaluation using plain digital radiography. Osteoarthritis and Cartilage 19:1343-1348.

Leung KS, Siu WS, Cheung NM, Lui PY, Chow DHK, James A, Qin L. 2001. Goats as an osteopenic animal model. Journal of Bone and Mineral Research 16:2348-2355.

Lewbart GA, Cohen EB, Hirschfeld M, Muñoz-Pérez JP, García J, Fu A, Chen EP, Lohmann KJ. 2018. Field-based radiographic imaging of marine megafauna: marine iguanas (Amblyrhynchus cristatus) as a case study. Frontiers in Marine Science 5:40.

Lewiecki MJ, Binkley N. 2017. DXA: 30 years and counting: introduction to the $30^{\text {th }}$ anniversary issue. Bone 104:1-3.

Lill CA, Fluegel AK, Schneider E. 2000. Sheep model for fracture treatment in osteoporotic bone: A pilot study about different induction regimens. Journal of Orthopaedic Trauma 14:559-565. 
Lin JT, Lane JM. 2004. Osteoporosis: A Review. Clinical Orthopaedics and Related Research 425:126-134.

Lotz JC, Cheal EJ, Hayes WC. 1991. Fracture prediction for the proximal femur using finite element models: part I - linear analysis. Journal of Biomechanics 113:353-360.

Lucić H, Vuković S, Posavac V, Gomerčić MD, Gomerčić T, Galov A, Skrtic D, Ćurković S, Gomerčić H. 2010. Application of dual energy X-ray absorptiometry method for small animals in measuring bone mineral density of the humerus of bottlenose dolphins (Tursiops truncatus) from the Adriatic Sea. Veterinarski Arhiv 80:299-310.

Mack PB, Vose GP, Nelson JD. 1959. New development in equipment for the roentgenographic measurement of bone density. American Journal of Roentgenology 82:303-310.

Marcus R, Bouxsein M. 2008. The nature of osteoporosis. In: Marcus R, Feldman D, Nelson DA, Rosen EJ, (Eds). Osteoporosis. Academic; San Diego. pp. 27-36.

Marks SC Jr., Odgren PR. 2002. Structure and development of the skeleton. In: Bilezikian JP, Raisz LG, Rodan GA (Eds.). Principles of Bone Biology. $2^{\text {nd }}$ Edition. Academic Press. pp. 3-16.

Martin RK, Albright JP, Jee WSS, Taylor GN, Clarke WR. 1981. Bone loss in the beagle tibia: Influence of age, weight, and sex. Calcified Tissue International 33:233-238.

Matkovic V, Fontana D, Tominac C, Goel P, Chesnut CH. 1990. Factors that influence peak bone mass formation: a study of calcium balance and the inheritance of bone mass in adolescent females. American Journal of Clinical Nutrition 52(5):878-888.

Mazess R, Chestnut CH, McClung M, Genant H. 1992. Enhanced precision with dualenergy X-ray absorptiometry. Calcified Tissue International 51:14-17.

McCarthy RN, Jeffcott LB, McCartney RN. 1990. Ultrasound speed in equine cortical bone: effects of orientation, density, porosity, and temperature. Journal of Biomechanics 23:1139-1143.

Metcalfe NH. 2007. In what ways can human skeletal remains be used to understand health and disease from the past? Postgraduate Medical Journal 83:281-284.

Miller PD. 2017. The history of bone densitometry. Bone 104:4-6.

Nagai S, Shindo H. 1997. Mechanical strength of bone in canine osteoporosis model: Relationship between bone mineral content and bone fragility. Journal of Orthopaedic Science 2:428-433. 
Nielson CM, Marshall LM, Adams AL, LeBlanc ES, Cawthon PM, Ensrud K, Stefanick ML, Barrett-Connor E, Orwoll ES. 2011. BMI and fracture risk in older men: the osteoporotic fractures in men study (MrOS). Journal of Bone and Mineral Research 26:496-502.

Njeh CF, Boivin CM, Langton CM. 1997. The role of ultrasound in the assessment of osteoporosis: a review. Osteoporosis International 7:7-22.

O'Connor T. 2000. The Archaeology of Animal Bones. Texas A\&M University Press. Sutton Publishing. 206 p.

Olsen BR, Reginato AM, Wang W. 2002. Bone development. Annual Review of Cell and Developmental Biology. 16:191-220.

O'Shea TJ. 1999. Environmental contaminants and marine mammals. In Biology of Marine Mammals (J.E. Reynolds and S.A. Rommel, eds.), pp 485-563. Smithsonian Institute Press, Washington, DC.

Ott SM. 1990. Attainment of peak bone mass. Journal of Clinical Endocrinology and Metabolism 71:1082A-1082C.

Ott SM, O’Hanlan M, Lipkin EW, Newell-Morris L. 1997. Evaluation of vertebral volumetric vs. areal bone mineral density during growth. Bone 20:553-556.

Pisani P, Renna MD, Conversano F, Casciaro E, Muratore M, Quarta E, Paola MD, Casciaro S. 2013. Screening and early diagnosis of osteoporosis through X-ray and ultrasound based techniques. World Journal of Radiology 5:398-410.

Price WA. 1901. The science of dental radiology. Dental Cosmos 43:483-503.

Reich SB, Levitin J, Felton LR. 1958. A roentgen method of evaluating density of bone. American Journal of Roentgenology 79:705-708.

Reinwald S, Burr D. 2008. Review of nonprimate, large animal models for osteoporosis research. Journal of Bone and Mineral Research 23:1353-1368.

Ryser-Degiorgis M. 2013. Wildlife heath investigations: needs, challenges and recommendations. BMC Veterinary Research 9:223.

Salazar S, Denkinger J. 2010. Possible effects of climate change on the populations of Galapagos pinnipeds. Galapagos Research 67:45-49.

Sartoris DJ, Resnick D. 1990. Current and innovative methods for noninvasive bone densitometry. Radiologic Clinics of North America 28:257-278. 
Schraer H, Schraer R, Trostle HG, D'Alfonso A. 1959. The validity of measuring bone density from roentgenograms by means of a bone density computing apparatus. Archives of Biochemistry and Biophysics 83:486-500.

Seilern-Moy K, Vielgrader H, Gerritsmann H, Walzer C. 2017. Radiography in the field: assessing a lightweight, handheld, battery-powered dentistry unit for field diagnostic applications. Journal of Zoo and Wildlife Medicine 48:31-39.

Smith SY, Varela A, Jolette J. 2011. Nonhuman primate models of osteoporosis. In: Duque G, Watanabe K (Eds.). Osteoporosis Research. Springer, London.

Sonne C, Dietz R, Born EW, Riget FF, Kirkegaard M, Hyldstrup L, Letcher RJ, Muir DCG. 2004. Is bone mineral composition disrupted by organochlorines in east Greenland Polar Bears (Ursus maritimus)? Environmental Health Perspectives 112:1711-1716.

Sophocleous A, Idris AI. 2014. Rodent models of osteoporosis. BoneKEy Reports 3:614.

Stevenson DE, Wilson AA. 1964. Metabolic disorders of domestic animals. Blackwell Scientific Publications; Oxford.

Thorndike EA, Turner AS. 1998. In search of an animal model from postmenopausal disease. Frontiers in Bioscience 3:c17-c26.

Thrall DE. 2018. Textbook of Veterinary Diagnostic Radiology, $7^{\text {th }}$ Ed. Philadephia, PA Elsevier $1000 \mathrm{p}$.

Torgerson DJ, Campbell MK, Reid DM. 1995. Life-style, environmental and medical factors influencing peak bone mass in women. Rheumatology 34:620-624.

Townsend FI, Smith CR, Rowles TK. 2018. Health assessment of bottlenose dolphins in capture-release studies. In: Gulland FMD, Dierauf LA, Whitman KL, eds. CRC Handbook of Marine Mammal Medicine. Boca Raton, FL: CRC Press. pp. 823-834.

Turner AS. 2001. Animal models of osteoporosis - necessity and limitations. European Cells and Materials 1:66-81.

Turner RT, Maran A, Lotinun S, Hefferan T, Evans GL, Zhang M, Sibonga JD. 2001. Animal models for osteoporosis. Reviews in Endocrine and Metabolic Disorders 2:117127.

van der Schalie WH, Gardner HS, Bantle JA, DeRosa, CT, Finch RA, Reif JS, Reuter RH, Backer LC, Burger J, Folmar LC, Stokes WS. 1999. Animals as sentinels of human health hazards of environmental chemicals. Environmental Health Perspectives 107:309-315. 
Venn-Watson S, Smith CR, Gomez F, Jensen ED. 2011. Physiology of aging among healthy, older bottlenose dolphins (Tursiops truncatus) comparisons with aging humans. Journal of Comparative Physiological Biology 5:667-680.

Wells RS. 2014. Social structure and life history of bottlenose dolphins near Sarasota Bay, Florida: Insights from four decades and five generations. In: Primates and Cetaceans. Yamagiwa J, Karczmarski L (Eds.). Primatology Monographs. Springer, Tokyo. pp 149172.

Wen XX, Xu X, Wang FQ, Feng YF, Zhao X, Yan YB, Lei W. 2015. Temporal changes of microarchitectural and mechanical parameters of cancellous bone in the osteoporotic rabbit. BioMed Research International E263434. 11pp.

Zotti A, Poggi R, Cozzi B. 2009. Exceptional bone density DXA values of the rostrum of a deep-diving marine mammal: a new technical insight in the adaptation of bone to aquatic life. Skeletal Radiology 38:1123-1125.

\section{Chapter 2}

Bianchi ML, Baim S, Bishop NJ, Gordon CM, Hans DB, Langman CB, Leonard MB, Kalkwarf HJ. 2010. Official positions of the International Society for Clinical Densitometry (ISCD) on DXA evaluation in children and adolescents. Pediatric Nephrology 25:37-47.

Bonnick SL. 2010. Bone densitometry in clinical practice. Humana Press, New York, NY.

Butti C, Corain L, Cozzi B, Podesta M, Pirone A, Affronte M, Zotti A. 2007. Age estimation in the Mediterranean bottlenose dolphin Tursiops truncatus (Montagu 1821) by bone density of the thoracic limb. Journal of Anatomy 211:639-646.

Cunha E, Baccino E, Martrille L, Ramsthaler F, Prieto J, Schuliar Y, Lynnerup N, Cattaneo C. 2009. The problem of aging human remains and living individuals. Forensic Science International 193:1-13.

Franklin D. 2010. Forensic age estimation in human skeletal remains: Current concepts and future directions. Legal Medicine 12:1-7.

Guglielmini C, Zotti A, Bernardini D, Pietra M, Podesta M, Cozzi B. 2002. Bone density of the arm and forearm as an age indicator in specimens of stranded striped dolphins (Stenella coeruleoalba). The Anatomical Record 267:225-230.

Hohn AA. 1980. Age determination and age related factors in the teeth of Western North Atlantic bottlenose dolphins. Scientific Report to the Whales Research Institute 32:39-66.

Hohn AA, Scott MD, Wells RS, Sweeney JC, Irvine AB. 1989. Growth layers in teeth from known-age, free-ranging bottlenose dolphins. Marine Mammal Science 3:315-342. 
Hohn AA. 2018. Age estimation. Pages 10-14 in B. Würsig, J.G.M. Thewissen and K.M. Kovacs (eds.), Encyclopedia of Marine Mammals. Academic Press, San Diego, CA.

Merritt C. 2017. Inaccuracy and bias in adult skeletal age estimation: Assessing the reliability of eight methods on individuals of varying body sizes. Forensic Science International 275:315. e1-315. E11.

Stolen MK, Barlow J. 2003. A model life table for bottlenose dolphins (Tursiops truncatus) from the Indian River Lagoon system, Florida, U.S.A. Marine Mammal Science 19:630649.

Wells RS. 2009. Learning from nature: Bottlenose dolphin care and husbandry. Zoo Biology 28:635-651.

Wells RS. 2014. Social structure and life history of common bottlenose dolphins near Sarasota Bay, Florida: Insights from four decades and five generations. Pages 149-172 in: J. Yamagiwa and L. Karczmarski, eds. Primates and cetaceans: Field research and conservation of complex mammalian societies, Primatology Monographs, Tokyo, Japan: Springer.

Zweifel JR, Perrin WF. 1980. Fitting curves to odontocete tooth layer/length data. Pages 216-229 In: W. F. Perrin and A. C. Myrick, eds. Age determination of toothed whales and sirenians. Report of the International Whaling Commission, Special Issue 3.

\section{Chapter 3}

Azevedo CT, Lima JY, de Azevedo RM, Neto EBS, Pessanha W, Barbosa LA, ..., da Silveira LS. 2015. Thoracic limb bone development in Sotalia guianensis (Van Beneden 1864) along the coastline of Espírito Santo, Brazil. Journal of Mammalogy 96:541-551.

Bhudhikanok GS, Wang MC, Eckert K, Matkin C, Marcus R, Bachrack LK. 1996. Differences in bone mineral in the young Asian and Caucasian Americans may reflect differences in bone size. Journal of Bone Mineral Research 11:1545-1556.

Butti C., L. Corain, B. Cozzi, M. Podestá, A. Pirone, M. Affronte, and A. Zotti. 2007. Age estimation in the Mediterranean bottlenose dolphin Tursiops truncatus (Montagu 1821) by bone density of the thoracic limb. Journal of Anatomy 211:639-646.

Civitelli R., Gonnelli S, Zacchei F, Bigazzi S, Vattimo A, Avioli LV, Gennari C. 1988. Bone turnover in postmenopausal osteoporosis. Effect of calcitonin treatment. Journal of Clinical Investigation 82(4):1268-1274.

Guglielmini C, Zotti A, Bernardini D, Pietra M, Podesta M, Cozzi B. 2002. Bone density of the arm and forearm as an age indicator in specimens of stranded striped dolphins (Stenella coeruleoalba). The Anatomical Record 267:225-230. 
Hart LB, Wells RS, Schwacke LH. 2013. Reference ranges for body condition in wild bottlenose dolphins (Tursiops truncatus). Aquatic Biology 18:63-68.

Joblon MJ, Pokras MA, Morse B, Harry CT, Rose KS, Sharp SM, Niemeyer ME, Patchett KM, Sharp WB, Moore MJ. 2008. Body condition scoring system for delphinids based on short-beaked common dolphins (Delphinus delphis). Journal of Marine Animals and Their Ecology 7:5-13.

Lim S, Joung H, Shin CS, Lee HK, Kim KS, Shin EK, Kim HY, Lim MK, Cho Sl. 2004. Body composition changes with age have gender specific impacts on bone mineral density. Bone 35:792-798.

Lucic H, Vukovic S, Posavac V, Gomerčić MD, Gomerčić T, Galov A, Škrtić D, Ćurković S, Gomerčić H. 2010. Application of dual energy X-ray absorptiometry method for small animals in measuring bone mineral density of the humerus of bottlenose dolphins (Tursiops truncatus) from the Adriatic Sea. Veterinarski Arhiv 80:299-310.

Powell JWB, Duffield DA, Kaufman, JJ, McFee WE. 2019. Bone density cannot accurately predict age in the common bottlenose dolphin, Tursiops truncatus. Marine Mammal Science. DOI: $10.1111 / \mathrm{mms} .12591$.

Shepherd JA, Cheng XG, Lu Y, et al. 2002. Universal standardization of forearm bone densitometry. Journal of Bone and Mineral Research 17:734-745.

Sonne C, Dietz R, Born EW, Riget FF, Kirkegaard M, Hyldstrup L, Letcher RJ, Muir DCG. 2004. Is bone mineral composition disrupted by organochlorines in east Greenland Polar Bears (Ursus maritimus)? Environmental Health Perspectives 112:1711-1716.

Sözen T, Özişik L, Başaran NÇ. 2017. An overview and management of osteoporosis. European Journal of Rheumatology 4:46-56.

Staessen JA, Roles HA, Emelianov D, Kuznetsova T, Thijis L, Vangronsveld J, Fagard R. 1999. Environmental exposure to cadmium, forearm bone density, and risk of fractures: prospective population study. The Lancet 353:1140-1144.

Swift SN, Baek K, Swift JM, Bloomfield SA. 2012. Restriction of dietary energy intake has a greater impact on bone integrity than does restriction of calcium in exercising female rats. Journal of Nutrition 142:1038-1045.

Talbot SM, Rothkopf MM, Shapses SA. 1998. Dietary restriction of energy and calcium alters bone turnover and density in younger and older female rats. Journal of Nutrition 128:640-645.

Wells RS, Rhinehart HL, Hansen LJ, Sweeney JC, Townsend FI, Stone R, Casper DR, 
Scott M, Hohn AA, Rowles TK. 2004. Bottlenose dolphins as marine ecosystem sentinels: Developing a health monitoring system. EcoHealth 1:246-254.

Wells RS. 2009. Learning from nature: Bottlenose dolphin care and husbandry. Zoo Biology 28: 635-651.

Wells RS. 2014. Social structure and life history of common bottlenose dolphins near Sarasota Bay, Florida: Insights from four decades and five generations. pp 149-172 In: J. Yamagiwa and L. Karczmarski (Eds.), Primates and cetaceans: Field research and conservation of complex mammalian societies, Primatology Monographs, Tokyo, Japan: Springer.

Zemel BS, Leonard MB, Kelly A, Lappe JM, Gilsanz V, Oberfield S, Mahboudi S, Shepherd JA, Hangartner TN, Frederick MM, Winer KK, Kalkwarf HJ. 2010. Height adjustment in assessing dual energy x-ray absorptiometry measurements of bone mass and density in children. Journal of Clinical Endocrinology and Metabolism 95:1265-1273.

\section{Chapter 4}

Afaneh A, Alzebda S, Ivchenko V, Kalashnikov AN. 2011. Ultrasonic measurements of temperature in aqueous solutions: why and how. Physics Research International 156396. doi:10.1155/2011/156396.

Attix FH. 1986. Introduction to Radiological Physics and Radiation Dosimetry. John Wiley and Sons, New York, NY.

Barkmann R, Dencks S, Laugier P, Padilla F, Brixen K, Ryg J, Seekamp A, Mahlke L, Bremer A, Heller M, Glüer CC. 2010. Femur ultrasound (FemUS) - first clinical results on hip fracture discrimination and estimation of femoral BMD. Osteoporosis International 21:969-976.

Barratclough A, Sanz-Requena R, Marti-Bonmarti L, Schmitt, TL, Jense, E, and Garcia Parraga D. 2019. Radiographic assessment of pectoral fin bone maturation in bottlenose dolphins (Tursiops truncatus), as a novel technique to accurately estimate chronological age. PlosOne 14(9): e0222722.

Bonnick SL. 2010. Bone Densitometry in Clinical Practice: Application and Interpretation. $3^{\text {rd }}$ Ed. Human Press. 520 pp.

Butti C, Corain L, Cozzi B, Podesta M, Pirone A, Affronte M, Zotti A. 2007. Age estimation in the Mediterranean bottlenose dolphin Tursiops truncatus (Montagu 1821) by bone density of the thoracic limb. Journal of Anatomy 211:639-646.

Dhalnaut A, Hoff M, Syversen U, Haugeberg G. 2016. Technologies for assessment of bone reflecting bone strength and bone mineral density in elderly women: an update. Womens Health 12(2):209-216. 
Glüer CC. 1997. Quantitative ultrasound techniques for the assessment of osteoporosis: Expert agreement on current status. Journal of Bone and Mineral Research 12:1280-1288.

Hans D, Baim S. 2017. Quantitative ultrasound (QUS) in the management of osteoporosis and assessment of fracture risk. Journal of Clinical Densitometry 2:322-333.

Hartl F, Tyndall A, Kraenzlin M, Bachmeier C, Gückel C, Senn U, Hans D, Theiler R. 2002. Discriminatory ability of quantitative ultrasound parameters and bone mineral density in a population-based sample of postmenopausal women with vertebral fractures: results of the Basel Osteoporosis Study. Journal of Bone and Mineral Research 17:321330.

Kaufman JJ, Einhorn TA. 1993. Ultrasound assessment of bone. Journal of Bone and Mineral Research 8:517-525.

Kaufman JJ, Luo GM. 2017. A new dual-mode ultrasonic technique for assessing cortical bone. Journal of the Acoustic Society of America 142:2565.

Kaufman JJ, Luo GM, Lieberman M, Rosenfeld S, Rosenbaum A, Siffert RSS. 2010. Ultrasonic assessment of the radius. Journal of Bone and Mineral Research 22(Suppl 4):S569-S570.

Kaufman JJ, Luo G, Siffert R. 2007. A portable real-time ultrasonic bone densitometer. Ultrasound in Medicine and Biology 33:1445-1452.

Kaufman JJ, Luo GM, Siffert RS. 2008. Ultrasound Simulation in Bone (Invited Paper). IEEE Transactions on Ultrasonics, Ferroelectrics, and Frequency Control 56:1205-1218.

LeFloch V, Luo GM, Kaufman JJ, Siffert RS. 2008. Ultrasonic assessment of the radius in vitro. Ultrasound in Medicine and Biology 34:1972-1979.

Louis O, Moreels X, Osteaux M. 1998. Reproducibility of phalanx osteosonography and relation with forearm peripheral quantitative computed tomography: single finger versus average measurement on the last four fingers. European Journal of Radiology 28:270-275.

Metcalfe NH. 2007. In what ways can human skeletal remains be used to understand health and disease from the past? Postgraduate Medical Journal 83:281-284.

Njeh CF, Boivin CM, Langton CM. 1997. The role of ultrasound in the assessment of osteoporosis: a review. Osteoporosis International 7:7-22.

Powell JWB, Duffield DA, Kaufman JJ, McFee WE. 2019. Bone density cannot accurately predict age in the common bottlenose dolphin. Tursiops truncatus. Marine Mammal Science DOI:10.1111/mms.12591. 
Powell JWB, Duffield DA, Kaufman JJ, Luo GM, Lovewell GM, Wells RS, McFee WE. Bone mineral density of the common bottlenose dolphin radius: a primary skeletal site and normative reference dataset for clinical bone densitometry. In Preparation.

Ramteke SM, Kaufman JJ, Arpadi SM, Shiau S, Strehlau R, Patel F, Mbete N, Coovadia A, Yin MT. 2017. Unusually high calcaneal speed of sound measurements in children with small foot size. Ultrasound in Medicine and Biology 43:357-361.

Rowles TK, Schwacke LH, Hall AJ, Barbieri M. 2018. Population health assessment study design. In: Gulland FMD, Dierauf LA, Whitman KL (Eds.). CRC Handbook of Marine Mammal Medicine. Boca Raton, FL: CRC Press. pp. 813-822.

Siffert RS, Kaufman JJ. 2007. Ultrasonic bone assessment: "The time has come". Bone 40:5-8.

Sözen T, Özişik L, Başaran NC. 2017. An overview and management of osteoporosis. European Journal of Rheumatology 4:46-56.

Stein EM, Rosete F, Young P, Kamada-Kosseh M, McMahon DJ, Luo G, Kaufman JJ, Shane E, Siffert RS. 2013. Clinical assessment of the $1 / 3^{\text {rd }}$ radius using a new desktop ultrasonic bone densitometer. Ultrasound in Medicine and Biology 39:388-395.

Townsend FI, Smith CR, Rowles TK. 2018. Health assessment of bottlenose dolphins in capture-release studies. In: Gulland FMD, Dierauf LA, Whitman KL, eds. CRC Handbook of Marine Mammal Medicine. Boca Raton, FL: CRC Press. pp. 823-834.

U.S. Food and Drug Administration, Center for Drug Evaluation and Research. UltraScan650 Bone Sonometer K161919 approval letter, April 5, 2017. Retrieved July 18, 2019, from www.accessdata.fda.gov/scripts/cdrh/cfdocs/cfPMN/pmn.cfm?ID=K161919

\section{Chapter 5}

Aguilar A, Borrell A. 1994. Abnormally high polychlorinated biphenyl levels in striped dolphins (Stenella coeruleoalba) affected by the 1990-1992 Mediterranean epizootic. Science of the Total Environment 154:237-247.

Allen MJ. 2003. Biochemical markers of bone metabolism in animals: uses and limitations. Veterinary Clinical Pathology 32:101-113.

Barnthouse LW, Stahl SG. 2017. Assessing and managing natural resource damages: Continuing challenges and opportunities. Environmental Management 59:709-717.

Berens-McCabe EJ, Gannon DP, Barros NB, Wells RS. 2010. Prey selection by resident common bottlenose dolphins (Tursiops truncatus) in Sarasota Bay, Florida. Marine Biology 157:931-942. 
Blake GM, Herd RJM, Patel R, Fogelman I. 2000. The effect of weight change on total body dual-energy X-ray absorptiometry: results from a clinical trial. Osteoporosis International 11:832-839.

Bonnick SL. 2010. Bone densitometry in clinical practice. Humana Press. New York, NY.

Danion M, Deschamp MH, Thomas-Guyon H, Bado-Nilles A, Le Floch S, Quentel C, Sire JY. 2011. Effect of an experimental oil spill on vertebral bone tissue quality in European sea bass (Dicentrarchus labrax L.). Ecotoxicology and Environmental Safety 74:18881895.

Duckler GL, Van Valkenburgh B. 1998. Osteological corroboration of pathological stress in a population of endangered Florida pumas (Puma concolor coryi). Animal Conservation 1:39-46.

Fire SE, Flewelling LJ, Naar J, Twiner MJ, Henry MS, Pierce RH, Gannon DP, Wang Z, Davidson L, Wells RS. 2008a. Prevalence of brevetoxins in prey fish of bottlenose dolphins in Sarasota Bay, Florida. Marine Ecology Progress Series 368:283-294.

Fire SE, Flewelling LJ, Wang Z, Naar J, Henry MS, Pierce RH, Wells RS. 2008b. Florida red tide and brevetoxins: Association and exposure in live resident bottlenose dolphins (Tursiops truncatus) in the eastern Gulf of Mexico, U.S.A. Marine Mammal Science 24: 831-844.

Gannon DP, Berens EJ, Camilleri SA, Gannon JG, Bruegen MK, Barleycorn AA, Palubok VI, Kirkpatrick GJ, Wells RS. 2009. Effects of Karenia brevis harmful algal blooms on nearshore fish communities in southwest Florida. Marine Ecology Progress Series 378:171-186.

Glüer CC. 1997. Quantitative ultrasound techniques for the assessment of osteoporosis: Expert agreement on current status. Journal of Bone and Mineral Research 12:1280-1288.

Hart L, Wells R, Schwacke L. 2013. Body mass index and maximum girth reference ranges for bottlenose dolphins (Tursiops truncatus) in the southeastern United States. Aquatic Biology 18:63-68.

Hart LB, Wells RS, Kellar N, Balmer BC, Hohn AA, Lamb SV, Rowles T, Zolman ES, Schwacke LH. 2015. Adrenal hormones in common bottlenose dolphins (Tursiops truncatus): Influential factors and reference intervals. PloS One 10:e0127432.

International Society for Clinical Densitometry (ICSD). 2019. 2019 ISCD official positions. Retrieved from www.icsd.org/official-positions/2019-iscd-official-positionsadult/ 
Kanis JA, McCloskey EV, Johansson H, Oden A, Melton LJ, Khaltaev N. 2008. A Reference standard for the description of osteoporosis. Bone 42:467-475.

Kaufman JJ, Einhorn TA. 1993. Ultrasound assessment of bone. Journal of Bone and Mineral Research 8:517-525.

Mead JG, Potter CW. 1990. Natural history of bottlenose dolphins along the central Atlantic coast of the United States. In S Leatherwood \& RR Reeves (Eds.). The bottlenose dolphin (pp. 165-195). San Diego, CA: Academic Press.

Metcalfe NH. 2007. In what ways can human skeletal remains be used to understand health and disease from the past? Postgraduate Medical Journal 83:281-284.

Njeh CF, Boivin CM, Langton CM. 1997. The role of ultrasound in the assessment of osteoporosis: a review. Osteoporosis International 7:7-22.

Pluijm SMF, Visser M, Smit JH, Popp-Snijders C, Roos JC, Lips P. 2001. Determinants of bone mineral density in older men and women: body composition as mediator. Journal of Bone and Mineral Research 16:2142-2151.

Powell JR, Wells RS. 2011. Recreational fishing depredation and associated behaviors involving common bottlenose dolphins (Tursiops truncatus) in Sarasota Bay, Florida. Marine Mammal Science 27:111-129.

Read AJ, Wells RS, Hohn AA, Scott MD. 1993. Patterns of growth in wild bottlenose dolphins, Tursiops truncatus. Journal of Zoology 231:107-123.

Rillo OL, Di Stefano CA, Bermudez J, Maldonado Cocco JA. 1994. Idiopathic osteoporosis during pregnancy. Clinical Rheumatology 13:299-304.

Rowles TK, Schwacke LH, Hall AJ, Barbieri M. 2018. Population health assessment study design. In FMD Gulland, LA Dierauf, KL Whitman (Eds.). CRC Handbook of Marine Mammal Medicine ( $3^{\text {rd }}$ ed., pp. 813-822). Boca Raton, FL: CRC Press.

Salari P, Abdollahi M. 2014. The influence of pregnancy and lactation on maternal bone health: a systematic review. Journal of Family and Reproductive Health 8:135-148.

Schwacke LH, Hall AJ, Townsend FI, Wells RS, Hansen LJ, Hohn AA, Bossart GD, Fair PA, Rowles TK. 2009. Hematological and serum biochemical reference intervals for freeranging common bottlenose dolphins (Tursiops truncatus) and variation in the distributions of clinicopathological values related to geographic sampling site. American Journal of Veterinary Research 70:973-985.

Schwacke LH, Thomas L, Wells RS, McFee WE, Hohn AA, Mulin KD, Zolman ES, Quigley BM, Rowles TK, Schwacke JH. 2017. Quantifying injury to common bottlenose 
dolphins from the Deepwater Horizon oil spill using as age-, sex-, and class-structured population model. Endangered Species Research 33:265-279.

Sergeant DE, Caldwell DK, Caldwell MC. 1973. Age, growth, and maturity of bottlenosed dolphins (Tursiops truncatus) from northeast Florida. Journal of the Fisheries Research Board of Canada 30:1009-1011.

Shepherd JA, Cheng XG, Lu Y, Njeh C, Toschke J, Engelke K, Grigorian M, Genant HK. 2002. Universal standardization of forearm bone densitometry. Journal of Bone and Mineral Research 17:734-745.

Sonne C, Dietz R, Born EW, Riget FF, Kirkegaard M, Hyldstrup L, Letcher RJ, Muir DCG. 2004. Is bone mineral composition disrupted by organochlorines in east Greenland Polar Bears (Ursus maritimus)? Environmental Health Perspectives 112:1711-1716.

Staessen JA, Roles HA, Emelianov D, Kuznetsova T, Thijis L, Vangronsveld J, Fagard R. 1999. Environmental exposure to cadmium, forearm bone density, and risk of fractures: prospective population study. Lancet 353:1140-1144.

Tolley KA, Read AJ, Wells RS, Urian KW, Scott MD. 1995. Sexual dimorphism in wild bottlenose dolphins (Tursiops truncatus) from Sarasota, Florida. Journal of Mammalogy 76:1190-1198.

Townsend FI, Smith CR, Rowles TK. 2018. Health assessment of bottlenose dolphins in capture-release studies. In FMD Gulland, LA Dierauf, KL Whitman (Eds.), CRC Handbook of Marine Mammal Medicine (3 ${ }^{\text {rd }}$ ed., pp. 823-834). Boca Raton, FL: CRC Press.

Wells RSW, Scott MD. 2018. Bottlenose dolphin, Tursiops truncatus, common bottlenose dolphin. In B Wrsig, JGM Thewissen, KM Kovacs (Eds.). Encyclopedia of Marine Mammals ( $3^{\text {rd }}$ ed, pp. 118-125). Cambridge, MA: Academic Press.

\section{Chapter 6}

Gray NM, Kainec K, Madar S, Tomko L, Wolfe S. 2007. Sink or swim? Bone density as a mechanism for buoyancy control in early cetaceans. Anatomical Record 290:638-653.

Stein BR. 1989. Bone density and adaptation in semiaquatic mammals. Journal of Mammalogy 70:467-476.

Wall WP. 1983. The correlation between high limb-bone density and aquatic habits in recent mammals. Journal of Paleontology 57:197-207. 
Appendix A. Bone mineral density (BMD) values as defined with dual-energy X-ray absorptiometry (DXA) for bottlenose dolphins, Tursiops truncatus, in this study provided as an open-source descriptive dataset for bottlenose dolphin BMD values.

\begin{tabular}{|c|c|c|c|c|c|c|}
\hline Field \# & $\begin{array}{c}\text { Sex } \\
(\mathbf{M} / \mathbf{F})\end{array}$ & $\begin{array}{l}\text { TL } \\
(\mathbf{c m})\end{array}$ & $\begin{array}{l}\text { Age } \\
(\mathbf{y r})\end{array}$ & $\begin{array}{c}\text { L/R } \\
\text { Radius }\end{array}$ & $\begin{array}{l}\text { Radius BMD } \\
\quad\left(\mathbf{g} / \mathrm{cm}^{2}\right)\end{array}$ & $\begin{array}{c}\text { GC ROI BMD } \\
\left(\mathbf{g} / \mathbf{c m}^{2}\right)\end{array}$ \\
\hline SC0516 & $\mathrm{M}$ & 115 & 0 & $\mathrm{R}$ & 0.3508 & 0.4270 \\
\hline SC0948 & $\mathrm{M}$ & 108 & 0 & $\mathrm{R}$ & 0.3658 & 0.4845 \\
\hline SC1030 & $\mathrm{M}$ & 105 & 0 & $\mathrm{R}$ & 0.2843 & 0.3683 \\
\hline SC1031 & $\mathrm{M}$ & 91 & 0 & $\mathrm{R}$ & 0.3298 & 0.4643 \\
\hline SC1038 & $\mathrm{F}$ & 96 & 0 & $\mathrm{R}$ & 0.2366 & 0.3424 \\
\hline SC1039 & $\mathrm{F}$ & 100 & 0 & $\mathrm{R}$ & 0.3511 & 0.4624 \\
\hline SC1043 & M & 108.5 & 0 & $\mathrm{R}$ & 0.3299 & 0.4132 \\
\hline SC1135 & $\mathrm{F}$ & 101 & 0 & $\mathrm{R}$ & 0.3306 & 0.4695 \\
\hline SC1142 & M & 101 & 0 & $\mathrm{R}$ & 0.2794 & 0.3406 \\
\hline SC1145 & $\mathrm{F}$ & 94 & 0 & $\mathrm{R}$ & 0.2347 & 0.3101 \\
\hline SC1146 & $\mathrm{M}$ & 87 & 0 & $\mathrm{R}$ & 0.2869 & 0.4239 \\
\hline SC1168 & $\mathrm{M}$ & 100 & 0 & $\mathrm{R}$ & 0.3612 & 0.4640 \\
\hline SC1171 & $\mathrm{M}$ & 100 & 0 & $\mathrm{R}$ & 0.2858 & 0.3728 \\
\hline SC1176 & M & 110 & 0 & $\mathrm{R}$ & 0.4016 & 0.5390 \\
\hline SC1216 & M & 90 & 0 & $\mathrm{R}$ & 0.2254 & 0.3158 \\
\hline SC0841 & $\mathrm{M}$ & 127 & 0.16 & $\mathrm{R}$ & 0.3799 & 0.4861 \\
\hline SC1059 & $\mathrm{M}$ & 127 & 0.37 & $\mathrm{R}$ & 0.3192 & 0.4187 \\
\hline MML0115 & $\mathrm{F}$ & 147 & 0.5 & $\mathrm{R}$ & 0.3205 & 0.4367 \\
\hline MML1211 & $\mathrm{F}$ & 169.3 & 0.5 & $\mathrm{R}$ & 0.4834 & 0.6920 \\
\hline SC0426 & $\mathrm{M}$ & 158 & 0.5 & $\mathrm{R}$ & 0.3914 & 0.5784 \\
\hline SC0725 & $\mathrm{M}$ & 166 & 0.65 & $\mathrm{R}$ & 0.3738 & 0.4948 \\
\hline SC1052 & M & 135 & 0.68 & $\mathrm{R}$ & 0.2639 & 0.3702 \\
\hline SC0043 & $\mathrm{M}$ & 145 & 0.75 & $\mathrm{R}$ & 0.3189 & 0.4220 \\
\hline SC0903 & $\mathrm{F}$ & 158 & 0.77 & $\mathrm{~L}$ & 0.5577 & 0.7511 \\
\hline SC9636 & $\mathrm{M}$ & 149 & 0.8 & $\mathrm{R}$ & 0.4250 & 0.5525 \\
\hline SC0326 & $\mathrm{M}$ & 156 & 0.85 & $\mathrm{~L}$ & 0.3398 & 0.4478 \\
\hline SC9842 & $\mathrm{M}$ & 168 & 0.9 & $\mathrm{R}$ & 0.4423 & 0.5805 \\
\hline SC0739 & M & 160 & 0.94 & $\mathrm{R}$ & 0.4069 & 0.5602 \\
\hline SC0451 & $\mathrm{F}$ & 168 & 1 & $\mathrm{R}$ & 0.3798 & 0.5295 \\
\hline SC0629 & M & 173 & 1 & $\mathrm{R}$ & 0.4606 & 0.6238 \\
\hline SC9817 & M & 153 & 1 & $\mathrm{R}$ & 0.3840 & 0.4829 \\
\hline SC0722 & M & 149 & 1.25 & $\mathrm{R}$ & 0.3471 & 0.4897 \\
\hline SC1029 & $\mathrm{F}$ & 146 & 1.25 & $\mathrm{~L}$ & 0.3834 & 0.5122 \\
\hline SC0148 & $\mathrm{M}$ & 137 & 1.5 & $\mathrm{R}$ & 0.4039 & 0.5400 \\
\hline SC0332 & M & 176 & 1.5 & $\mathrm{R}$ & 0.5219 & 0.6025 \\
\hline
\end{tabular}




\begin{tabular}{|c|c|c|c|c|c|c|}
\hline Field \# & $\begin{array}{c}\text { Sex } \\
(\mathbf{M} / \mathbf{F})\end{array}$ & $\begin{array}{c}\text { TL } \\
(\mathbf{c m})\end{array}$ & $\begin{array}{l}\text { Age } \\
(\mathbf{y r})\end{array}$ & $\begin{array}{c}\text { L/R } \\
\text { Radius }\end{array}$ & $\begin{array}{c}\text { Radius BMD } \\
\left(\mathrm{g} / \mathrm{cm}^{2}\right)\end{array}$ & $\begin{array}{c}\text { GC ROI BMD } \\
\left(\mathrm{g} / \mathrm{cm}^{2}\right)\end{array}$ \\
\hline SC0332 & $\mathrm{M}$ & 176 & 1.5 & $\mathrm{~L}$ & 0.5174 & 0.6111 \\
\hline SC1060 & M & 154 & 1.5 & $\mathrm{R}$ & 0.3058 & 0.3938 \\
\hline SC1255 & $\mathrm{F}$ & 162 & 1.5 & $\mathrm{R}$ & 0.3706 & 0.4779 \\
\hline SC9702 & M & 195 & 1.5 & $\mathrm{R}$ & 0.5439 & 0.7178 \\
\hline SC0806 & $\mathrm{F}$ & 139 & 2 & $\mathrm{R}$ & 0.3974 & 0.5937 \\
\hline SC9620 & M & 188 & 2 & $\mathrm{~L}$ & 0.5392 & 0.7027 \\
\hline SC0028 & $\mathrm{F}$ & 172 & 2.5 & $\mathrm{R}$ & 0.4269 & 0.5680 \\
\hline SC0028 & $\mathrm{F}$ & 172 & 2.5 & $\mathrm{~L}$ & 0.4408 & 0.5869 \\
\hline SC0325 & M & 183 & 2.5 & $\mathrm{~L}$ & 0.3760 & 0.5044 \\
\hline SC0743 & M & 191 & 2.5 & $\mathrm{R}$ & 0.4879 & 0.6422 \\
\hline SC1233 & M & 173 & 2.5 & $\mathrm{R}$ & 0.5085 & 0.6839 \\
\hline SC1235 & M & 168 & 2.5 & $\mathrm{R}$ & 0.5215 & 0.7507 \\
\hline SC9334 & M & 194 & 2.5 & $\mathrm{R}$ & 0.5338 & 0.7416 \\
\hline SC9334 & M & 194 & 2.5 & $\mathrm{~L}$ & 0.5242 & 0.7613 \\
\hline SC9708 & M & 176 & 2.5 & $\mathrm{R}$ & 0.4390 & 0.6193 \\
\hline SC0906 & $\mathrm{F}$ & 169 & 2.75 & $\mathrm{R}$ & 0.3736 & 0.4354 \\
\hline MML0503 & M & 186 & 3 & $\mathrm{R}$ & 0.5254 & 0.7039 \\
\hline SC0049 & M & 195 & 3 & $\mathrm{R}$ & 0.4737 & 0.5826 \\
\hline $\mathrm{SC} 0228$ & M & 184 & 3 & $\mathrm{R}$ & 0.4521 & 0.6401 \\
\hline SC0503 & $\mathrm{M}$ & 194 & 3 & $\mathrm{~L}$ & 0.4751 & 0.6433 \\
\hline SC0701 & $\mathrm{F}$ & 193 & 3 & $\mathrm{R}$ & 0.6027 & 0.8361 \\
\hline SC0910 & M & 183 & 3 & $\mathrm{R}$ & 0.4216 & 0.5290 \\
\hline SC1046 & M & 190 & 3 & $\mathrm{R}$ & 0.5060 & 0.7151 \\
\hline SC1110 & $\mathrm{F}$ & 197 & 3 & $\mathrm{~L}$ & 0.5170 & 0.7540 \\
\hline SC1128 & $\mathrm{F}$ & 159 & 3 & $\mathrm{R}$ & 0.3196 & 0.4042 \\
\hline SC1203 & $\mathrm{F}$ & 175 & 3 & $\mathrm{~L}$ & 0.5436 & 0.7185 \\
\hline SC9936 & $\mathrm{M}$ & 200 & 3 & $\mathrm{R}$ & 0.4125 & 0.5188 \\
\hline SC9518 & M & 198 & 3.25 & $\mathrm{R}$ & 0.4298 & 0.5950 \\
\hline SC9518 & M & 198 & 3.25 & $\mathrm{~L}$ & 0.4299 & 0.5662 \\
\hline MML0325 & M & 201 & 3.5 & $\mathrm{R}$ & 0.5180 & 0.7242 \\
\hline SC0452 & $\mathrm{M}$ & 194 & 3.5 & $\mathrm{R}$ & 0.6294 & 0.8835 \\
\hline SC0728 & $\mathrm{F}$ & 198 & 3.75 & $\mathrm{R}$ & 0.4789 & 0.6827 \\
\hline SC0002 & $\mathrm{F}$ & 138 & 4 & $\mathrm{R}$ & 0.2608 & 0.3436 \\
\hline SC0002 & $\mathrm{F}$ & 138 & 4 & $\mathrm{~L}$ & 0.2548 & 0.3372 \\
\hline SC0005 & M & 190 & 4 & $\mathrm{R}$ & 0.3836 & 0.4796 \\
\hline SC0322 & M & 175 & 4 & $\mathrm{R}$ & 0.3231 & 0.4238 \\
\hline SC0749 & $\mathrm{F}$ & 209 & 4 & $\mathrm{R}$ & 0.5044 & 0.7377 \\
\hline SC0812 & $\mathrm{M}$ & 180 & 4 & $\mathrm{R}$ & 0.3915 & 0.5183 \\
\hline MML0016 & $\mathrm{M}$ & 224 & 4.5 & $\mathrm{R}$ & 0.6655 & 0.8616 \\
\hline
\end{tabular}




\begin{tabular}{|c|c|c|c|c|c|c|}
\hline Field \# & $\begin{array}{c}\text { Sex } \\
(\mathrm{M} / \mathrm{F})\end{array}$ & $\begin{array}{c}\mathrm{TL} \\
(\mathrm{cm})\end{array}$ & $\begin{array}{l}\text { Age } \\
(\mathbf{y r})\end{array}$ & $\begin{array}{c}\mathrm{L} / \mathbf{R} \\
\text { Radius }\end{array}$ & $\begin{array}{c}\text { Radius BMD } \\
\left(\mathrm{g} / \mathrm{cm}^{2}\right)\end{array}$ & $\begin{array}{c}\text { GC ROI BMD } \\
\left(\mathrm{g} / \mathrm{cm}^{2}\right)\end{array}$ \\
\hline SC0036 & $\mathrm{M}$ & 207 & 4.5 & $\mathrm{R}$ & 0.5681 & 0.7335 \\
\hline MML0527 & $\mathrm{F}$ & 236 & 5 & $\mathrm{R}$ & 0.5419 & 0.7393 \\
\hline SC0545 & M & 210 & 5 & $\mathrm{R}$ & 0.5788 & 0.7720 \\
\hline SC0637 & M & 194 & 5 & $\mathrm{R}$ & 0.5331 & 0.7040 \\
\hline SC0808 & $\mathrm{F}$ & 200 & 5 & $\mathrm{R}$ & 0.5909 & 0.8149 \\
\hline SC1001 & M & 195 & 5 & $\mathrm{R}$ & 0.4843 & 0.6687 \\
\hline SC1003 & M & 194 & 5 & $\mathrm{R}$ & 0.4949 & 0.6449 \\
\hline SC1050 & M & 200 & 5 & $\mathrm{R}$ & 0.5524 & 0.7615 \\
\hline SC1106 & M & 202 & 5 & $\mathrm{R}$ & 0.5153 & 0.6755 \\
\hline SC9758 & M & 215 & 5 & $\mathrm{R}$ & 0.6500 & 0.9101 \\
\hline SC0834 & $\mathrm{F}$ & 207 & 5.5 & $\mathrm{R}$ & 0.5273 & 0.6588 \\
\hline SC0755 & M & 184 & 6 & $\mathrm{R}$ & 0.4132 & 0.5185 \\
\hline SC9804 & M & 195 & 6 & $\mathrm{R}$ & 0.5036 & 0.6741 \\
\hline MML0222 & $\mathrm{F}$ & 273 & 7 & $\mathrm{R}$ & 0.6059 & 0.8156 \\
\hline SC1156 & M & 221 & 7 & $\mathrm{R}$ & 0.5569 & 0.7329 \\
\hline SC0752 & M & 212 & 8 & $\mathrm{~L}$ & 0.6194 & 0.8379 \\
\hline SC0816 & M & 227 & 8.5 & $\mathrm{R}$ & 0.6502 & 0.8149 \\
\hline SC0203 & M & 206 & 9 & $\mathrm{R}$ & 0.6169 & 0.8996 \\
\hline SC0842 & $\mathrm{F}$ & 209 & 9 & $\mathrm{R}$ & 0.5085 & 0.6311 \\
\hline SC9739 & M & 224 & 9.5 & $\mathrm{R}$ & 0.5324 & 0.7053 \\
\hline SC0608 & M & 204 & 10 & $\mathrm{R}$ & 0.6369 & 0.9004 \\
\hline SC0757 & $\mathrm{F}$ & 225 & 10 & $\mathrm{R}$ & 0.6465 & 0.8352 \\
\hline SC0952 & M & 221 & 10 & $\mathrm{R}$ & 0.7731 & 1.0020 \\
\hline SC1122 & M & 216 & 10 & $\mathrm{R}$ & 0.4538 & 0.5614 \\
\hline SC1236 & M & 223 & 10 & $\mathrm{R}$ & 0.6396 & 0.8751 \\
\hline SC9610 & M & 205 & 10 & $\mathrm{~L}$ & 0.5650 & 0.7358 \\
\hline SC0603 & M & 232 & 11 & $\mathrm{~L}$ & 0.7343 & 1.0590 \\
\hline SC0904 & $\mathrm{F}$ & 221 & 11 & $\mathrm{R}$ & 0.5112 & 0.6790 \\
\hline MML9414 & M & 199 & 12 & $\mathrm{R}$ & 0.5961 & 0.7976 \\
\hline SC0166 & M & 232 & 12 & $\mathrm{~L}$ & 0.6427 & 0.9506 \\
\hline SC0630 & M & 236 & 12 & $\mathrm{R}$ & 0.7800 & 1.0060 \\
\hline SC0938 & $\mathrm{F}$ & 233 & 12 & $\mathrm{R}$ & 0.6606 & 0.8715 \\
\hline SC1228 & $\mathrm{F}$ & 222 & 12 & $\mathrm{R}$ & 0.5656 & 0.7641 \\
\hline SC9846 & M & 221.4 & 12 & $\mathrm{~L}$ & 0.6309 & 0.8062 \\
\hline SC0821 & M & 256 & 12.5 & $\mathrm{R}$ & 0.7196 & 0.9736 \\
\hline SC0932 & $\mathrm{F}$ & 227 & 13 & $\mathrm{~L}$ & 0.6741 & 0.9439 \\
\hline SC0946 & $\mathrm{M}$ & 216 & 13 & $\mathrm{R}$ & 0.6014 & 0.7283 \\
\hline MML0413 & $\mathrm{F}$ & 250 & 14 & $\mathrm{R}$ & 0.6458 & 0.9119 \\
\hline SC0638 & M & 217 & 14 & $\mathrm{R}$ & 0.5712 & 0.7879 \\
\hline
\end{tabular}




\begin{tabular}{|c|c|c|c|c|c|c|}
\hline Field \# & $\begin{array}{c}\text { Sex } \\
(\mathrm{M} / \mathrm{F})\end{array}$ & $\begin{array}{c}\text { TL } \\
(\mathbf{c m})\end{array}$ & $\begin{array}{l}\text { Age } \\
(\mathbf{y r})\end{array}$ & $\begin{array}{c}\text { L/R } \\
\text { Radius }\end{array}$ & $\begin{array}{c}\text { Radius BMD } \\
\qquad\left(\mathrm{g} / \mathrm{cm}^{2}\right)\end{array}$ & $\begin{array}{c}\text { GC ROI BMD } \\
\left(\mathrm{g} / \mathrm{cm}^{2}\right)\end{array}$ \\
\hline SC1019 & $\mathrm{F}$ & 244 & 14 & $\mathrm{R}$ & 0.7758 & 1.0230 \\
\hline SC0712 & M & 226 & 15 & $\mathrm{~L}$ & 0.6553 & 0.8175 \\
\hline SC0845 & M & 221 & 15 & $\mathrm{R}$ & 0.6787 & 0.8507 \\
\hline SC0155 & $\mathrm{F}$ & 253 & 17 & $\mathrm{R}$ & 0.8440 & 1.0660 \\
\hline SC0501 & M & 254 & 17 & $\mathrm{R}$ & 0.6821 & 0.8646 \\
\hline SC9437 & M & 252 & 17 & $\mathrm{~L}$ & 0.8722 & 1.1190 \\
\hline SC9919 & M & 257 & 17 & $\mathrm{R}$ & 0.7880 & 1.1350 \\
\hline SC0617 & M & 267 & 18 & $\mathrm{R}$ & 0.8793 & 1.1700 \\
\hline SC9509 & M & 264 & 18 & $\mathrm{R}$ & 0.8610 & 1.1370 \\
\hline SC9730 & M & 225 & 18 & $\mathrm{R}$ & 0.8421 & 1.1340 \\
\hline $\mathrm{SC} 0424$ & M & 257 & 19 & $\mathrm{R}$ & 0.7196 & 0.9917 \\
\hline SC9421 & M & 255 & 19 & $\mathrm{R}$ & 0.7793 & 1.0380 \\
\hline MML9628 & M & 271 & 20 & $\mathrm{R}$ & 0.8532 & 1.1930 \\
\hline SC0505 & M & 252 & 20 & $\mathrm{R}$ & 0.7217 & 0.8849 \\
\hline MML0614 & M & 262 & 21 & $\mathrm{R}$ & 0.8046 & 1.0540 \\
\hline MML9014 & M & 295 & 21 & $\mathrm{R}$ & 0.9114 & 1.3350 \\
\hline SC0222 & M & 261 & 21 & $\mathrm{~L}$ & 0.6577 & 0.8306 \\
\hline SC0747 & $\mathrm{F}$ & 234 & 21 & $\mathrm{R}$ & 0.5933 & 0.7794 \\
\hline SC1175 & $\mathrm{F}$ & 249 & 21 & $\mathrm{R}$ & 0.6954 & 0.9406 \\
\hline SC9835 & M & 248 & 21 & $\mathrm{R}$ & 0.8663 & 1.1500 \\
\hline SC9508 & M & 277 & 21.5 & $\mathrm{R}$ & 0.9183 & 1.2450 \\
\hline SC9508 & M & 277 & 21.5 & $\mathrm{~L}$ & 0.8844 & 1.1390 \\
\hline MML0216 & M & 268 & 22 & $\mathrm{R}$ & 0.8527 & 1.2820 \\
\hline SC0642 & M & 254 & 22 & $\mathrm{~L}$ & 0.7953 & 0.9439 \\
\hline SC0840 & M & 276 & 22 & $\mathrm{~L}$ & 0.8617 & 1.1120 \\
\hline SC1207 & $\mathrm{F}$ & 250 & 22 & $\mathrm{R}$ & 0.5868 & 0.7686 \\
\hline MML0619 & $\mathrm{M}$ & 255 & 23 & $\mathrm{R}$ & 0.7029 & 0.9380 \\
\hline SC0745 & M & 261 & 23 & $\mathrm{~L}$ & 0.8745 & 1.1150 \\
\hline SC0817 & M & 261 & 23 & $\mathrm{R}$ & 0.7508 & 0.8073 \\
\hline SC1253 & $\mathrm{F}$ & 247 & 23 & $\mathrm{R}$ & 0.7175 & 0.9232 \\
\hline SC0140 & $\mathrm{M}$ & 260 & 24 & $\mathrm{R}$ & 0.9509 & 1.2120 \\
\hline SC0140 & $\mathrm{M}$ & 260 & 24 & $\mathrm{~L}$ & 0.9378 & 1.1060 \\
\hline SC0217 & $\mathrm{M}$ & 258 & 24 & $\mathrm{R}$ & 0.8087 & 0.9948 \\
\hline SC0623 & $\mathrm{M}$ & 247 & 24 & $\mathrm{R}$ & 0.8736 & 1.1240 \\
\hline SC1164 & M & 254 & 24 & $\mathrm{~L}$ & 0.8523 & 0.9589 \\
\hline SC9442 & M & 264 & 24 & $\mathrm{R}$ & 0.9142 & 1.2380 \\
\hline MML0332 & $\mathrm{M}$ & 253 & 25 & $\mathrm{R}$ & 0.9119 & 1.2770 \\
\hline SC0731 & $\mathrm{F}$ & 249 & 25 & $\mathrm{R}$ & 0.7026 & 0.8498 \\
\hline SC0058 & M & 279 & 26 & $\mathrm{R}$ & 0.9372 & 1.2270 \\
\hline
\end{tabular}




\begin{tabular}{|c|c|c|c|c|c|c|}
\hline Field \# & $\begin{array}{c}\text { Sex } \\
(\mathbf{M} / \mathbf{F})\end{array}$ & $\begin{array}{c}\text { TL } \\
(\mathbf{c m})\end{array}$ & $\begin{array}{l}\text { Age } \\
(\mathbf{y r})\end{array}$ & $\begin{array}{c}\mathbf{L} / \mathbf{R} \\
\text { Radius }\end{array}$ & $\begin{array}{c}\text { Radius BMD } \\
\left(\mathrm{g} / \mathrm{cm}^{2}\right)\end{array}$ & $\begin{array}{c}\text { GC ROI BMD } \\
\left(\mathrm{g} / \mathrm{cm}^{2}\right)\end{array}$ \\
\hline SC0058 & $\mathrm{M}$ & 279 & 26 & $\mathrm{~L}$ & 0.9326 & 1.1420 \\
\hline SC0704 & $\mathrm{F}$ & 246 & 26 & $\mathrm{R}$ & 0.7057 & 0.9287 \\
\hline SC0902 & $\mathrm{F}$ & 252 & 26 & $\mathrm{R}$ & 0.6882 & 0.9175 \\
\hline SC1006 & M & 240 & 26 & $\mathrm{R}$ & 0.6399 & 0.7755 \\
\hline SC9628 & M & 262 & 26 & $\mathrm{R}$ & 0.8707 & 1.0810 \\
\hline SC0826 & M & 249 & 27 & $\mathrm{~L}$ & 0.7885 & 0.9702 \\
\hline SC1205 & M & 245 & 27 & $\mathrm{R}$ & 0.6588 & 0.8962 \\
\hline SC0727 & $\mathrm{F}$ & 233 & 28 & $\mathrm{R}$ & 0.6548 & 0.9512 \\
\hline SC0813 & $\mathrm{F}$ & 264 & 28 & $\mathrm{~L}$ & 0.7323 & 0.9228 \\
\hline SC0703 & $\mathrm{F}$ & 247.5 & 29 & $\mathrm{~L}$ & 0.6752 & 0.8644 \\
\hline SC0708 & $\mathrm{F}$ & 237 & 29 & $\mathrm{R}$ & 0.6242 & 0.7774 \\
\hline SC0740 & M & 250 & 29 & $\mathrm{R}$ & 0.8543 & 1.0970 \\
\hline SC1170 & $\mathrm{F}$ & 233 & 29 & $\mathrm{R}$ & 0.6827 & 0.8568 \\
\hline SC0534 & M & 261 & 30 & $\mathrm{R}$ & 0.8826 & 1.1670 \\
\hline SC1037 & M & 263 & 30 & $\mathrm{R}$ & 0.8212 & 1.0390 \\
\hline SC9524 & M & 258 & 30 & $\mathrm{R}$ & 0.9949 & 1.2430 \\
\hline MML0223 & M & 130 & 31.5 & $\mathrm{R}$ & 0.3326 & 0.4505 \\
\hline MML1205 & M & 259.5 & 32 & $\mathrm{R}$ & 0.7420 & 0.9682 \\
\hline SC0448 & M & 275.5 & 32 & $\mathrm{R}$ & 0.9880 & 1.2770 \\
\hline SC0538 & $\mathrm{M}$ & 272 & 32 & $\mathrm{~L}$ & 1.0100 & 1.3850 \\
\hline SC0825 & $\mathrm{M}$ & 274 & 32 & $\mathrm{R}$ & 0.8139 & 1.0120 \\
\hline SC0947 & M & 265 & 33 & $\mathrm{R}$ & 0.8210 & 1.0440 \\
\hline SC9413 & $\mathrm{M}$ & 272 & 33 & $\mathrm{R}$ & 0.9998 & 1.4060 \\
\hline MML0229 & $\mathrm{F}$ & 265 & 34 & $\mathrm{R}$ & 0.8005 & 0.9906 \\
\hline SC1028 & $\mathrm{F}$ & 243 & 34 & $\mathrm{R}$ & 0.7738 & 0.9943 \\
\hline SC1206 & $\mathrm{F}$ & 259 & 34 & $\mathrm{R}$ & 0.6650 & 0.8527 \\
\hline SC1240 & $\mathrm{F}$ & 244 & 34 & $\mathrm{R}$ & 0.6886 & 0.8119 \\
\hline MML0236 & M & 278 & 35 & $\mathrm{R}$ & 0.7067 & 0.9536 \\
\hline SC0455 & M & 260 & 35 & $\mathrm{~L}$ & 0.7681 & 0.9504 \\
\hline SC1256 & $\mathrm{U}$ & 246 & 35 & $\mathrm{R}$ & 0.6744 & 0.9832 \\
\hline SC9737 & $\mathrm{M}$ & 263 & 35 & $\mathrm{~L}$ & 0.9720 & 1.2100 \\
\hline SC0922 & $\mathrm{F}$ & 246 & 37 & $\mathrm{~L}$ & 0.7059 & 0.9694 \\
\hline MML0111 & M & 277 & 38 & $\mathrm{R}$ & 0.8602 & 1.1160 \\
\hline SC1232 & $\mathrm{F}$ & 229 & 40 & $\mathrm{R}$ & 0.6968 & 0.9544 \\
\hline SC0517 & $\mathrm{M}$ & 253 & 41 & $\mathrm{R}$ & 0.8593 & 1.1530 \\
\hline MML0606 & $\mathrm{M}$ & 263 & 44 & $\mathrm{R}$ & 0.8280 & 1.1660 \\
\hline MML0504 & $\mathrm{F}$ & 235 & 45 & $\mathrm{R}$ & 0.7781 & 0.9212 \\
\hline MML0910 & $\mathrm{F}$ & 246 & 50 & $\mathrm{R}$ & 0.6826 & 0.8701 \\
\hline
\end{tabular}


Appendix B. Quantitative ultrasound (QUS) values from bone mineral density (BMD) repeatability assay conducted on dolphins managed under human care.

\begin{tabular}{lcccccc} 
Dolphin & Scan \#1 & Scan \#2 & Scan \#3 & Scan \#4 & Mean & CV $^{\mathbf{2}}$ \\
\hline Hoku & 2.893 & 2.706 & 3.293 & 3.235 & 3.032 & 0.006 \\
Hua & 2.602 & 2.982 & 2.956 & 2.741 & 2.820 & 0.003 \\
Kolohe & 3.730 & 3.595 & 3.348 & 3.184 & 3.464 & 0.004 \\
Liho & 2.896 & 3.061 & 3.079 & 3.016 & 3.013 & 0.001 \\
Lono & 3.148 & 3.159 & 3.374 & 3.296 & 3.244 & 0.001 \\
Merlin & 1.236 & 1.402 & 1.382 & 1.372 & 1.348 & 0.002 \\
Nianoa & 2.834 & 2.881 & 2.675 & 2.668 & 2.737 & 0.001 \\
Noelani & 2.211 & 2.210 & 1.840 & 1.808 & 1.911 & 0.011 \\
Spree & 2.251 & 2.566 & 2.239 & 2.369 & 2.356 & 0.003 \\
Tapeko & 1.699 & 1.837 & 1.588 & 1.809 & 1.733 & 0.003
\end{tabular}


Appendix C. Bone density measurements of live, free-ranging bottlenose dolphins during capture-release health assessments from 2014-2019.

\begin{tabular}{|c|c|c|c|c|}
\hline Dolphin & Age (yrs) & Sex & TL (cm) & QUS NTD $(\mu s)$ \\
\hline F245 & 2 & $\mathrm{~F}$ & 204 & 2.383 \\
\hline F255 & 2 & $\mathrm{~F}$ & 192 & 2.2616 \\
\hline F263 & 2 & $\mathrm{~F}$ & 189 & 2.8581 \\
\hline F267 & 2 & $\mathrm{~F}$ & 178 & 2.5151 \\
\hline F269 & 2 & $\mathrm{~F}$ & 185 & 1.8527 \\
\hline F289 & 2 & $\mathrm{~F}$ & 196 & 2.512 \\
\hline F259 & 3 & $\mathrm{~F}$ & 216 & 2.8994 \\
\hline F283 & 4 & $\mathrm{~F}$ & 201 & 2.5758 \\
\hline F275 & 6 & F & 224 & 2.8946 \\
\hline F277 & 6 & $\mathrm{~F}$ & 236 & 2.636 \\
\hline F241 & 7 & $\mathrm{~F}$ & 242 & 2.3477 \\
\hline F209 & 11 & $\mathrm{~F}$ & 236 & 3.0245 \\
\hline F213 & 11 & $\mathrm{~F}$ & 235 & 2.9829 \\
\hline F199 & 13 & $\mathrm{~F}$ & 236 & 1.6569 \\
\hline F133 & 15 & $\mathrm{~F}$ & 242 & 3.2322 \\
\hline F223 & 15 & $\mathrm{~F}$ & 251 & 2.7526 \\
\hline F123 & 17 & $\mathrm{~F}$ & 241 & 2.8826 \\
\hline F151 & 17 & $\mathrm{~F}$ & 232 & 3.2258 \\
\hline F155 & 23 & $\mathrm{~F}$ & 246 & 3.3826 \\
\hline $\mathrm{F} 271$ & 23 & $\mathrm{~F}$ & 243 & 3.352 \\
\hline FB33 & 31 & $\mathrm{~F}$ & 258 & 2.6647 \\
\hline FB7 & 33 & $\mathrm{~F}$ & 248 & 3.0435 \\
\hline F286 & 3 & $\mathrm{M}$ & 194 & 2.573 \\
\hline F294 & 3 & $\mathrm{M}$ & 202 & 2.4018 \\
\hline F292 & 4 & $\mathrm{M}$ & 216 & 2.4273 \\
\hline F296 & 4 & M & 228 & 3.599 \\
\hline F306 & 4 & $\mathrm{M}$ & 208 & 2.6885 \\
\hline F288 & 6 & $\mathrm{M}$ & 224 & 3.2213 \\
\hline F264 & 11 & $\mathrm{M}$ & 239 & 2.8117 \\
\hline F266 & 12 & $\mathrm{M}$ & 244 & 3.8263 \\
\hline F246 & 14 & $\mathrm{M}$ & 253 & 2.7648 \\
\hline F173 & 15 & M & 257 & 3.7555 \\
\hline F196 & 16 & M & 269 & 3.6458 \\
\hline F238 & 17 & $\mathrm{M}$ & 263 & 3.2885 \\
\hline F146 & 19 & $\mathrm{M}$ & 277 & 4.3464 \\
\hline F188 & 20 & M & 257 & 3.5775 \\
\hline F178 & 21 & $\mathrm{M}$ & 272 & 3.0922 \\
\hline F276 & 22 & $\mathrm{M}$ & 274 & 4.0717 \\
\hline F242 & 24 & M & 281 & 3.5299 \\
\hline F164 & 25 & M & 262 & 3.2037 \\
\hline
\end{tabular}

